\title{
ANÁLISE DE EXISTÊNCIA DE MÁXIMA FASE ESTÁVEL DE LACTATO EM EXERCÍCIO RESISTIDO EM POPULAÇÃO JOVEM E IDOSA
}

Dissertação de mestrado apresentada ao Programa de PósGraduação Interunidades Bioengenharia - Escola de Engenharia de São Carlos / Faculdade de Medicina de Ribeirão Preto / Instituto de Química de São Carlos da Universidade de São Paulo como parte dos requisitos para a obtenção do título de mestre em Ciências.

Área de Concentração: Bioengenharia

Orientador: Prof. Dr. Vilmar Baldissera

São Carlos,

2010 


\section{Programa de Pós-Graduação Interunidades em Bioengenharia}

EESC / FMRP / IQSC

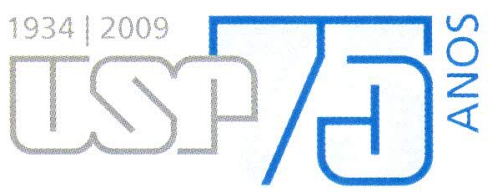

NUNO MANUEL FRADE DE SOUZA

MESTRADO EM CIÊNCIAS

ÅREA DE BIOENGENHARIA

DISSERTAÇÃO APRESENTADA AO PROGRAMA DE PÓS - GRADUAÇÃO INTERUNIDADES BIOENGENHARIA EESC - FMRP - IQSC DA UNIVERSIDADE DE SÃO PAULO PARA OBTENÇÃO DO TÍTULO DE MESTRE EM CIÊNCIAS NA ÁREA DE BIOENGENHARIA.

Aprovado em27/10/2010

PROF. DR. VILMAR BALDISSERA (ORIENTADOR)

Resultado: APROUADO

PROFA. DRA. AUDREY BORGHI E SILVA

Resultado: AMNOUADO

PROF. DR. JOÃO PAULO BOTERO

Resultado:

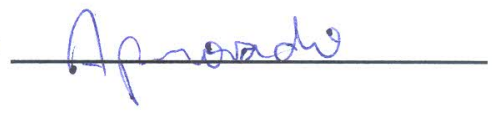

Universidade Federal de São Carlos - UFSCar

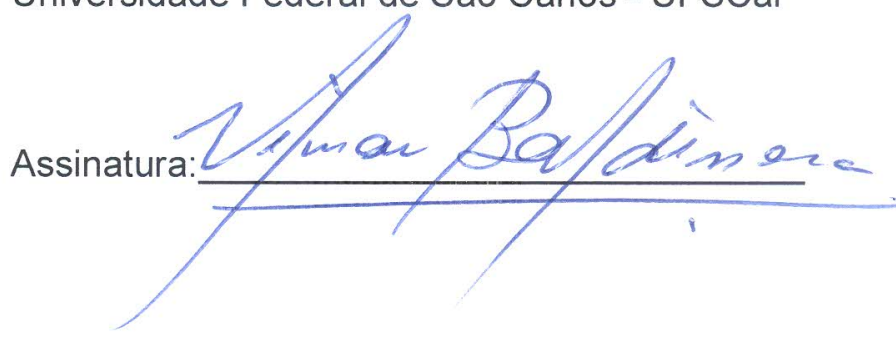

Universidade Federal de São Carlos - UFSCar Assinatura:

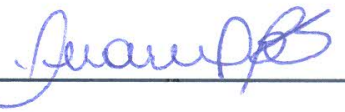

Centro Universitário Central Paulista UNICEP

Assinatura:

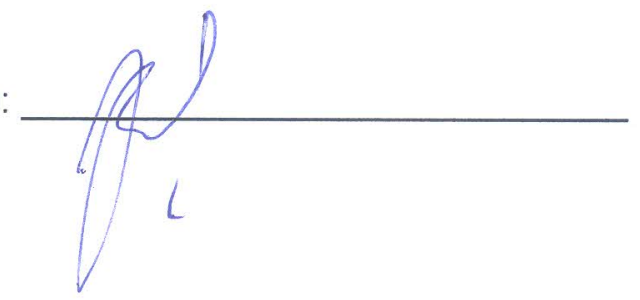




\section{DEDICATÓRIA}

Dedico especialmente este trabalho a minha esposa, Denise, pela confiança, carinho e principalmente compreensão neste momento importante de nossas vidas. Sem dúvida que nosso amor superou qualquer distância.

À minha família, principalmente na figura de meus pais, que desde criança me incentivaram para o conhecimento e procura por novos desafios. Mesmo sem imaginarem que o faria tão longe de casa. Sou hoje o homem que sou por tudo o que me transmitiram. 


\section{AGRADECIMENTOS}

Agradeço a todos os meus amigos e colegas de laboratório que me acolheram nesta etapa da minha vida. Novos amigos eu realizei e sei que amizades assim podem durar para sempre. Obrigado por tudo. Ao Rodrigo, que posso considerar meu irmão acadêmico, Vivian, minha prima acadêmica e parceiros na realização deste projeto e a todos meus demais colegas que me auxiliaram direta ou indiretamente.

Uma palavra especial para uma pessoa que acreditou em mim desde o início e que não tenho palavras para descrever como me sinto lisonjeado em fazer parte do seu grupo de pesquisa, meu orientador Vilmar Baldissera. Obrigado por tudo e por mais que ainda vai acontecer. 


\section{RESUMO}

SOUSA, N. M. F. Análise de existência de máxima fase estável de lactato em exercício resistido em população jovem e idosa. 2010. 95f. Dissertação (Mestrado) - Programa de Pós-graduação Interunidades em Bioengenharia EESC/FMRP/IQSC, Universidade de São Paulo (USP), São Carlos, 2010.

A máxima fase estável do lactato (MFEL) é considerada uma intensidade critica em exercício dinâmico e sua intensidade é específica do grupo etário. No entanto, apesar da relação existente entre a intensidade de esforço e os ajustes cardiovasculares, metabólicos e ventilatórios durante o exercício resistido, a MFEL foi muito pouco estudada neste tipo de exercício. O objetivo do estudo foi verificar e comparar a existência de MFEL nos exercícios leg press (LP) e supino reto (SR) em dois grupos: jovens e idosos. Além disso, analisar o comportamento das variáveis ergoespirométricas $\left(\mathrm{VE}, \mathrm{VO}_{2}\right.$ e $\mathrm{VCO}_{2}$ ), lactacidemia, freqüência cardíaca $(\mathrm{FC})$, pressão arterial (PA) e percepção subjetiva de esforço (PSE) na intensidade da MFEL. Foram avaliados 13 homens jovens (26,1 $\pm 2,9$ anos) e 11 idosos $(68,9 \pm 4,0$ anos) saudáveis e com experiência mínima de 6 meses em treinamento resistido, que passaram por teste de 1 repetição máxima (1RM), teste crescente para determinação do limiar anaeróbio (LAn) e mais três sessões para a determinação da MFEL. Todas as sessões foram realizadas no mesmo horário do dia, separadas por 48 a 72 horas de intervalo. O LAn, expresso em \%1RM, foi significativamente superior no LP em relação ao SR para os dois grupos estudados (LP: 27,8 $\pm 3,6$ $\% 1 R M$ nos jovens e 27,9 $\pm 5,0 \% 1 R M$ nos idosos; SR: $24,0 \pm 3,0 \% 1 R M$ nos jovens e $21,5 \pm 3,1 \% 1 \mathrm{RM}$ nos idosos). Não foram observadas diferenças estatisticamente significativas na intensidade do LAn entre os grupos em cada aparelho. A lactacidemia na intensidade do LAn foi significativamente inferior no LP $(1,86 \pm 0,63$ mmol. $\mathrm{L}^{-1}$ nos jovens e $1,23 \pm 0,34 \mathrm{mmol} . \mathrm{L}^{-1}$ nos idosos) em relação ao SR $(2,08 \pm$ $0,41 \mathrm{mmol} . \mathrm{L}^{-1}$ nos jovens e $1,91 \pm 0,40 \mathrm{mmol} . \mathrm{L}^{-1}$ nos idosos). A intensidade da MFEL no grupo de jovens foi $29,2 \pm 6,7 \% 1 \mathrm{RM}$ no LP e $21,7 \pm 4,4 \% 1 \mathrm{RM}$ no SR. No grupo e idosos, a MFEL ocorreu a 30,9 $\pm 4,9 \% 1 \mathrm{RM}$ no LP e $23,3 \pm 6,6 \% 1 \mathrm{RM}$ no SR. A MFEL ocorre em intensidade significativamente menor no aparelho SR para os dois grupos $(p \leq 0,05)$, sem diferenças estatisticamente significativas entre os grupos. Não houve diferença significativa entre as intensidades do LAn e da MFEL para os dois grupos nos dois aparelhos. Durante a realização do exercício na MFEL, ocorreu a estabilização dos parâmetros ergoespirométricos, FC, PA e PSE entre a série 9 e série 15. Estes resultados demonstram que é possível determinar MFEL nos exercícios LP e SR para as duas populações estudadas. A MFEL ocorre em intensidades superiores no exercício LP. A intensidade da MFEL, expressa em percentual de 1RM, é semelhante à intensidade do LAn.

Palavras-chave: Exercício resistido. Limiar anaeróbio. Máxima fase estável do lactato. Idosos. 


\begin{abstract}
SOUSA, N. M. F. Maximal lactate steady state analysis in resistance exercise in young and older groups. 2010. 95f. Dissertação (Mestrado) - Programa de Pósgraduação Interunidades em Bioengenharia EESC/FMRP/IQSC, Universidade de São Paulo (USP), São Carlos, 2010.
\end{abstract}

The maximal lactate steady state (MLSS) is considered a critical intensity of dynamic exercise and its intensity is specific to the age group. However, despite the relationship between exercise intensity and cardiovascular, metabolic and ventilatory adjustments during resistance exercise, the MLSS was unknown in this type of exercise. The purpose of the study was to verify and to compare if there is a maximal lactate steady state (MLSS) for leg press (LP) and bench press (BP) exercises in two different groups: young and older people. Furthermore, to evaluate the ventilatory responses ( $\mathrm{VE}, \mathrm{VO}_{2}$ e $\mathrm{VCO}_{2}$ ), blood lactate concentration (BLC), heart rate $(\mathrm{HR})$, blood pressure and rate of perceived exertion (RPE) to those exercises performed on MLSS intensity. 13 young men $(26,1 \pm 2,9$ years) and 11 elderly healthy men $(68,9 \pm$ 4,0 years) with a minimal experience of 6 months of resistance training volunteered for the study. Volunteers underwent a 1 repetition maximum test (1RM), an incremental test to determine anaerobic threshold (AT) and three more sessions to determine MLSS. Session were performed on the same time of day and separated by a 48-72h interval. AT intensity (\%1RM) was significantly higher for LP than BP for the two groups studied (LP: 27,8 $\pm 3,6 \% 1 \mathrm{RM}$ for young group and 27,9 $\pm 5,0 \% 1 \mathrm{RM}$ for elderly; BP: 24,0 $\pm 3,0 \% 1 \mathrm{RM}$ for young group and 21,5 $\pm 3,1 \% 1 \mathrm{RM}$ for elderly). There was no significant difference between groups in the AT intensity. BLC on AT was significantly lower for LP $\left(1,86 \pm 0,63 \mathrm{mmol}^{-1}\right.$ for young group and $1,23 \pm 0,34$ mmol. $\mathrm{L}^{-1}$ for elderly) than BP $\left(2,08 \pm 0,41 \mathrm{mmol}^{-\mathrm{L}^{-1}}\right.$ for young and 1,91 $\pm 0,40$ mmol. $\mathrm{L}^{-1}$ for elderly). MLSS intensity for young group was $29,2 \pm 6,7 \% 1 \mathrm{RM}$ in LP and $21,7 \pm 4,4 \% 1 \mathrm{RM}$ in BP. For elderly, MLSS was 30,9 $\pm 4,9 \% 1 \mathrm{RM}$ in LP and 23,3 $\pm 6,6 \% 1 \mathrm{RM}$ in BP. MLSS intensity was significantly lower in BP for both groups $(p \leq 0,05)$, with no statistical differences between groups. There was no significant difference between AT and MLSS intensities on both groups. During exercise on MLSS, ventilatory parameters, HR, blood pressure and RPE stabilized between set 9 and set 15. These results show that it is possible to identify MLSS on the LP and BP exercises for both populations. MLSS intensity is higher in LP exercise, when compared to BP. MLSS intensity is similar to the AT intensity.

Key-words: Resistance exercise. Anaerobic threshold. Maximal lactate steady state. Elderly. 


\section{LISTA DE FIGURAS}

Figura 3.1 - Teste crescente máximo para determinação do LAn

Figura 3.2 - Sessão de teste com intensidade constante para determinação da

MFEL

Figura 3.3 - Diagrama de definição da intensidade do teste constante para determinação da MFEL .44

Figura 4.1 - Determinação do Limiar Anaeróbio para um voluntário (voluntário A)

através de ajuste algorítmico para o aparelho leg press .51

Figura 4.2 - Comparação entre jovens e idosos na intensidade máxima e no LAn nos exercícios LP e SR .52

Figura 4.3 - Determinação da MFEL para um voluntário (voluntário B) do grupo de idosos no exercício SR .56

Figura 4.4 - Intensidade da MFEL e LAn nos exercícios LP e SR 57

Figura 4.5 - Lactacidemia final durante o exercício na MFEL para os grupos

jovens e idosos nos exercícios LP e SR .58

Figura 4.6 - Média e desvio padrão da concentração de lactato sanguíneo durante os testes contínuos com intensidade constante no exercício LP no grupo de idosos .59

Figura 4.7 - Valores médios e desvio padrão da VE no grupo de idosos (A)

e de jovens (B) durante exercício na MFEL para o LP e SR 63

Figura 4.8 - Valores médios e desvio padrão do $\mathrm{VO}_{2}$ durante exercício na MFEL para o grupo de idosos $(A)$ e de jovens $(B)$ no exercício LP e SR 64

Figura 4.9 - Valores médios e desvio padrão do $\mathrm{VCO}_{2}$ durante exercício na MFEL para o grupo de idosos (A) e de jovens (B) no exercício LP e SR .64 
Figura 4.10 - Comportamento da FC no grupo de idosos (A) e de jovens (B) durante exercício na MFEL para LP e SR

Figura 4.11 - Média e desvio padrão da PA durante exercício na MFEL para o

LP no grupo de idosos .67

Figura 4.12 - Valores médios e desvio padrão da PSE durante exercício na MFEL no LP e SR para o grupo de idosos (A) e de jovens (B) .69 


\section{LISTA DE TABELAS}

Tabela 1.1 - Metodologias para determinação da Máxima Fase estável de

Lactato 32

Tabela 3.1 - Características antropométricas dos voluntários 38

Tabela 4.1 - Resultados do teste crescente máximo no leg press e supino reto para o grupo de idosos .49

Tabela 4.2 - Resultados do teste crescente máximo no leg press e supino reto para o grupo de jovens. .50

Tabela 4.3 - Valores da concentração de lactato sanguíneo e da intensidade correspondente à MFEL e intensidade acima da MFEL para os dois grupos nos dois aparelhos estudados 60

Tabela 4.4 - Parâmetros ergoespirométricos durante MFEL no exercício

SR e LP para idosos .61

Tabela 4.5 - Parâmetros ergoespirométricos durante MFEL no exercício SR e LP para jovens 62 


\section{SUMÁRIO}

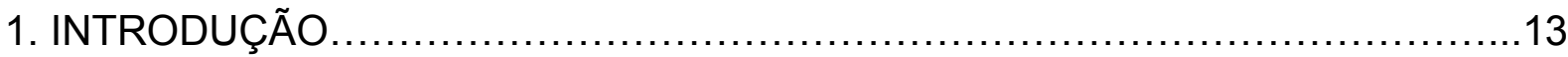

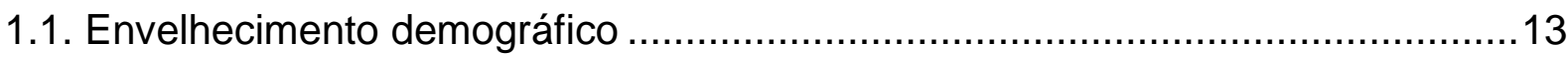

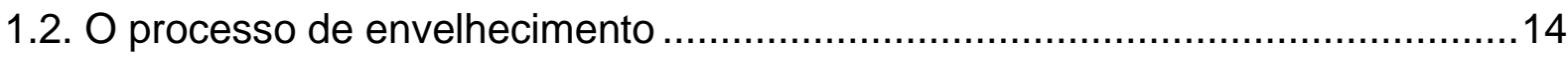

1.3. Alterações fisiológicas, estruturais e funcionais com o envelhecimento ............15

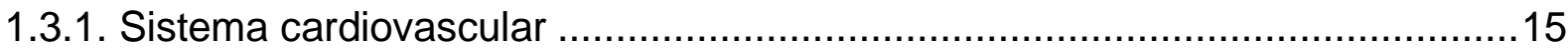

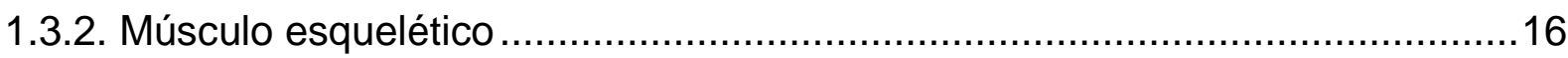

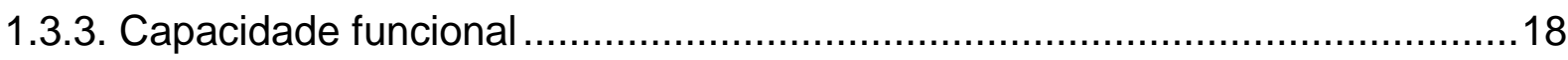

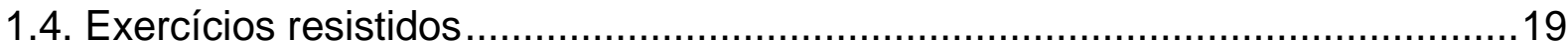

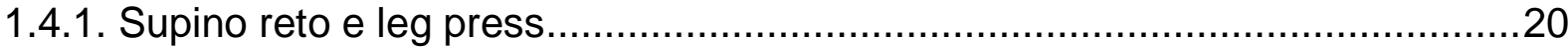

1.5. Exercício resistido e suas respostas hemodinâmicas, musculares e cardíacas.21

1.6. Bases fisiológicas para o treinamento resistido........................................25

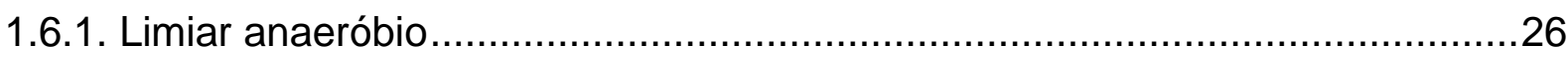

1.6.2. Determinação do limiar anaeróbio em exercício resistido ..........................28

1.6.3. Máxima fase estável do lactato ..........................................................30

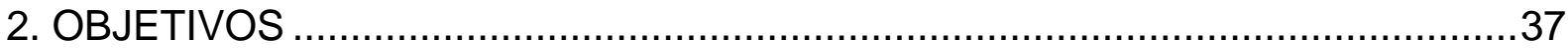

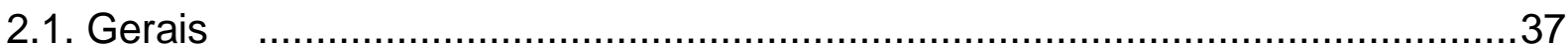

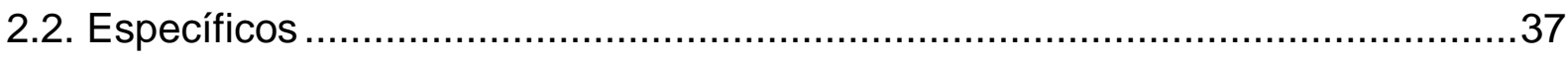

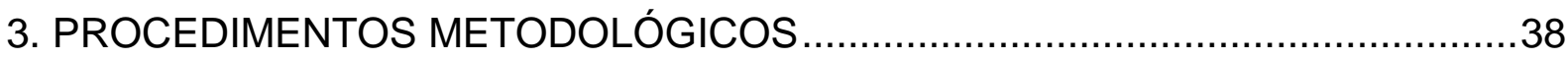

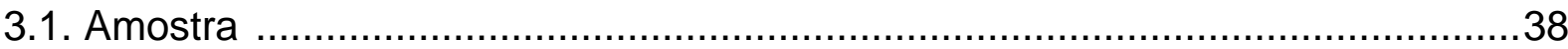

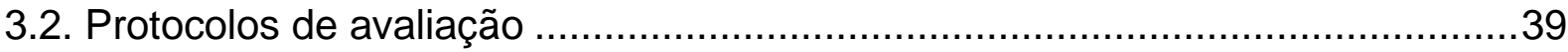

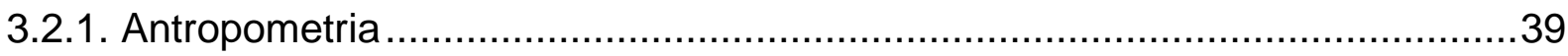

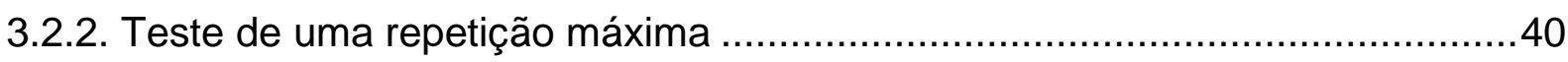


3.2.3. Teste crescente

3.2.4. Máxima fase estável de lactato (MFEL) ……..............................................42

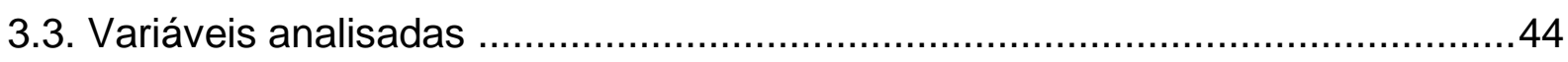

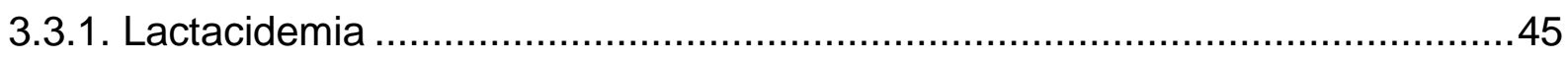

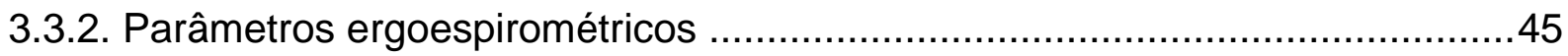

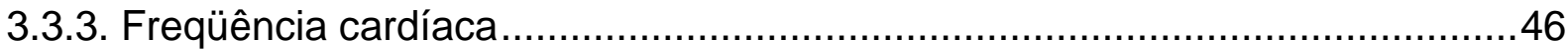

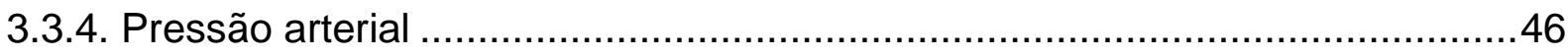

3.3.5. Escala de percepção de esforço ……………….....................................47

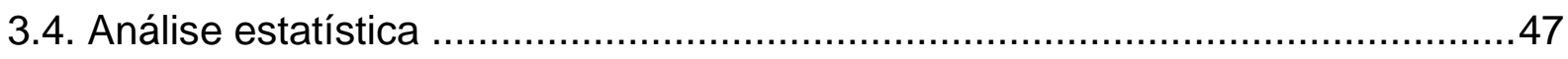

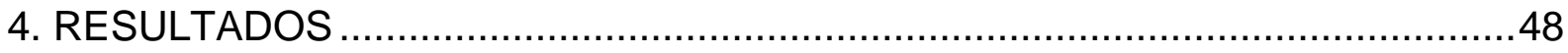

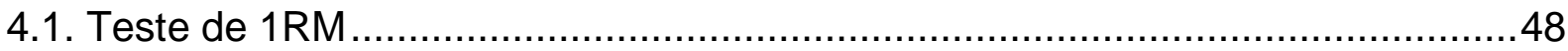

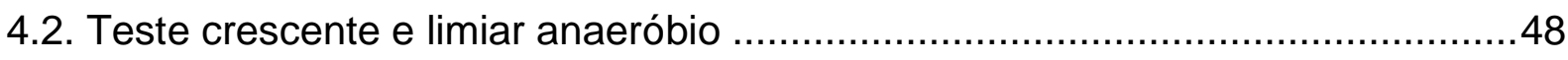

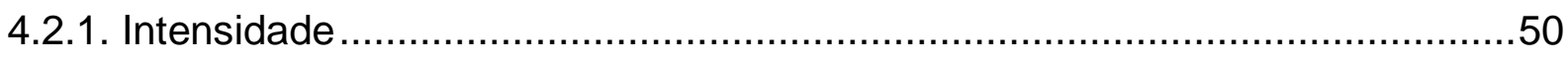

4.2.2. Concentração de lactato sanguíneo ………………………………….....52

4.2.3. Parâmetros ergoespirométricos ..............................................................53

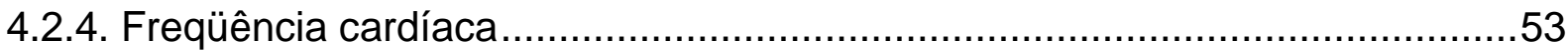

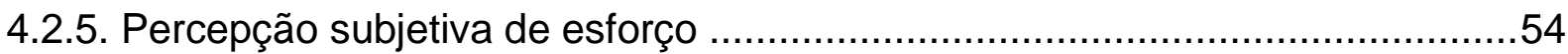

4.3. Máxima fase estável do lactato .................................................................5

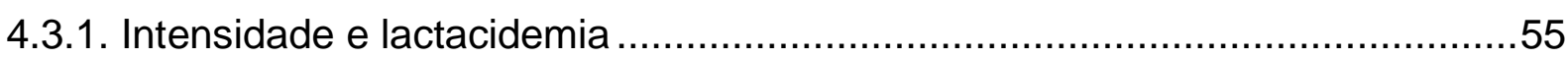

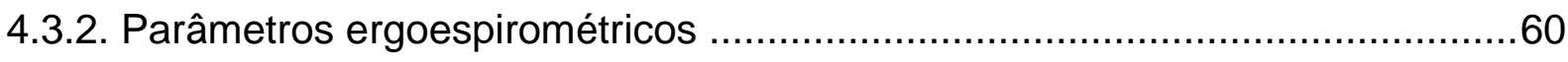

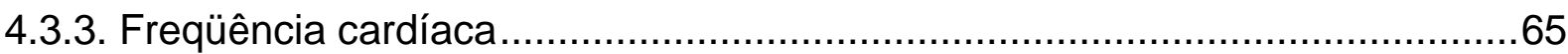

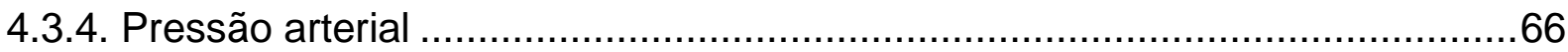

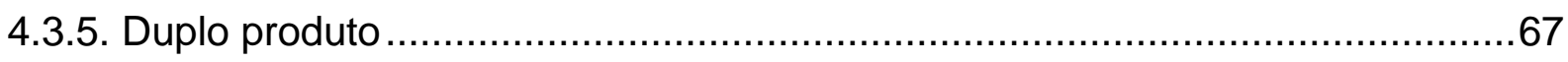

4.3.6. Percepção subjetiva de esforço ………………......................................68

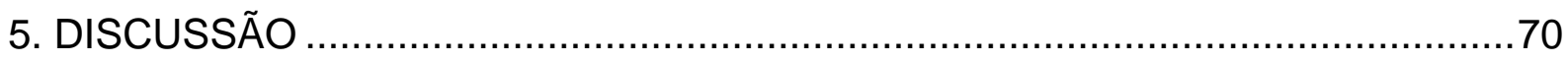


6. CONCLUSÃO

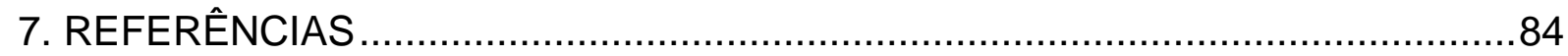

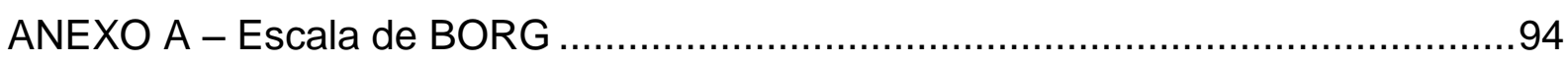

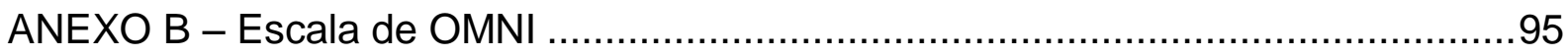




\section{INTRODUÇÃO}

\subsection{Envelhecimento demográfico}

A Organização Mundial da Saúde (OMS) classifica cronologicamente como idoso, pessoa com mais de 65 anos de idade em países desenvolvidos e com mais de 60 anos de idade em países em desenvolvimento. Segundo dados do Instituto Brasileiro de Geografia e Estatística (IBGE), os idosos são hoje 14,5 milhões de pessoas, cerca de $8,6 \%$ da população total do país ${ }^{1}$.

Ainda de acordo com o IBGE, a população brasileira vive, hoje, em média, 68,6 anos, 2,5 anos a mais do que no início da década de noventa ${ }^{1}$. Estima-se que em 2020 a população com mais de 60 anos no país deva chegar a 30 milhões de pessoas ( $13 \%$ do total), e a esperança de vida, a 70,3 anos. O envelhecimento da população brasileira é reflexo do aumento da expectativa de vida, devido ao avanço no campo da saúde e à redução da taxa de natalidade. Prova disso é a participação dos idosos com 75 anos ou mais no total da população - em 1991, eles eram 2,4 milhões $(1,6 \%)$ e, em 2000, 3,6 milhões $(2,1 \%)$. Além de se traduzir no aumento do número de idosos, traduz-se também no tempo vivido por eles, no envelhecimento de certos segmentos populacionais (crescimento do número de famílias nas quais existe pelo menos um idoso) e na mudança dos arranjos familiares.

Este constante envelhecimento da população coloca novos desafios em termos sociais e econômicos e assumindo cada vez mais importância nas políticas de saúde. A própria Assembléia Geral das Nações Unidas em 1995, alertou os governos para que fossem introduzidas medidas específicas de apoio a todos os níveis a esse grupo etário em crescimento². 


\subsection{O processo de envelhecimento}

O envelhecimento tem sido descrito como um processo, ou um conjunto de processos, inerentes a todos os seres vivos e que se expressa pela perda de capacidade de adaptação e pela diminuição da funcionalidade, estando associado a alterações físicas e fisiológicas ${ }^{3}$. Caracteriza-se por um conjunto de alterações involutivas que se repercutem nos diversos aparelhos e sistemas do organismo, desde as capacidades cognitivas, mnésicas, associativas e outras do foro neuropsíquico, até às capacidades físicas mais elementares propriamente ditas, como sejam a resistência muscular, a força, a velocidade e a flexibilidade ${ }^{4}$. Deste modo, o envelhecimento está associado a uma cascata de mudanças morfológicas e fisiológicas que, naturalmente, predispõem os idosos a uma progressiva fraqueza, declínio funcional, morbilidade, invalidez, reduzida qualidade de vida e aumento da mortalidade ${ }^{5}$.

Do ponto de vista fisiológico, o envelhecimento não ocorre uniformemente em toda a população. Portanto, não é aconselhável a definição de "idoso" por meio de alguma idade cronológica específica ou de classes de idades ${ }^{6}$. Spidurso reforça a idéia, mencionando que a idade cronológica não coincide necessariamente com a idade biológica, devido às diferenças de funcionamento orgânico, podendo apresentar diferenças de indivíduo para indivíduo ${ }^{7}$. Nas pessoas idosas, o estado de saúde depende menos da idade cronológica relacionando-se mais com o ciclo de vida, em que a saúde e a doença fazem parte do contínuo, numa espécie de escala natural da vida. Um dos fatores que mais contribui para este processo e que pode conduzir a doenças crônicas é o sedentarismo ${ }^{8}$. 
A prática de atividades motoras em idade mais avançada poderá retardar o processo de envelhecimento, podendo não prolongar a longevidade do idoso, mas melhorando a sua qualidade de vida, tornando-o menos vulnerável a qualquer tipo de distúrbio, quer fisiológico, quer psicológico ou social ${ }^{9}$.

\subsection{Alterações fisiológicas, estruturais e funcionais com o envelhecimento}

As mudanças morfológicas e funcionais que acontecem no decorrer da vida devem-se à conjugação de três fatores: fenômeno do envelhecimento, presença de doenças e estilo de vida ${ }^{10}$. O primeiro fator, envelhecimento, é amplamente associado a alterações em todos os sistemas fisiológicos, como será referido em seguida.

\subsubsection{Sistema cardiovascular}

Alterações cardiovasculares típicas com o envelhecimento incluem a transformação das grandes artérias centrais em vasos rígidos ${ }^{11}$. Os vasos rígidos dos idosos perdem a capacidade de impulsionar o sangue durante o período da diástole, pois diminuem os movimentos de distensão e recolhimento, acabando por ser primordialmente o coração a exercer a função de impulsionar o sangue.

Além de mudanças dos constituintes da camada intima dos vasos sanguíneos que leva ao seu enrijecimento, a capacidade das células endoteliais do lúmen dos vasos de sintetizar peptídeos vasodilatadores também diminui com a idade ${ }^{12}$. Assim, ocorre um declínio na distensibilidade vascular e uma tendência para o aumento do 
trabalho cardíaco com o aumento da idade. Estas alterações contribuem também para a redução da reserva cardíaca e tolerância ao exercício.

Analisando centralmente, o coração de um idoso trabalha contra uma póscarga aumentada devido ao enrijecimento da vasculatura central. Portanto, mesmo em idosos normotensos, os miócitos do ventrículo esquerdo apresentam hipertrofia resultante do estresse das paredes do miocárdio. No entanto, tal estimulação dos miócitos também aumenta o processo de apoptose, associado a fibrose e enrijecimento das paredes ventriculares. Deste modo, apesar do coração da maioria dos idosos apresentarem uma suave hipertrofia, os ventrículos estão enrijecidos e propensos a anormalidades de enchimento diastólico e arritmias $^{13}$. Todos esses fatores aumentam a probabilidade de redução do débito cardíaco e aumento da incapacidade funcional ${ }^{14}$.

O envelhecimento também está associado a uma diminuição da regulação autonômica do ritmo cardíaco, com predominante down-regulation dos receptores $\beta$ adrenérgicos ${ }^{15}$, menores índices favoráveis da variabilidade da freqüência cardíaca, e susceptibilidade adicional a $\operatorname{arritmias}^{16}$.

\subsubsection{Músculo esquelético}

Sarcopenia é o termo usado para descrever redução da massa muscular esquelética relacionada ao envelhecimento, provocando a redução do número e tamanho de células do músculo esquelético, diminuindo sua capacidade contrátil ${ }^{17}$.

Entre a segunda e a quinta década de vida, perde-se cerca de $0,5 \%$ a $1 \%$ de massa muscular por ano, declínio este que aumenta nos anos seguintes ${ }^{18}$, diminuindo a performance muscular ${ }^{19}$. A perda de massa muscular afeta 
principalmente o déficit de força observado na terceira idade ${ }^{20-22}$, uma vez que a força muscular diminui cerca de $15 \%$ por década entre os 60 e 80 anos e, a partir dessa idade a diminuição chega a $30 \%$ por década ${ }^{23}$. Esta evidência se torna mais forte através de alguns estudos que demonstraram que, apesar da diminuição da massa muscular, os idosos são capazes de ativar totalmente as unidades motoras durante uma contração voluntária máxima, sugerindo a manutenção do drive central com o envelhecimento ${ }^{24,25}$.

Lexell $^{26}$ demonstrou que a perda de massa muscular está diretamente relacionada com a diminuição do número de fibras musculares, número este que cai cerca de $35 \%$ entre os 52 e os 77 anos de idade ${ }^{27}$, independente da sua tipologia ${ }^{28-}$ 32. Além do declínio no número de fibras explicarem a perca de massa muscular durante o envelhecimento, a atrofia muscular das fibras também é responsável por tal processo ${ }^{28-32}$, atrofia que já é específica ao tipo de fibras. Em outro estudo, Lexell observou que o tamanho das fibras do tipo II (fibras rápidas) é $26 \%$ menor em relação a um adulto jovem, enquanto que as fibras do tipo I não apresentam alterações no seu tamanho ${ }^{30}$. Mesmo em uma análise apenas das fibras rápidas, as fibras do tipo IIB apresentam maiores índices de atrofia que as fibras do tipo $\| A^{28,33}$. A atrofia seletiva das fibras musculares presentes no músculo esquelético é devida a alterações na regulação genética muscular. Assim, fibras senescentes do tipo IIA apresentam um declínio no seu mRNA, uma diminuição acentuada da transcrição das fibras do tipo IIB, mas nenhuma alteração do mRNA das fibras do tipo ${ }^{34}$, contribuindo para a atrofia das fibras de contração rápida sem aparente alteração das fibras de contração lenta. Por este motivo, os movimentos dos idosos são caracterizados como movimentos "lentos", ou seja, começam a perder a capacidade de realizar movimentos com velocidade alta. 


\subsubsection{Capacidade funcional}

A capacidade funcional do idoso também sofre uma diminuição, no entanto, o decréscimo que normalmente é atribuído ao aumento da idade, como freqüência cardíaca máxima e débito cardíaco, apenas representa uma pequena parte do declínio funcional ${ }^{35}$. Alterações relacionadas com a idade, na distribuição de sangue aos tecidos periféricos, biomecânica celular modificada e redução da massa isenta de gordura são os maiores responsáveis pela diminuição da capacidade funcional ${ }^{36}$.

Uma das variáveis mais importantes para a população idosa é a capacidade aeróbia, mensurada através do consumo máximo de oxigênio $\left(\mathrm{VO}_{2 m a ́ x}\right)$, uma vez que níveis baixos de $\mathrm{VO}_{2 m a ́ x}$ reflete uma capacidade funcional fraca. Esta variável declina a partir da segunda década de vida ${ }^{6}$, sendo sua magnitude dependente de fatores genéticos, bem como dos níveis de atividade física realizada pelo indivíduo ${ }^{37}$. Contudo, sua redução observada com o envelhecimento pode estar relacionada tanto à diminuição do débito cardíaco máximo, como da captação de oxigênio pelos tecidos $^{38}$ - diminuição da diferença arterio-venosa de oxigênio, ou mesmo, a fatores respiratórios.

Desta forma, intervenção que aprimore os sistemas fisiológicos, como o exercício físico, pode ter um papel relevante em diminuir a incidência de doenças crônicas, dependência e mortalidade em pessoas idosas ${ }^{39}$. Neste contexto, o treinamento físico resistido tem sido enfaticamente incentivado para pessoas idosas $^{40}$, devidamente ajustado às suas capacidades físicas e reserva funcional, de forma a preservar e desenvolver suas funções cardiovasculares, ventilatórias e metabólicas em um nível mais alto que os indivíduos sedentários de idade 
equivalente ${ }^{41}$. Conseqüentemente, a prática de exercícios resistidos pode aumentar a síntese e a manutenção de proteínas contráteis e tornar mais lenta a perda que ocorre normalmente na massa e força muscular ${ }^{40,41}$.

\subsection{Exercícios resistidos}

Os chamados exercícios resistidos, de musculação, ou exercícios contra resistência, geralmente são realizados com pesos, embora existam outras formas de oferecer resistência à contração muscular.

Nos dias de hoje, o treinamento resistido, popularmente denominado de musculação, é uma das modalidades de exercício mais praticadas ${ }^{42}$. Apresenta-se como uma forma segura de realização de exercício físico quando adequadamente prescrito e realizado, justificando sua indicação para pessoas debilitadas, idosas, obesas, diabéticas, cardiopatas e crianças ${ }^{43}$. A segurança músculo-esquelética do treinamento resistido deve-se à ausência dos principais fatores indutores de lesões, como impacto, traumas e quedas, variações de velocidade e direção de movimento ${ }^{43}$.

Segundo Kraemer et al. ${ }^{44}$, o treinamento resistido possui alguns fatores que podem ser manipulados e que irão influenciar as respostas agudas e crônicas do praticante, denominados variáveis do treinamento resistido. Estas variáveis podem ser direcionadas durante o treinamento para o alcance dos objetivos prédeterminados, e envolvem: 1) Intensidade; 2) Volume; 3) Intervalos entre as séries; 4) Seqüência dos exercícios; 5) Velocidade de movimento; 6) Exercícios selecionados e estrutura do treino; 7) Freqüência de treinamento; 8) Ações musculares utilizadas. Analisando cautelosamente cada uma delas, percebe-se que 
podem ser muito variadas, e o conjunto delas resulta em um número grande de possibilidades na montagem das sessões de treinamento ${ }^{45}$.

De acordo com Wernbom et $a l .^{46}$, a quantificação da dose-resposta destas variáveis e as adaptações advindas de sua manipulação é fundamental para a prescrição apropriada dos exercícios resistidos, apesar de que é clara a dificuldade em se isolar qualquer uma das variáveis para que possa ser estudada.

\subsubsection{Supino reto e leg press}

No universo da musculação, uma grande variedade de exercícios pode ser adotada para desenvolver um mesmo agrupamento muscular. Entretanto, um exercício normalmente é o mais indicado para cada situação específica. Desse modo, o estudo biomecânico torna-se importante para a seleção dos exercícios, de modo a otimizar os estímulos em cada segmento corporal.

Entre os exercícios mais utilizados destaca-se o Leg Press 45ำ (LP) para o desenvolvimento da musculatura da parte inferior do corpo e o Supino Reto (SR) para desenvolver a musculatura da parte superior do corpo.

O LP ou extensão do joelho no aparelho é caracterizado pela extensão do joelho com o quadril flexionado, tendo seu início com o indivíduo sentado com as costas apoiadas e os pés posicionados sobre a plataforma do aparelho. O mesmo deverá inspirar, desbloquear a trava de segurança e flexionar os joelhos ao máximo, de modo a levá-los até o nível das costelas na caixa torácica - fase excêntrica. Expirar ao final do movimento finalizando com a extensão dos joelhos - fase concêntrica. Este exercício multiarticular desenvolve os maiores e mais poderosos 
músculos do corpo, possuindo similaridades biomecânicas e neuromusculares para muitos movimentos esportivos ou do dia a dia, como caminhar, correr ou saltar.

Em relação ao SR, ele se realiza deitado em decúbito dorsal sobre um banco e braços em extensão, segurando uma barra. Na fase excêntrica do movimento ocorre a flexão do cotovelo e abdução horizontal da articulação escapulo-umeral, até ao ponto onde a barra encosta no tórax. Por sua vez, durante a fase concêntrica do movimento realiza-se a adução horizontal da articulação escapulo-umeral e extensão do cotovelo. Também é um exercício multiarticular, possuindo similaridades biomecânicas e neuromusculares com movimentos esportivos e do dia a dia, como natação ou o simples movimento de pegar e transportar objetos.

Assim, a decisão pela escolha destes dois exercícios para desenvolvimento da pesquisa se deu por várias razões, que passamos a enumerar: (1) um exercício para a parte inferior do corpo e outro para a parte superior; (2) um exercício envolvendo maior massa muscular, o LP, e outro envolvendo menor massa muscular, o SR; (3) exercício com alavanca facilitadora do movimento e outro com alavanca mais difícil; (4) exercícios vastamente utilizados tanto na prática de musculação como para pesquisa; (5) exercícios multiarticulares, exigindo maior coordenação neural entre os músculos ${ }^{47}$, podendo apresentar um padrão diferenciado na solicitação dos músculos motores primários e sinergistas.

\subsection{Exercício resistido e suas respostas hemodinâmicas, musculares e} cardíacas

Embora os programas de exercícios físicos tenham tradicionalmente enfatizado os exercícios dinâmicos para ganho de capacidade aeróbia, pesquisas 
recentes têm demonstrado que os exercícios resistidos também podem ser adicionados como forma complementar, proporcionando efeitos favoráveis na força e endurance muscular, na função cardiovascular, metabolismo, na redução do risco cardiovascular e nos aspectos psicossociais ${ }^{48-53}$.

É comum a caracterização de um exercício de natureza aeróbia pelo percentual do consumo máximo de oxigênio $\left(\mathrm{VO}_{2 m a ́ x}\right)$, no entanto, são poucos os estudos que avaliam o consumo de oxigênio $\left(\mathrm{VO}_{2}\right)$ em exercícios resistidos. Gotshalk et al..$^{54}$ avaliaram um grupo de voluntários durante um treinamento em circuito, com vários grupos musculares, a $40 \%$ de $1 \mathrm{RM}$ e demonstraram que 0 consumo de oxigênio é aproximadamente $50 \%$ do $\mathrm{VO}_{2 \text { máx }}$ determinado em esteira. Apesar de valores bem menores, os autores consideram suficiente para promover uma resposta de adaptação cardiovascular ao treinamento. Durante a realização do referido circuito, $\mathrm{o} \mathrm{VO}_{2}$ estabilizou após 7,5 minutos de exercício, porém, foram observados aumentos na freqüência cardíaca até ao término do circuito.

Seguindo a mesma linha, em trabalho realizado no nosso laboratório foi verificado o consumo de oxigênio e gasto energético em oito mulheres jovens e saudáveis, durante a realização de treinamento resistido em circuito na intensidade do LAn para cada exercício ${ }^{55}$. Encontraram-se valores médios de consumo de oxigênio de $0,53 \pm 0,08 \mathrm{~L} \cdot \mathrm{min}^{-1}$ e gasto energético de 2,68 $\pm 0,34 \mathrm{Kcal}$ por minuto, que foram significativamente menores que os valores encontrados quando as mesmas voluntárias realizaram exercício em esteira na intensidade do LAn $(1,44 \pm$ 0,27 L. $\mathrm{min}^{-1}$ e $7,16 \pm 1,36 \mathrm{Kcal} / \mathrm{min}$, respectivamente).

Entretanto, em outro estudo que avaliou as variáveis ventilatórias em exercícios resistidos isolados a $40 \%$ de $1 \mathrm{RM}$, o consumo de oxigênio durante a realização da rosca direta foi de aproximadamente $35 \%$ do $\mathrm{VO}_{2 \text { pico, }}$, determinado em 
ciclo ergômetro, enquanto que na realização do LP, que envolve maior massa muscular foi de $52 \%$ do exercício aeróbio ${ }^{56}$, em indivíduos com insuficiência cardíaca. Este estudo reforça a idéia de que quanto maior a massa muscular envolvida em um exercício maior é o consumo de oxigênio ${ }^{54}$. Porém, mesmo um exercício que envolva grande massa muscular como o LP ainda não induz a um consumo de oxigênio comparável àquele atingido em exercícios de corrida ou cicloergometro, apesar deste também ser dependente da carga imposta pelo exercício.

A intensidade do treinamento resistido dos estudos citados anteriormente foi baixa, relatando um consumo de oxigênio não acima de $50 \%$ do determinado em esteira. No entanto, quando a intensidade do exercício resistido aumenta, o consumo de oxigênio total também é maior, assim como o gasto energético ${ }^{57}$.

Ainda assim, é escassa a literatura sobre os ajustes cardiovasculares, ventilatórios e metabólicos nos diferentes tipos de exercício resistido, sendo que com relação a estes ajustes, atualmente é utilizada a técnica denominada de ergoespirometria, que tem por finalidade avaliar o desempenho físico ou a capacidade funcional de um indivíduo, conciliando a análise de gases espirados e variáveis respiratórias, bem como permite um valioso estudo da integração entre os sistemas cardiovascular, pulmonar e músculo-esquelético ${ }^{58}$.

Uma das principais contribuições que essa técnica traz é a possibilidade de se determinar a ventilação (VE), consumo de oxigênio (VO2), produção de dióxido de carbono (VCO2), quociente respiratório (QR) e gasto calórico, além de determinar fatores ligados a indicadores preditores de desempenho, identificação de intolerância ao exercício, transição metabólica, avaliação clínica e terapêutica de 
diversas doenças, prescrição de intensidade do exercício, índices de eficiência respiratória e cardiovascular e custo energético ${ }^{58,59}$.

Em relação às respostas hemodinâmicas, quanto maior a intensidade do exercício, maiores vão ser os aumentos de freqüência cardíaca (FC), pressão arterial (PA) e duplo-produto (DP) ${ }^{60,61}$. Tem sido demonstrado que a relação FC/PA é menor durante o exercício resistido dinâmico que durante o exercício aeróbio máximo, devido a uma diminuição da resposta pico da $\mathrm{FC}^{51}$. Durante os exercícios resistidos, ocorre aumento da perfusão subendocárdica e a elevação da pressão arterial diastólica e diminuição do retorno venoso, do volume diastólico do ventrículo esquerdo e da tensão da parede, contribuindo assim para a diminuição da resposta isquêmica em pacientes cardíacos ${ }^{51}$.

Os maiores aumentos de pressão arterial e freqüência cardíaca são observados quando ocorre a manobra de Valsalva juntamente com a execução do exercício $^{62}$. Além disso, a PA e FC aumentam durante a realização de uma série, sendo os picos encontrados nas últimas repetições ${ }^{61}$, o que faz com que a interdependência entre volume e intensidade também exerça influência nas respostas cardiovasculares.

O número de repetições de uma série também influencia as respostas pressóricas e de freqüência cardíaca. Lamotte et al. ${ }^{63}$ demonstrou tal evidência ao utilizar um protocolo de baixa intensidade com 4 séries de 17 repetições a $40 \%$ de $1 \mathrm{RM}$ e outro de alta intensidade com 4 séries de 10 repetições a $70 \%$ de $1 \mathrm{RM}$, observando maior resposta pressórica nas séries de baixa intensidade. Assim, além da resposta pressórica e freqüência cardíaca aumentarem com a intensidade do exercício, aumentos consideráveis do número de repetições também desencadeia um aumento nessas duas variáveis. 
Contudo, sabe-se que a magnitude destas respostas está relacionada à intensidade, duração, freqüência e volume de exercício resistido. Estes aspectos têm sido pouco explorados, considerando a população idosa, uma vez que a mesma necessita de adicionais cuidados para a realização do exercício resistido ou de força. Apesar dessa preocupação com esses indivíduos, é preciso que o treinamento resistido seja mais enfatizado, já que os idosos possuem uma plasticidade impressionante nas características fisiológicas, estruturais e relacionadas ao desempenho. O músculo esquelético responde ao treinamento vigoroso com um aprimoramento acentuado e rápido até a nona década de vida ${ }^{64}$.

Em suma, os ajustes cardiovasculares e respiratórios durante o exercício resistido estão na dependência da intensidade, duração e percentual da contração voluntária máxima ${ }^{65,66}$. Deste modo, a lactacidemia, as respostas da FC e das trocas gasosas podem ter uma relação estreita durante o exercício resistido nestes indivíduos.

\subsection{Bases fisiológicas para o treinamento resistido}

A crescente demanda pelo treinamento resistido tem incentivado a procura de melhores metodologias para prescrição destes exercícios. Dentre os métodos de avaliação para sua prescrição, o teste de uma repetição máxima (1RM) tem sido muito utilizado na população idosa ${ }^{67}$, estabelecendo o percentual de 1RM para se determinar a carga para o treinamento resistido.

Tradicionalmente, é recomendado na literatura a prescrição da intensidade de exercício resistido com percentuais de cargas entre 60 a $80 \%$ de 1RM para população idosa ${ }^{6}$. Entretanto, poucos estudos têm avaliado sistematicamente as 
respostas cardiovasculares, ventilatórias e metabólicas em diferentes intensidades de 1RM, com o objetivo de estudar o comportamento de tais variáveis e seus ajustes frente o envelhecimento. Considerando que estas variáveis têm grande utilidade na prescrição de exercícios físicos aeróbios, a busca do entendimento de tais ajustes possibilitará propor novas metodologias de avaliação para determinar a intensidade ótima de treinamento resistido.

Alguns autores têm observado que programas de treinamento resistido em altas intensidades, com diferentes tipos de população, produzem maiores benefícios que aqueles em baixas cargas de trabalho $0^{68-70}$. No entanto, poucos estudos têm analisado de forma sistematizada diferentes intensidades de exercício resistido com o objetivo de determinar a magnitude das respostas cardiorrespiratórias e metabólicas para então propor novos sistemas de treinamento com diferentes objetivos.

Dessa forma, o entendimento da contribuição aeróbia para o exercício resistido, bem como a demanda energética anaeróbia necessita de algumas investigações no campo da fisiologia aplicada ${ }^{71}$.

\subsubsection{Limiar anaeróbio}

Apesar de muita controvérsia sobre as causas do acúmulo de lactato durante o exercício físico ${ }^{72-74}$, existe consenso na literatura de que a partir de uma determinada intensidade do exercício crescente, o mesmo começa a acumular-se, chegando a provocar exaustão caso atinja concentrações muito elevadas. A intensidade onde ocorre o início do acumulo de lactato no sangue é de relevante 
importância para a prescrição de atividade física, denominada intensidade do Limiar Anaeróbio (LAn).

O termo LAn foi introduzido pela primeira vez em 1964 por Wasserman, que definiu como a intensidade de exercício na qual a concentração sanguínea de lactato começa a aumentar e a concentração de bicarbonato começa a diminuir ${ }^{75}$. Em 1967, propondo parâmetros ergoespirométricos para se estimar o ponto de inflexão da curva de lactato, Wasserman ${ }^{76}$ modificou o conceito de LAn para a intensidade de exercício acima da qual a concentração sanguínea de lactato aumenta de forma progressiva e a ventilação pulmonar se intensifica de maneira desproporcional ao oxigênio consumido.

Operacionalmente, o LAn pode ser definido como o momento, em relação à intensidade do esforço físico ou consumo de oxigênio, quando a produção de ATP é suplementada pela glicólise anaeróbia, com formação de ácido lático. Assim, é a intensidade do exercício onde ocorre a transição do metabolismo predominantemente aeróbio para anaeróbio. Neste sentido, o LAn reflete um ponto crítico, onde intensidades superiores levam a acumulo de lactato sanguíneo, enquanto que em intensidades inferiores ao LAn ocorre manutenção da lactacidemia ou então remoção de parte da quantidade de lactato presente no sangue ${ }^{77}$.

Robergs et al. ${ }^{78}$ propuseram um modelo para explicar o acúmulo de lactato no sangue em intensidades acima do LAn. Apesar da produção de lactato ocorrer no citosol, seu aparecimento é determinado pela incapacidade da célula de produzir o ATP nas mitocôndrias por meio da respiração celular. Quando a hidrólise do ATP e, portanto, sua demanda, excede a taxa de ressíntese de ATP mitocondrial, a célula deve recorrer à produção não mitocondrial de ATP, o que resulta na formação de ácido lático. Porém, cabe ressaltar que durante a formação da molécula de ácido 
lático existe o consumo de dois prótons $\left(\mathrm{H}^{+}\right)$, que são captados de uma molécula de $\mathrm{NADH}$, fazendo com que o ácido lático seja essencial para retardar a acidose e manter a produção de $\mathrm{NAD}^{+}$, um substrato da glicólise que permite o contínuo fornecimento de energia por esta via.

\subsubsection{Determinação do limiar anaeróbio em exercício resistido}

Um dos maiores problemas relacionados à determinação e utilização do LAn ocorre em função do grande número de terminologias empregadas pelos pesquisadores para identificar fenômenos iguais ou semelhantes.

Em exercício físico dinâmico, como corrida ou ciclismo, o LAn é amplamente determinado através de diversos protocolos crescentes com estágios variados de duração, sendo que a intensidade na qual ocorre o ponto de inflexão na curva de lactato é o LAn ${ }^{72}$.

Além da utilização da concentração sanguínea de lactato para determinação do limiar anaeróbio, existem outras metodologias que possibilitam tal determinação. O método do limiar ventilatório proposto por Wasserman ${ }^{72}$ é o mais utilizado. No entanto, existem outras metodologias como a análise de catecolaminas plasmáticas $^{79}$ ou o estudo da variabilidade da freqüência cardíaca ${ }^{80}$. Outro método bastante interessante e desenvolvido em nosso laboratório é a utilização de dosagens glicêmicas ${ }^{81}$ para determinação do limiar anaeróbio metabólico, sendo que a intensidade a qual corresponde a menor concentração de glicose sanguínea é denominada como a intensidade do limiar glicêmico (LG).

A procura por técnicas cada vez mais aperfeiçoadas para determinação do LAn permitiu o desenvolvimento de vários métodos matemáticos para análise de 
curvas de lactato sanguíneo, procurando retirar a subjetividade de uma simples análise visual ${ }^{82-84}$. Entre estes métodos, podemos destacar análise algorítmica, baseada no estudo de Orr et al. ${ }^{83}$ e utilizada por vários autores ${ }^{79,85}$. Neste modelo, a determinação do ponto de inflexão é realizada através da aplicação de dois modelos de regressão linear nos dados da concentração sanguínea, baseada no agrupamento da menor soma dos quadrados dos erros.

Através de todas essas metodologias, a literatura torna-se rica em relação às diversas técnicas de avaliação e utilização do limiar anaeróbio na prescrição do treinamento de exercícios aeróbios dinâmicos.

No entanto, apesar de literatura vasta para determinação do LAn em exercícios aeróbios dinâmicos, poucas pesquisas estudaram o comportamento da curva de lactacidemia em exercícios resistidos crescentes.

A determinação do LAn em exercícios resistidos foi inicialmente realizada por Barros et al. ${ }^{86}$, que determinaram o limiar anaeróbio de indivíduos treinados e destreinados nos exercícios LP e rosca direta. Em um protocolo desenvolvido pelos autores, foi realizado o teste de 1RM para os exercícios, seguido de um teste crescente, iniciado com $10 \%$ de $1 \mathrm{RM}$, e a cada série acrescentava-se $10 \%$ de 1RM. A duração de cada estágio foi de 1 minuto, onde realizavam 20 repetições, com dois minutos de intervalo passivo, tempo este destinado à coleta de sangue, feita imediatamente após o termino de cada estágio, e elevação da carga. Os autores demonstraram que o LAn ocorria em torno de $30 \%$ de $1 \mathrm{RM}$, tanto para indivíduos treinados como destreinados e independentemente da massa muscular envolvida.

Posteriormente, Moreira et al. $^{87}$ determinaram o LAn e LG em indivíduos fisicamente ativos com diabetes tipo 2 em exercícios resistidos. O protocolo incremental foi realizado com cargas de 10\%, 20\%, 25\%, 30\%, 35\%, 40\%, 50\%, 
$60 \%, 70 \%, 80 \%$ e $90 \%$ de $1 \mathrm{RM}$, com séries de 30 repetições, realizadas em 1 minuto, e dois minutos de intervalo para coleta de amostras de sangue nos exercícios LP e SR. O LAn e o LG para o LP foram encontrados em 31,0\% e 32,1\% de 1RM e para o SR em $29,9 \%$ e $32,1 \%$ de 1 RM, respectivamente.

Em relação a uma população idosa, Simões et al. ${ }^{88}$ também identificaram o LAn em aproximadamente $30 \%$ de $1 \mathrm{RM}$ para o exercício LP, através de exercício crescente com duração de estágios de quatro minutos e velocidade de 12 repetições por minuto.

Nos três estudos anteriormente descritos ${ }^{86-88}$, o LAn foi explicado, especialmente, pelo fator hemodinâmico provocado pelas contrações musculares. Em um teste crescente, ocorre aumento da pressão intramuscular que pode restringir o fluxo sanguíneo nos capilares, fazendo com que as células musculares tenham que produzir energia na ausência de oxigênio, através da via glicolítica com produção de ácido lático, posteriormente removido para o sangue.

A existência de um limiar anaeróbio em exercícios resistidos levanta a hipótese de que possa haver uma carga de trabalho de estabilização da lactacidemia, o que seria a máxima fase estável de lactato em exercícios resistidos.

\subsubsection{Máxima fase estável do lactato}

A máxima fase estável de lactato (MFEL) é definida como a maior concentração de lactato (cMFEL) que pode ser alcançada para a manutenção de um estado de equilíbrio em um exercício submáximo com carga de trabalho constante. Assim, a carga de trabalho correspondente à MFEL (wMFEL) representa a maior intensidade submáxima que pode ser realizada sem a contribuição do metabolismo 
anaeróbio $^{89,90}$. Acima da intensidade da MFEL, a cinética da concentração do lactato sanguíneo apresenta um claro aumento com o tempo durante um exercício com carga constante ${ }^{89,90}$.

Quando um exercício é realizado na MFEL, o lactato não se acumula no plasma, e presume-se que o metabolismo aeróbio seja suficiente para suprir toda a demanda energética do exercício, portanto a mensuração do consumo de oxigênio pode quantificar o consumo energético do exercício e, além disso, a fadiga é minimizada e o tempo de exaustão é relativamente longo ${ }^{77}$. Por este motivo, existe uma grande relação entre a carga de trabalho associada à MFEL e a performance em atividades de longa duração.

No entanto, devido à MFEL ser o principal método para determinação da maior carga de trabalho que pode ser mantida sem o contínuo acúmulo de lactato no sangue, foram desenvolvidos vários protocolos para sua mensuração ${ }^{89,} 90$.

Todos os métodos diferem, basicamente, no tempo de duração, período de observação da cinética do lactato e a sua concentração máxima de aumento aceite. A metodologia mais utilizada na literatura é a realização de séries de exercícios com intensidade constante e duração de 30 minutos em diferentes dias. Através dessas séries de exercícios, a MFEL é definida como a maior carga de trabalho onde a concentração de lactato sanguíneo não aumenta mais de $1 \mathrm{mmol} \cdot \mathrm{L}^{-1}$ nos últimos 20 minutos do teste ${ }^{90,91}$. A tabela 1.1 mostra os protocolos mais difundidos na literatura para determinação da MFEL.

A maioria das diferenças encontradas nas metodologias se deve ao fato de que o tempo para se atingir um estado de equilíbrio na lactacidemia pode demorar de 2 a 5 minutos, dependendo do grau de elevação do lactato e do incremento de carga durante o teste incremental ${ }^{92}$. Existe uma faixa de carga de trabalho em um 
exercício de intensidade constante em que o lactato sanguíneo se mantém estável após um primeiro aumento exponencial.

Tabela 1.1 - Metodologias para determinação da Máxima Fase estável de Lactato. Adaptado de Beneke ${ }^{93}$

\begin{tabular}{llll}
\hline Autores & Modalidade & $\begin{array}{l}\text { Duração do } \\
\text { teste (min) }\end{array}$ & $\begin{array}{l}\text { Aumento máximo da } \\
{\left[\text { Lac] }\left(\mathbf{m m o l}^{-1} \cdot \mathbf{m i n}^{-1} \text { ) }\right.\right.}\end{array}$ \\
\hline Aunola \& Rusko (1992) & Cicloergometro & $?$ & 0,025 \\
Beneke (1995) & Cicloergometro & 20 & 0,05 \\
Beneke et al. (1996) & Cicloergometro & 30 & 0,05 \\
Beneke \& Von Duvillard (1996) & Remoergometro & 30 & 0,05 \\
Billat et al. (1994) & Esteira & 20 e 30 & $?$ \\
Haverty et al. (1988) & Esteira & 20 & 0,02 \\
Heck (1990) & Cicloergometro & 30 & 0,05 \\
Heck et al. (1985) & Esteira & 28 & 0,05 \\
Mocellin et al. (1990) & Esteira & 15,5 & 0,04 ou 0,08 \\
Stockhausen et al. (1995) & Cicloergometro & 24 & 0,04 \\
Urhausen et al. (1993) & Cicloergometro & 30 & 0,05 \\
Williamsand Armstrong (1991) & Esteira & 10 & 0,1 \\
\hline
\end{tabular}

Outra variável importante é o tempo de exaustão nesta intensidade de exercício e, apesar de ainda ser pouco estudada, estima-se que seja por volta de 60 minutos $^{94}$. Baron et al. ${ }^{95}$ avaliaram o tempo de exaustão na MFEL em ciclo ergômetro e a resposta de vários parâmetros fisiológicos de indivíduos treinados, no intuito de determinar qual seria a causa de fadiga quando o exercício é realizado na MFEL. O tempo médio de exaustão foi de $55 \pm 8$ minutos e não foram observadas mudanças do décimo minuto até o término do exercício para as concentrações 
arteriais de piruvato, bicarbonato, hemoglobina, $\mathrm{pO}_{2}$, saturação do oxigênio $\left(\mathrm{sO}_{2}\right)$, osmolaridade, hematócrito, além do consumo de oxigênio, produção de $\mathrm{CO}_{2}\left(\mathrm{VCO}_{2}\right)$ e quociente respiratório $(\mathrm{QR})$. A partir do décimo minuto de exercício, ocorreu redução da lactacidemia, pressão parcial do $\mathrm{CO}_{2}\left(\mathrm{pCO}_{2}\right)$, aumento de $\mathrm{pH}$ e base excess (BE). Os parâmetros de percepção subjetiva de esforço (PSE), ventilação e freqüência cardíaca aumentaram do décimo minuto para o final do exercício. Apesar destas modificações, os autores não conseguiram determinar qual foi a causa da fadiga no exercício realizado na MFEL em ciclo ergômetro, e os mecanismos biológicos de fadiga foram associados a um controle homeostático de sistemas fisiológicos periféricos durante o exercício ${ }^{95}$.

O mesmo grupo de pesquisa ${ }^{96}$ já havia comprovado que a MFEL não corresponde a um completo estado estável fisiológico. Durante 30 minutos de exercício em ciclo ergômetro na MFEL, os parâmetros avaliados foram similares ao outro estudo realizado ${ }^{95}$, demonstrando que apesar da estabilização da lactacidemia, não se pode dizer que a MFEL corresponde a um completo estado estável fisiológico, onde ocorrem aumentos de freqüência cardíaca e ventilação, e portanto estes dois parâmetros não podem ser avaliados individualmente para determinar se um indivíduo está realizando um exercício na carga da MFEL.

A importância da avaliação e utilização da MFEL na prescrição de treinamento foi demonstrada por Billat et al. ${ }^{97}$, que treinaram 11 corredores fundistas experientes durante 6 semanas na velocidade da MFEL (vMFEL), e demonstraram que após o período de treinamento, os atletas apresentaram pequenos mas significantes aumentos na VMFEL e no consumo máximo de oxigênio $\left(\mathrm{VO}_{2 \text { máx }}\right)$. Outro benefício encontrado pelos autores foi aumento do tempo em que os indivíduos entraram em exaustão, que representa o chamado endurance, ou 
resistência muscular localizada, definido como a capacidade de suportar um exercício por longo período de tempo ${ }^{97}$. Em outro estudo ${ }^{98}$, foram avaliados corredores moderadamente treinados, que passaram por um período de treinamento de 4 semanas na vMFEL e também apresentaram aumentos na VMFEL e $V_{2} O_{2 m a ́ x}$ ainda maiores que aqueles encontrados no estudo de Billat. Esses estudos ${ }^{97,98}$ comprovam que a MFEL, além de parâmetro de avaliação e determinante de performance, também serve como estímulo de treinamento para a vMFEL, $\mathrm{VO}_{2 \max } \mathrm{e}$ endurance, indicando que indivíduos com menor grau de treinamento podem ser os maiores beneficiados pelo treino na VMFEL.

Além da avaliação em corredores, a MFEL também foi descrita em ciclistas ${ }^{99-}$ ${ }^{101}$, remadores ${ }^{102}$, triatletas $^{103}$ e em protocolos envolvendo ratos ${ }^{104,105}$. A possível influência da idade na intensidade da MFEL também já foi analisada. Mattern et al. ${ }^{106}$ referem que a intensidade da MFEL sofre uma diminuição com o processo de envelhecimento, independente da diminuição do $\mathrm{VO}_{2 m a ́ x}$. Os autores vão mais longe, afirmando uma diminuição de cerca $10 \%$ dos 25 para os 64 anos.

Entretanto, como mostrado na tabela 1.1, apesar de existirem vários protocolos para diferentes modalidades, não há estudos na literatura que tenham estabelecido a existência da MFEL em exercícios resistidos. Como descrito anteriormente, apenas encontramos na literatura escassos estudos ${ }^{86,} 87$ que demonstram a existência de LAn através de testes em carga crescente com determinação do ponto de inflexão da concentração de lactato sanguíneo.

O conceito de MFEL em exercício resistido proporcionaria um modelo de dois componentes, aeróbio e anaeróbio, de fornecimento bioenergético humano para este tipo de exercício, onde tem sido generalizado como predominantemente anaeróbio. Por outro lado, pode demarcar a transição do exercício resistido 
moderado para o exercício intenso. O exercício moderado poderia teoricamente ser mantido indefinidamente, por um longo período de tempo sem fadiga muscular. Neste contexto, é definida como hipótese deste estudo que em uma determinada intensidade de exercício resistido, o indivíduo poderá se exercitar com o maior número de repetições sem que ocorra aumento do lactato sanguíneo, considerada a MFEL. Considerando que as respostas são dependentes do \%1RM e da quantidade de massa muscular envolvida, da mesma forma que no exercício dinâmico, parece haver relação entre a intensidade de esforço com os ajustes cardiocirculatórios, ventilatórios e metabólicos envolvidos no exercício resistido. Em exercício dinâmico, todos estes parâmetros apresentam equilíbrio na MFEL, hipótese que será testada em exercício resistido.

No entanto, embora existam evidências de que há interação entre as respostas cardiovasculares, metabólicas e ventilatórias durante o exercício resistido, a existência de MFEL ainda não foi descrita na literatura. Sua existência permitirá uma análise comparativa das respostas metabólicas integradas do exercício de membros inferiores e membros superiores na MFEL. Além disso, também permitirá determinar as diferenças entre jovens e idosos nas respostas cardiovasculares, ergoespirométricas e lactacidémicas ao exercício resistido Neste sentido, a avaliação das respostas cardiovasculares, ergoespirométricas e de lactato, contribuirá para o entendimento dos ajustes integrados dos sistemas muscular, cardiovascular, respiratório e metabólico durante esta modalidade de exercício.

Desta forma, o estudo do entendimento integrado dos ajustes cardiorrespiratórios e metabólicos em um protocolo de exercício resistido em diferentes aparelhos fornecerá embasamento teórico para propor estratégias para 
melhor prescrição da intensidade do exercício resistido, de acordo com a melhora da endurance ou força em diferentes populações. 


\section{OBJETIVOS}

\subsection{Gerais}

Verificar a existência da máxima fase estável de lactato (MFEL) em exercícios resistidos para idosos e jovens e em que intensidade, expressa em percentual de 1RM, ela ocorre.

\subsection{Específicos}

2.2.1. Confirmar a existência do limiar anaeróbio nos exercícios Leg Press e Supino Reto para as duas populações estudadas;

2.2.2. Comparar a intensidade da máxima fase estável do lactato para as duas populações estudadas nos dois exercícios realizados;

2.2.3. Comparar a intensidade máxima alcançada e concentração sanguínea de lactato no final de teste crescente para os exercícios Leg Press e Supino Reto para as duas populações estudadas;

2.2.4. Verificar e comparar as respostas ergoespirométricas durante os exercícios Leg Press e Supino Reto nas duas populações, realizados na intensidade da MFEL;

2.2.5. Determinar e comparar o comportamento da PSE, pressão arterial, FC e duplo produto (DP) durante os exercícios Leg Press e Supino Reto nas duas populações, realizados na intensidade da MFEL. 


\section{PROCEDIMENTOS METODOLÓGICOS}

\subsection{Amostra}

Participaram do estudo 11 indivíduos idosos saudáveis e 13 jovens, todos do sexo masculino. As características antropométricas são apresentadas na Tabela 3.1.

Tabela 3.1 - Características antropométricas dos voluntários

\begin{tabular}{lcccccccc}
\hline & \multicolumn{3}{c}{ Jovens $(\mathrm{n}=13)$} & \multicolumn{5}{c}{ Idosos $(\mathrm{n}=11)$} \\
\hline & $\begin{array}{c}\text { Idade } \\
(\text { anos })\end{array}$ & $\begin{array}{c}\text { Estatura } \\
(\mathrm{cm})\end{array}$ & $\begin{array}{c}\text { Massa } \\
\text { Corporal } \\
(\mathrm{Kg})\end{array}$ & $\begin{array}{c}\mathrm{IMC} \\
\left(\mathrm{Kg} / \mathrm{m}^{2}\right)\end{array}$ & $\begin{array}{c}\text { Idade } \\
(\text { anos })\end{array}$ & $\begin{array}{c}\text { Estatura } \\
(\mathrm{cm})\end{array}$ & $\begin{array}{c}\text { Massa } \\
\text { Corporal } \\
(\mathrm{Kg})\end{array}$ & $\begin{array}{c}\text { IMC } \\
\left(\mathrm{Kg} / \mathrm{m}^{2}\right)\end{array}$ \\
\hline Média & 26,1 & 181,0 & 83,8 & 25,5 & 68,9 & 170,5 & 76,1 & 26,1 \\
DP & 2,9 & 7,0 & 8,7 & 2,1 & 4,0 & 4,8 & 7,8 & 1,8 \\
Mínimo & 21,0 & 170,0 & 70,0 & 23,1 & 60 & 162,0 & 64,8 & 24,0 \\
Máximo & 33,0 & 192,0 & 98,5 & 29,1 & 73 & 176,0 & 89,6 & 29,3 \\
\hline
\end{tabular}

DP: Desvio Padrão; IMC: Índice de Massa Corporal.

Os critérios de inclusão utilizados para seleção da amostra foram os seguintes: (1) gênero masculino; (2) faixa etária de 20 a 35 anos e de 60 a 75 anos; (3) realização de atividades físicas no mínimo 1 hora por sessão e três vezes por semana, com experiência prévia em pelo menos seis meses em treinamento resistido.

Também foram adotados alguns critérios de exclusão, como: (1) tabagismo; (2) etilismo; (3) problemas cardíacos ou respiratórios; (4) problemas articulares ou musculares que limitassem a realização dos movimentos; (5) patologias que 
pudessem interferir no metabolismo do indivíduo, como diabetes, dislipidemias e anemia; (6) uso de recursos ergogênicos ou esteróides anabólicos androgênicos nos seis meses que antecederam o estudo.

O projeto foi aprovado pelo comitê de ética da Universidade Federal de São Carlos através do parecer número 494.2009. Os indivíduos foram informados dos riscos inerentes ao experimento e assinaram um termo de consentimento livre esclarecido antes da participação nos testes.

\subsection{Protocolos de avaliação}

\subsubsection{Antropometria}

A estatura foi medida com os indivíduos descalços, em posição ortostática, com a utilização de um estadiômetro com precisão de $1 \mathrm{~mm}$ ( secaß). Uma fita posicionada a 2 metros do solo era baixada até tocar o vértix da cabeça do voluntário, e a altura identificada no estadiômetro era registrada.

A massa corporal foi verificada em balança digital com precisão de $100 \mathrm{~g}$ (TANITA®), com os indivíduos em posição ortostática e voltados de costas para o marcador da balança. Para a medição os voluntários trajavam apenas shorts leves, e do peso identificado foram retirados $200 \mathrm{~g}$, considerados o peso do traje utilizado.

O índice de massa corporal foi calculado a partir da razão da massa corporal, dividida pelo quadrado da altura. 


\subsubsection{Teste de uma repetição máxima}

Após uma breve familiarização dos movimentos a realizar, o primeiro procedimento realizado foi o teste de uma repetição máxima (1RM) para os exercícios supino reto e leg press. Uma repetição máxima é a maior quantidade de peso, em kilogramas $(\mathrm{kg})$, que pode ser erguida em um movimento, sem que haja modificações no padrão de movimento.

Antes do inicio do teste, foi permitido aos indivíduos realizarem uma breve sessão de alongamento como as realizadas antes de seus treinos, caso julgassem necessário. Em seguida, todos os indivíduos executavam uma série de aquecimento de oito repetições a 50\% de 1 RM estimada de acordo com a experiência de treinamento dos participantes e da relação conhecida na literatura entre o número de repetições máximas realizadas e o percentual de $1 \mathrm{RM}^{107}$. Após dois minutos de descanso, uma série de três repetições a 70\% da 1RM estimada foi realizada. Os levantamentos seguintes foram repetições simples com cargas progressivamente mais pesadas até a 1RM ser determinada. Foram respeitados cinco minutos de descanso entre as tentativas e os dois exercícios foram realizados em dias diferentes. Durante os intervalos ocorreu o ajuste dos pesos para a tentativa seguinte. $O$ ajuste de carga foi feito a partir da informação cedida pelo avaliado, e o número de tentativas para determinação da carga máxima foi de cinco $^{108}$. Apenas para o grupo de idosos, após 48 horas da determinação de 1RM foi realizado o reteste, de forma a mensurar a reprodutibilidade do mesmo. O valor médio dos dois testes foi assumido como $1 \mathrm{RM}$, sendo que não podia variar mais que $5 \%$ entre si. $\mathrm{O}$ procedimento de determinação de $1 \mathrm{RM}$ foi realizado para permitir a utilização de suas frações (ex. 10\% de 1RM) no teste crescente e na quantificação da intensidade 
do exercício, visto que esta quantificação em percentual de 1RM é uma das formas mais comuns dentro da prática de treinamento resistido e principalmente em estudos científicos ${ }^{45}$.

\subsubsection{Teste crescente}

O teste crescente para determinação do LAn consistiu em séries de 20 repetições realizadas em 1 minuto ( 3 segundos cada repetição), e dois minutos de intervalo entre as séries para coleta de sangue e aumento da carga (figura 3.1). A intensidade inicial foi de $10 \%$ de $1 \mathrm{RM}$, com as séries subseqüentes realizadas com $20 \%, 25 \%, 30 \%, 35 \%, 40 \%, 50 \%, 60 \%, 70 \%$ e $80 \%$ de $1 \mathrm{RM}$. Esta divisão de

intensidades foi escolhida pelo fato de que estudos prévios ${ }^{86-88}$, bem como testes realizados em nosso laboratório demonstram que o LAn em exercícios resistidos encontra-se por volta de $30 \%$ de $1 \mathrm{RM}$, independentemente do exercício realizado. Portanto, este fracionamento de cargas nos permite uma determinação mais precisa do LAn.

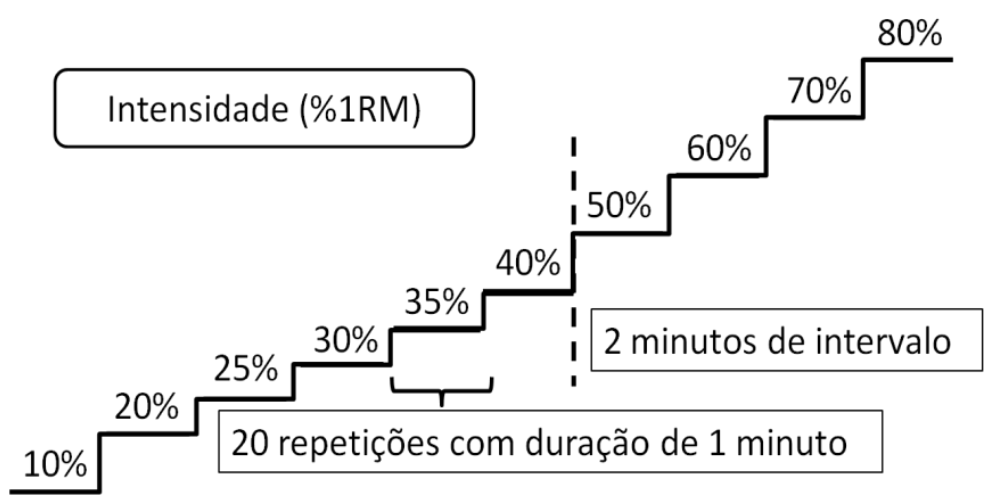

Figura 3.1 - Teste crescente máximo para determinação do LAn. 
O teste foi interrompido quando o voluntário não conseguia realizar 20 repetições com determinada intensidade, que foi considerada a intensidade máxima do teste.

A intensidade correspondente ao LAn foi determinada através de um modelo algorítmico baseado no estudo de Orr et al..$^{83}$. Através deste modelo, os valores de lactato sanguíneo sofrem uma regressão linear dupla, transformando os dados em duas retas que contêm todos os pontos. A regressão linear dupla é baseada no agrupamento da menor soma dos quadrados dos erros. A intercepção das duas retas corresponde ao LAn, expresso em percentual de 1RM e concentração de lactato. Desta forma, a figura é organizada em um gráfico cartesiano, onde o eixo das ordenadas corresponde à concentração de lactato sanguíneo e o eixo das abscissas à intensidade do exercício em percentual de 1RM. As duas retas, contendo todos os pontos, são representadas no gráfico e sua intercepção corresponde ao LAn (ver figura 4.1).

\subsubsection{Máxima fase estável de lactato (MFEL)}

A MFEL foi determinada em três sessões de exercício, com diferentes intensidades. A primeira sessão foi realizada na intensidade equivalente ao LAn dos indivíduos, previamente determinado no teste crescente. A intensidade da segunda e terceira sessão foi determinada em função da resposta da lactacidemia obtida no primeiro teste.

Cada sessão consistiu em 15 séries de 20 repetições, com duração de um minuto cada série e padronização de velocidade igual à utilizada no teste crescente (figura 3.2). A velocidade era controlada por um pesquisador experiente, com 
feedback verbal e visual sempre que o voluntário alterasse essa velocidade. $\mathrm{O}$ intervalo entre as séries foi de um minuto, e deste modo a duração do teste foi de 30 minutos, como preconizado por Beneke et al. ${ }^{93}$ para determinação de MFEL em exercícios aeróbios. Em intensidades superiores à MFEL, alguns indivíduos não conseguiram realizar todas as séries com um número total de 20 repetições. Assim, o teste era dado como encerrado caso não fossem completadas 15 repetições em uma série ou incapacidade de realizar os movimentos com biomecânica correta.

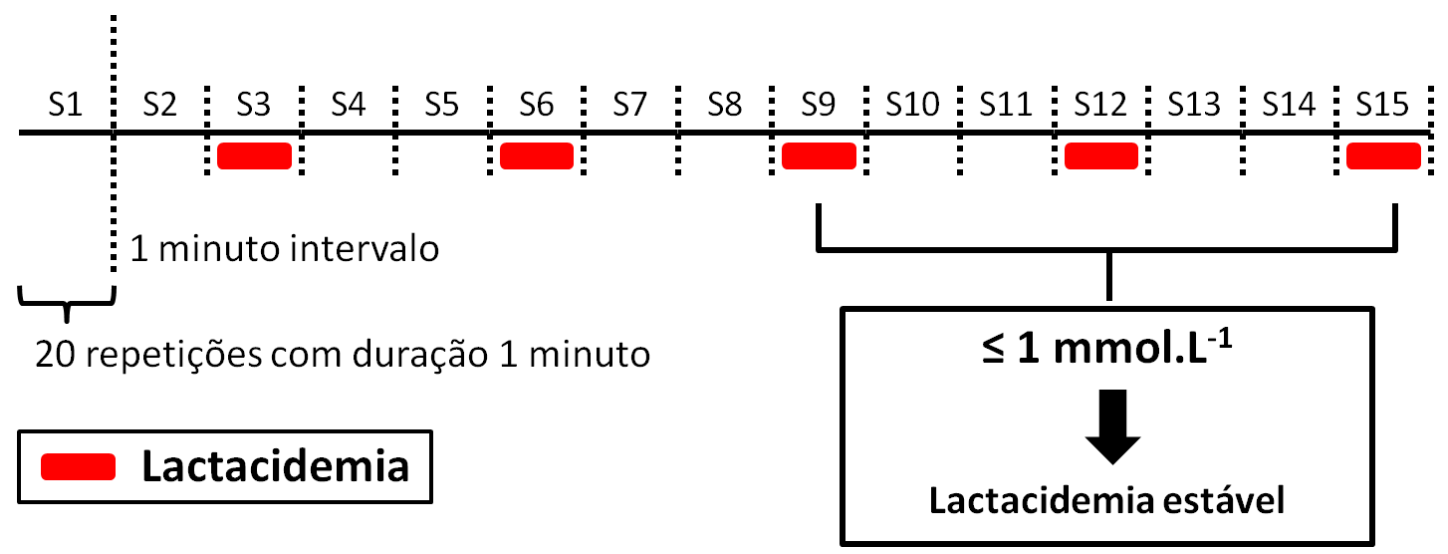

Figura 3.2 - Sessão de teste com intensidade constante para determinação da MFEL.

Como exemplificado na figura 3.3, caso a lactacidemia permanecesse estável, ou seja, com variação menor ou igual a $1,0 \mathrm{mmol} \cdot \mathrm{L}^{-1}$ da $9^{\text {a }}$ para a $15^{\mathrm{a}}$ série, a intensidade era aumentada em dois estágios para o segundo teste (ex. de $30 \%$ para 40\% de 1RM). O critério de escolha entre a $9^{\mathrm{a}}$ e $15^{\mathrm{a}}$ série será discutido na seção discussão. Por outro lado, caso a lactacidemia apresentasse elevação maior que 1,0 mmol. $L^{-1}$ da $9^{a}$ para a $15^{a}$ série, ou seja, não ficasse estável, a intensidade era diminuída em dois estágios (ex. de $30 \%$ para $20 \%$ de $1 \mathrm{RM}$ ). Este procedimento foi utilizado também na terceira sessão, no entanto, o ajuste era realizado apenas em 
um estágio (ex. de $20 \%$ para $25 \%$, caso a variação da lactacidemia fosse menor que $\left.1 \mathrm{mmol} . \mathrm{L}^{-1}\right)$. Por meio deste ajuste de intensidade entre os testes, todos os voluntários realizaram uma sessão em que não houve estabilização da lactacidemia, considerada como acima da MFEL, e uma carga onde ocorreu estabilização da concentração de lactato sanguíneo, considerada como a MFEL para o exercício.

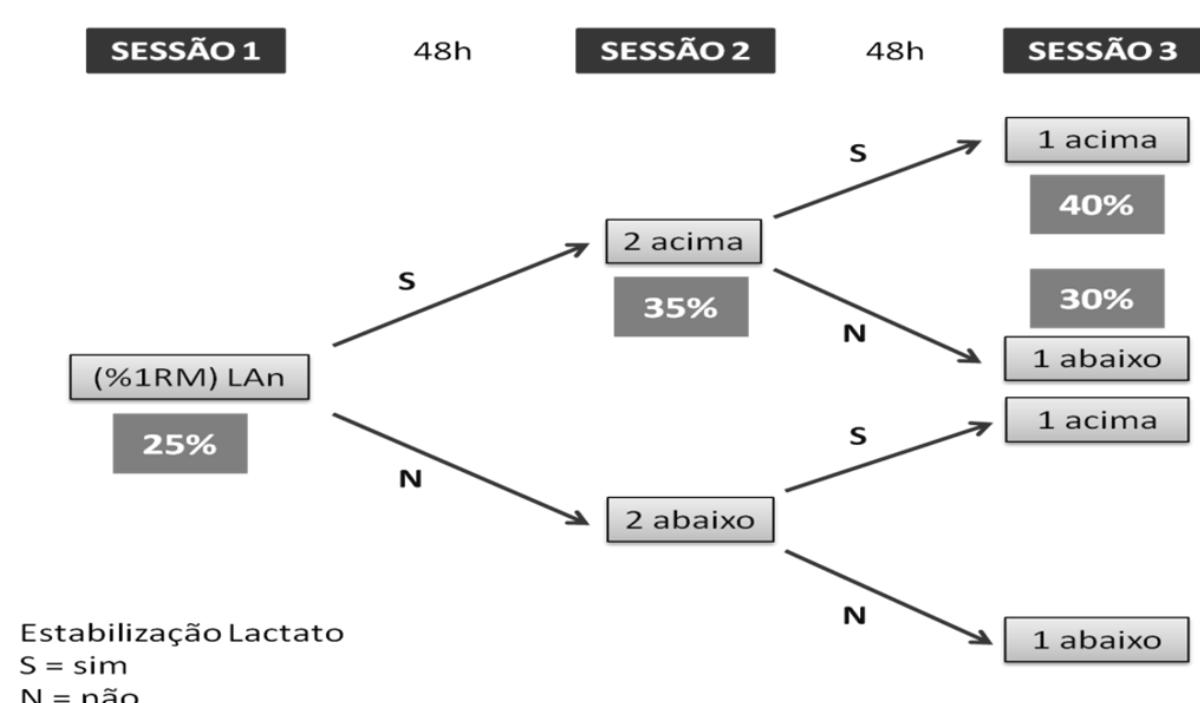

Figura 3.3 - Diagrama para definição da intensidade do teste constante para determinação da

\subsection{Variáveis analisadas}

Durante o teste crescente e os testes de intensidade constante, as variáveis avaliadas foram a lactacidemia, parâmetros ergoespirométricos, frequência cardíaca $(\mathrm{FC})$, pressão arterial (PA) e escala de percepção de esforço (PSE). 


\subsubsection{Lactacidemia}

Uma amostra de $25 \mu \mathrm{l}$ de sangue foi coletada do lobo da orelha para a análise da lactacidemia em lactímetro eletro-enzimático (YSI 1500 Sport, Yellowsprings®). A coleta foi realizada em repouso e 30 segundos após o término de cada série no teste crescente, e no repouso e 30 segundos após as séries 3, 6, 9, 12 e 15 nos testes de intensidade constante para determinação da MFEL. Sempre que possível, a amostra de sangue era analisada diretamente no lactímetro, ou seja, imediatamente após a sua coleta. No entanto, quando tal procedimento não era possível, a amostra de sangue era armazenada e congelada em tubos de Ependorff, com uma solução de $50 \mu \mathrm{l}$ de fluoreto de sódio a $1 \%$, e analisada no máximo até 5 dias do seu armazenamento. Cerca de $80 \%$ de todas as amostras de sangue foram analisadas imediatamente após a sua coleta.

\subsubsection{Parâmetros ergoespirométricos}

Os parâmetros ergoespirométricos avaliados foram: ventilação (VE), consumo de oxigênio $\left(\mathrm{VO}_{2}\right)$ e produção de dióxido de carbono $\left(\mathrm{VCO}_{2}\right)$. Os dados foram coletados com auxilio de um analisador de gases portátil (VO2000, Medgraphics®), e foram gravados em um computador com a utilização do software Aerografic. O analisador de gases foi calibrado imediatamente antes de cada teste com uma amostra de ar local, como indicado pelo manual de instruções do fabricante do produto. Antes do inicio do registro de cada teste, o voluntário era instruído a respirar normalmente até que os valores se apresentassem dentro da normalidade. 
Em todos os testes, utilizou-se o pneumotacógrafo de fluxo médio. O registro dos resultados foi realizado através da média a cada 20 segundos de teste.

Dois minutos antes dos testes, os dados eram registrados e considerados como valores de repouso e, para o registro dos valores de cada série do teste crescente e dos testes de intensidade constante, os valores considerados foram a média dos últimos 20 segundos de cada série.

\subsubsection{Freqüência cardíaca}

A freqüência cardíaca foi mensurada através de um monitor cardíaco da

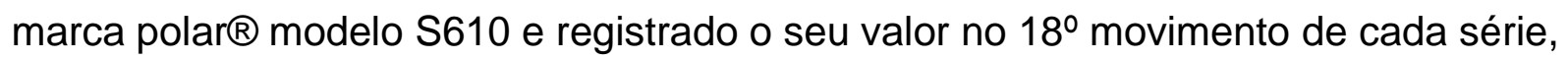
tanto no teste crescente como nos testes de carga constante para determinação da MFEL.

A FC máxima $\left(\mathrm{FC}_{\text {máx }}\right)$ foi prevista através da fórmula de Karvonen et al. ${ }^{109}$ $\left(\mathrm{FC}_{\text {máx }}=220-\right.$ idade da pessoa $)$.

\subsubsection{Pressão arterial}

A pressão arterial foi registrada, como medida de segurança, apenas no aparelho LP para o grupo de idosos, por impossibilidade de mensuração no aparelho SR. Através do método auscultatório, um pesquisador treinado registrou os valores de pressão arterial sistólica (PAS) e diastólica (PAD) imediatamente antes do voluntário completar cada série, tanto no teste crescente como nos testes de carga constante para determinação da MFEL no exercício LP. 
O DP foi calculado através do produto entre a PAS e a FC.

\subsubsection{Escala de percepção de esforço}

Durante a realização do teste crescente e dos testes de carga constante, foram apresentadas duas escalas de percepção de esforço imediatamente após o final de cada série, escala de $\mathrm{BORG}^{110}$ (Anexo A) e escala de OMNI ${ }^{111}$ (Anexo B), onde o voluntário relatava de forma numérica o esforço percebido.

\subsection{Análise estatística}

A análise descritiva foi realizada através de média \pm desvio padrão. Teste de normalidade de Kolmogorov-Smirnov foi realizado para a determinação da normalidade das amostras. A homogeneidade da amostra foi determinada através do teste de Levene. O teste ANOVA de dupla entrada (exercício e faixa etária), com pós teste de Tukey, foi utilizado para as comparações entre intensidade máxima, intensidade do LAn e MFEL. Para a análise das variáveis ventilatórias, freqüência cardíaca e escala de percepção de esforço durante a MFEL também foi utilizada ANOVA de dupla entrada (exercício e tempo) com pós-teste de Tukey, quando necessário. O nível de significância adotado foi de $p \leq 0,05$. 


\section{RESULTADOS}

\subsection{Teste de $1 \mathrm{RM}$}

Para o grupo de idosos, o valor médio \pm desvio padrão de 1RM no exercício $\mathrm{LP}$, que envolve maior massa muscular, foi de $238,2 \pm 53,4 \mathrm{~kg}$, enquanto que no exercício SR, envolvendo menor massa muscular, foi de $58,1 \pm 6,3 \mathrm{~kg}$. O coeficiente de correlação entre o primeiro teste e o reteste foi 0,99 para o LP e 0,96 para o SR. Este coeficiente de correlação demonstra a fidedignidade do teste de $1 \mathrm{RM}$ para 0 grupo de idosos, podendo destacar como principal fator para estes valores o fato dos idosos serem treinados em exercício resistido e conhecerem perfeitamente os exercícios estudados.

Relativamente ao grupo de jovens, o valor médio \pm desvio padrão no exercício LP foi $294,0 \pm 38,0 \mathrm{~kg}$, significativamente maior que no grupo de idosos. Quanto ao SR, o grupo de jovens apresentou $1 \mathrm{RM}$ de $91,8 \pm 20,7 \mathrm{~kg}$, também significativamente maior que no grupo de idosos. Para o grupo jovem não foi realizado o reteste.

\subsection{Teste crescente e limiar anaeróbio}

Os principais resultados obtidos durante o teste crescente máximo no exercício LP e SR para o grupo de idosos são apresentados na tabela 4.1. Como se pode observar, intensidade relativa ao percentual de 1RM, concentração de lactato sanguíneo e o $\mathrm{VCO}_{2}$ foram significativamente maiores no final do exercício LP que no SR. As escalas de percepção de esforço atingiram valores muito próximos do 
máximo, principalmente no exercício LP. A intensidade relativa ao LAn também foi significativamente maior no exercício LP que no SR, assim como os valores de $\mathrm{VCO}_{2}$. Contrariamente, a concentração de lactato sanguíneo foi significativamente menor no LP que no SR. Os restantes parâmetros não apresentaram diferenças na intensidade do LAn.

A descrição da tabela será realizada por tópicos, para facilitação da compreensão dos resultados durante o teste crescente máximo nos dois aparelhos.

Tabela 4.1 - Resultados do teste crescente máximo no leg press e supino reto para o grupo de idosos, $\mathrm{n}=11$ (média \pm desvio padrão).

\begin{tabular}{|c|c|c|c|c|}
\hline & \multicolumn{2}{|c|}{ Leg Press } & \multicolumn{2}{|c|}{ Supino Reto } \\
\hline & Máx & LAn & Máx & LAn \\
\hline Intensidade (\%1RM) & $64,5^{*} \pm 6,9$ & $27,9 * \pm 5,0$ & $56,7 \pm 7,1$ & $21,5 \pm 3,1$ \\
\hline$[\mathrm{Lac}]\left(\mathrm{mmol} . \mathrm{L}^{-1}\right)$ & $5,85^{*} \pm 0,84$ & $1,23^{*} \pm 0,34$ & $4,38 \pm 1,18$ & $1,91 \pm 0,40$ \\
\hline $\mathrm{VO}_{2}\left(\mathrm{~mL} \cdot \mathrm{kg}^{-1} \cdot \mathrm{min}^{-1}\right)$ & $9,01 \pm 2,62$ & $6,28 \pm 2,36$ & $8,04 \pm 2,37$ & $5,84 \pm 1,35$ \\
\hline $\mathrm{VCO}_{2}\left(\mathrm{~L} \cdot \mathrm{min}^{-1}\right)$ & $0,92 * \pm 0,22$ & $0,49^{*} \pm 0,17$ & $0,78 \pm 0,16$ & $0,46 \pm 0,11$ \\
\hline VE $\left(L^{\prime} \cdot \min ^{-1}\right)$ & $24,5 \pm 6,6$ & $12,3 \pm 3,7$ & $23,2 \pm 5,0$ & $13,0 \pm 2,6$ \\
\hline $\mathrm{FC}(\mathrm{bpm})$ & $119,7 \pm 13,6$ & $95,3 \pm 10,1$ & $119,4 \pm 19,6$ & $92,2 \pm 8,4$ \\
\hline BORG & $19,2 \pm 1,4$ & $10,3 \pm 3,1$ & $18,0 \pm 2,6$ & $9,4 \pm 2,5$ \\
\hline OMNI & $9,4 \pm 1,1$ & $3,3 \pm 2,5$ & $8,4 \pm 2,4$ & $2,8 \pm 1,1$ \\
\hline
\end{tabular}

Máx: na intensidade máxima; LAn: Limiar Anaeróbio.

*Diferença entre LP e SR $(p \leq 0,05)$;

Do mesmo modo, a tabela 4.2 apresenta os resultados do teste crescente máximo nos exercícios LP e SR para o grupo de jovens. Os resultados obtidos são semelhantes ao grupo de idosos, ou seja, diferenças estatisticamente significativas entre LP e SR para a intensidade relativa ao percentual de 1RM, concentração de lactato sanguíneo e VCO2 no final do exercício e intensidade relativa ao LAn. 
Tabela 4.2 - Resultados do teste crescente máximo no leg press e supino reto para o grupo de jovens, $n=13$ (média \pm desvio padrão).

\begin{tabular}{|c|c|c|c|c|}
\hline & \multicolumn{2}{|c|}{ Leg Press } & \multicolumn{2}{|c|}{ Supino Reto } \\
\hline & Máx & LAn & Máx & LAn \\
\hline Intensidade (\%1RM) & $67,8^{*} \pm 9,3$ & $27,8^{*} \pm 3,6$ & $50,0 \pm 8,2$ & $24,0 \pm 3,0$ \\
\hline$[$ Lac $]\left(\mathrm{mmol}^{\left.-\mathrm{L}^{-1}\right)}\right.$ & $8,36^{*} \pm 2,34$ & $1,86^{*} \pm 0,63$ & $5,51 \pm 1,04$ & $2,08 \pm 0,41$ \\
\hline $\mathrm{VO}_{2}\left(\mathrm{~mL} \cdot \mathrm{kg}^{-1} \cdot \mathrm{min}^{-1}\right)$ & $13,59 \pm 5,04$ & $8,84 \pm 2,05$ & $10,23 \pm 3,45$ & $7,45 \pm 1,47$ \\
\hline $\mathrm{VCO}_{2}\left(\mathrm{~L} \cdot \mathrm{min}^{-1}\right)$ & $1,52 * \pm 0,36$ & $0,77^{*} \pm 0,21$ & $1,11 \pm 0,27$ & $0,73 \pm 0,16$ \\
\hline VE $\left(\right.$ L. $\left.\min ^{-1}\right)$ & $39,9 \pm 14,0$ & $15,6 \pm 3,7$ & $31,5 \pm 6,6$ & $18,2 \pm 4,9$ \\
\hline $\mathrm{FC}(\mathrm{bpm})$ & $164,3 \pm 18,9$ & $117,5 \pm 16,3$ & $155,3 \pm 25,9$ & $112,4 \pm 18,1$ \\
\hline BORG & $19,8 \pm 0,4$ & $8,9 \pm 1,8$ & $19,6 \pm 0,9$ & $9,3 \pm 2,6$ \\
\hline OMNI & $10,0 \pm 0,0$ & $2,7 \pm 1,1$ & $9,8 \pm 0,6$ & $2,7 \pm 1,8$ \\
\hline
\end{tabular}

Máx: na intensidade máxima; LAn: Limiar Anaeróbio.

*Diferença entre LP e SR $(p \leq 0,05)$;

\subsubsection{Intensidade}

Em relação ao grupo de idosos, a intensidade máxima atingida durante o teste crescente no LP foi $64,5 \pm 6,9 \% 1 \mathrm{RM}$, significativamente maior que no $\mathrm{SR}$, onde foi $56,7 \pm 7,1 \% 1 \mathrm{RM}$.

O LAn, expresso em percentual de $1 \mathrm{RM}$, foi $27,9 \pm 5,0 \% 1 \mathrm{RM}$ para o LP e $21,5 \pm 3,1 \% 1 \mathrm{RM}$ para o SR, também significativamente maior no exercício LP. A figura 4.1 mostra a determinação do LAn para um voluntário no exercício crescente no LP, através da aplicação de um modelo algorítmico nos valores de lactato sanguíneo. 


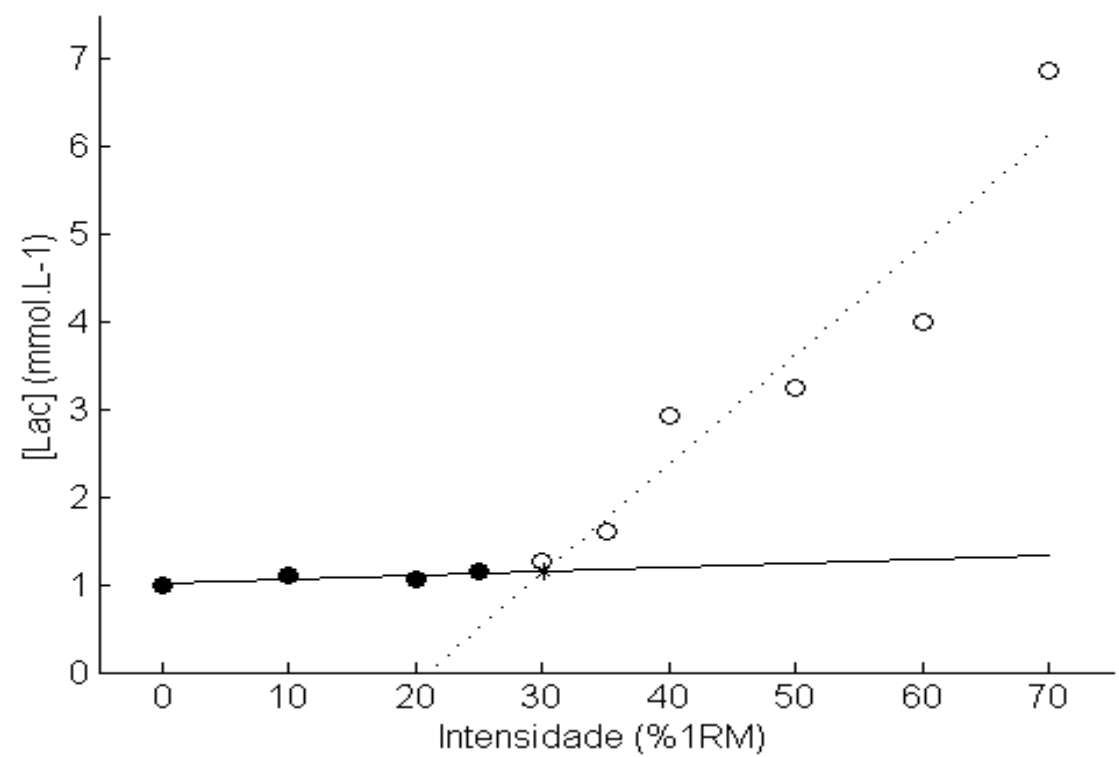

Figura 4.1 - Determinação do Limiar Anaeróbio para um voluntário (voluntário A) através de ajuste algorítmico para o aparelho leg press. Círculos fechados: pontos pertencentes à primeira reta de regressão linear; círculos abertos: pontos pertencentes à segunda reta de regressão linear.

O grupo de jovens atingiu intensidade máxima de 67,8 \pm 9,3 \%1RM no exercício LP, também significativamente maior que no $S R$, onde foi $50,0 \pm 8,2$ $\% 1 \mathrm{RM}$.

Ainda para o grupo de jovens, o LAn no exercício LP foi significativamente maior (27,8 $\pm 3,6 \% 1 \mathrm{RM})$ que no exercício SR $(24,0 \pm 3,0 \% 1 \mathrm{RM})$.

Quanto comparadas as intensidades nos dois exercícios, tanto máxima como no LAn, observa-se que não existem diferenças estatisticamente significativas entre os grupos, como demonstrado na figura 4.2. Ou seja, o grupo de idosos atingiu intensidade máxima, expresso em percentual de 1RM, em cada exercício semelhante ao grupo de jovens, semelhança também apresentada para a intensidade do LAn. 


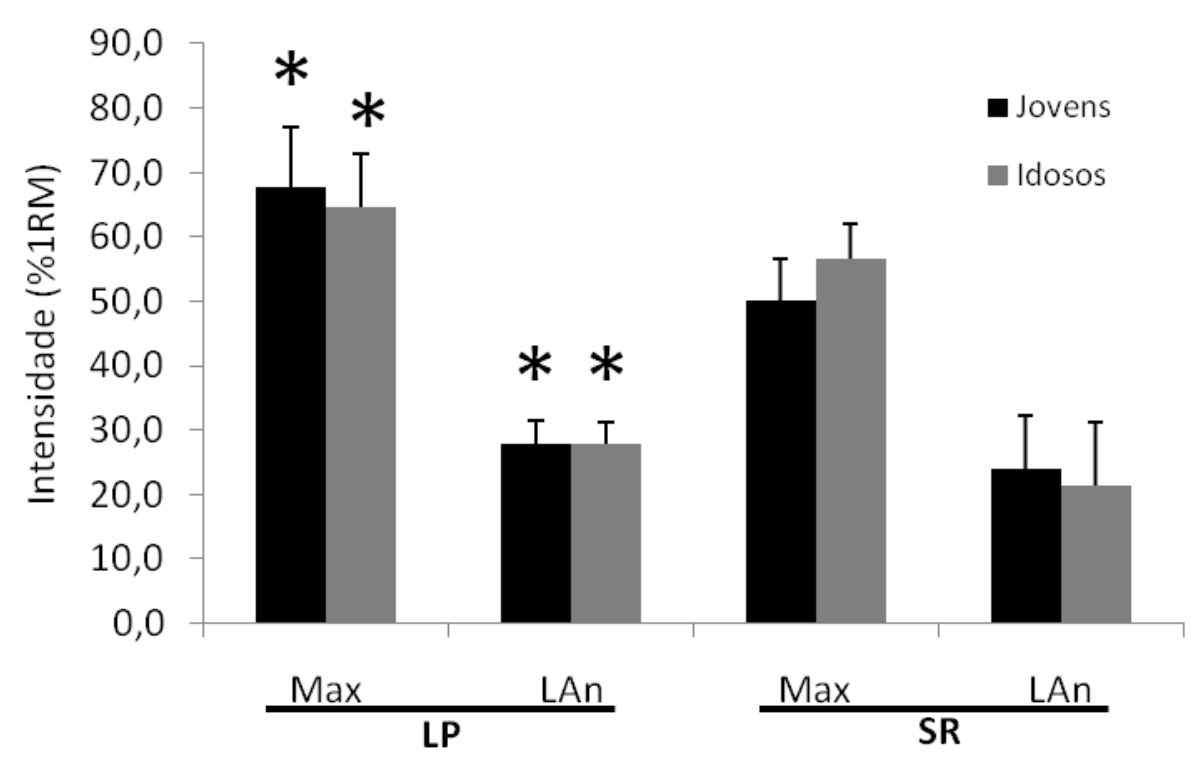

Figura 4.2 - Comparação entre jovens e idosos na intensidade máxima e no LAn nos exercícios LP e SR (média \pm desvio padrão).

LP: Leg Press; SR: Supino Reto; Max: intensidade máxima; LAn: limiar anaeróbio;

*Diferença entre LP e SR $(p \leq 0,05)$

\subsubsection{Concentração de lactato sanguíneo}

No final do teste crescente máximo para o grupo de idosos, a lactacidemia no LP foi $5,85 \pm 0,84 \mathrm{mmol}^{-\mathrm{L}^{-1}}$, significativamente maior que no $\mathrm{SR}$, onde foi $4,38 \pm 1,18$ mmol.L-1 . Por outro lado, a concentração de lactato sanguíneo referente ao LAn foi significativamente maior no SR $\left(1,23 \pm 0,34 \mathrm{mmol}^{-1}\right)$ que no $\operatorname{LP}(1,91 \pm 0,41$ mmol. $\left.L^{-1}\right)$.

Comportamento muito semelhante foi apresentado no teste crescente máximo para o grupo de jovens. Assim, a lactacidemia no final do exercício LP foi 8,36 $\pm 2,34$ mmol. $\mathrm{L}^{-1}$, também significativamente maior que no exercício $\mathrm{SR}$, onde foi 5,51 $\pm 1,04$ mmol.L-1 . Os valores de concentração de lactato na intensidade do LAn foram significativamente menores no exercício $\operatorname{LP}\left(1,86 \pm 0,63 \mathrm{mmol} . \mathrm{L}^{-1}\right)$ em relação ao SR $\left(2,08 \pm 0,41 \mathrm{mmol} \cdot \mathrm{L}^{-1}\right)$. 
Apesar do comportamento da lactacidemia ter sido muito semelhante entre os grupos, sua concentração máxima foi significativamente maior para o grupo de jovens, comparado com o grupo de idosos.

\subsubsection{Parâmetros ergoespirométricos}

Através da análise das tabelas 4.1 e 4.2, podemos observar que os valores referentes ao $\mathrm{VO}_{2}$ e à $\mathrm{VE}$ não apresentaram diferenças estatisticamente significativas entre o exercício LP e o SR, tanto no final de cada exercício como na intensidade referente ao LAn. Por outro lado, o exercício LP apresentou valores significativamente superiores de $\mathrm{VCO}_{2}$ para os dois grupos estudados nas intensidades máxima e referente ao LAn.

Quando comparados os dois grupos, observa-se que todos os parâmetros ergoespirométricos $\left(\mathrm{VO}_{2}, \mathrm{VCO}_{2}\right.$ e $\left.\mathrm{VE}\right)$ atingem valores significativamente superiores para o grupo de jovens em relação aos idosos, tanto na intensidade máxima como na intensidade referente ao LAn (expressos em \%1RM), nos dois exercícios estudados.

\subsubsection{Freqüência cardíaca}

Analisando o grupo de idosos (tabela 4.1), a FC atingida no final do teste crescente é bastante semelhante para os dois exercícios, correspondendo a $79 \%$ da $\mathrm{FC}_{\text {máx }}$ prevista para $\mathrm{O} \mathrm{LP}$ e SR. A FC referente ao LAn correspondeu a 
aproximadamente $63 \%$ da $\mathrm{FC}_{\max }$ para o LP e $61 \%$ da $\mathrm{FCmax}$ para o SR, sem diferenças estatisticamente significativas.

Relativamente ao grupo de jovens, como se pode observar através da tabela 4.2, no final do teste máximo para o LP a $F C_{\max }$ prevista foi $85 \%$ e no $S R$ foi $82 \%$, sem diferença significativa entre os aparelhos. Na intensidade do LAn, a FC correspondeu a $61 \%$ e $58 \%$ da $\mathrm{FC}_{\max }$ prevista, respectivamente para o LP e SR, sem diferenças estatisticamente significativas.

Comparando os dois grupos, apesar do grupo de jovens apresentar maiores percentagens de $\mathrm{FC}_{\max }$ no final de cada exercício, a diferença não foi significativa. $\mathrm{Na}$ intensidade referente ao $\mathrm{LAn}$, o percentual de $\mathrm{FC}_{\text {máx }}$ também não foi estatisticamente diferente entre os grupos para os dois aparelhos, apresentando valores muito próximos de $60 \%$ da $\mathrm{FC}_{\text {máx. }}$

\subsubsection{Percepção subjetiva de esforço}

A percepção subjetiva de esforço foi analisada através de duas escalas, escala de BORG e escala de OMNI.

Começando pelo grupo de idosos, apesar da máxima percepção de esforço ser maior no LP $(19,2 \pm 1,4)$, não houve diferença significativa para o SR $(18,0 \pm$ 2,6). Na intensidade do LAn também não houve diferença significativa entre os exercícios (10,3 $\pm 3,1$ no LP e 9,4 $\pm 2,5$ no SR).

Em relação ao grupo de jovens, também não houve diferença estatisticamente significativa entre os aparelhos na intensidade máxima atingida $(19,8 \pm 0,4$ no LP e 19,6 $\pm 0,9$ no SR) e intensidade referente ao LAn $(8,9 \pm 1,8$ no LP e 9,3 $\pm 2,6$ no SR). 
Relativamente à escala de $\mathrm{OMNI}$, o grupo de idosos também não apresentou diferença estatisticamente significativa entre os exercícios, quer na intensidade máxima $(9,4 \pm 1,1$ no LP e $8,4 \pm 2,4$ no SR), quer na intensidade referente ao LAn $(3,3 \pm 2,5$ no LP e $2,8 \pm 1,8$ no SR $)$.

Já para o grupo de jovens, todos os voluntários relataram uma percepção subjetiva de esforço igual a 10,0 na escala de OMNI na intensidade máxima do exercício LP, enquanto que o valor médio para o exercício $S R$ foi $9,8 \pm 0,6$. Mais uma vez, na intensidade do LAn, não houve diferença estatisticamente significativa entre os exercícios $(2,7 \pm 1,1$ no LP e $2,7 \pm 1,8$ no SR $)$.

O grupo de jovens relatou maior percepção subjetiva de esforço no final do teste crescente máximo para os dois exercícios nas duas escalas, valores estatisticamente significativos. Não foram observadas diferenças significativas para a percepção subjetiva de esforço na carga equivalente ao LAn.

\subsection{Máxima fase estável do lactato}

\subsubsection{Intensidade e lactacidemia}

Foi possível determinar a MFEL em exercício resistido para os dois grupos etários durante o teste contínuo com carga constante nos dois exercícios. A figura 4.3 apresenta a determinação da MFEL de um voluntário no exercício SR do grupo de idosos. Como se pode observar, foram realizadas 3 sessões de exercício com carga constante para determinação da maior intensidade onde a diferença de lactato sanguíneo fosse menor ou igual que $1,00 \mathrm{mmol}^{-1}{ }^{-1}$ entre S9 e S15, critério para 
definição de exercício estável. A maior intensidade onde tal fato ocorreu foi considerada a MFEL.

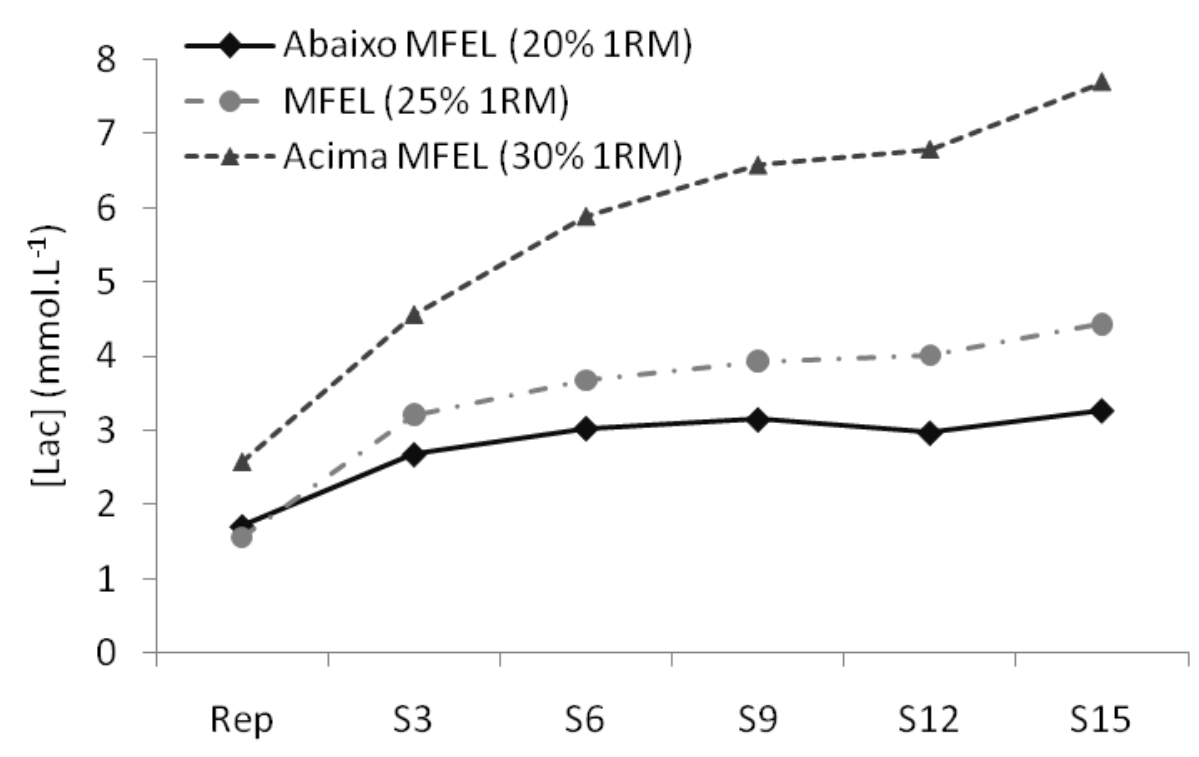

Figura 4.3 - Determinação da MFEL para um voluntário (voluntário B) do grupo de idosos no exercício SR.

Rep: repouso; S3: série 3; S6: série 6; S9: série 9; S12: série 12; S15: série 15.

Iniciando com o grupo de idosos, a intensidade da MFEL no LP foi $30,9 \pm 4,9$ \%1RM e no SR foi $23,3 \pm 6,6 \% 1 \mathrm{RM}$, como apresentado na figura 4.4. A comparação da MFEL nos dois exercícios mostrou que as intensidades são significativamente diferentes, ocorrendo em intensidades maiores para o LP do que para o SR. Relativamente ao grupo de jovens, a MFEL também é significativamente maior no LP $(29,2 \pm 6,7 \% 1 \mathrm{RM})$ que no SR $(21,7 \pm 4,4 \% 1 \mathrm{RM})$. No entanto, a comparação entre os grupos etários não mostrou diferenças significativas na intensidade da MFEL para cada exercício, ou seja, a MFEL no exercício LP ocorre na mesma intensidade para os dois grupos, o mesmo se sucedendo para o SR.

Voltando ao grupo de idosos, quando comparadas as intensidades do LAn e da MFEL em cada exercício, não houve diferença significativa para os aparelhos LP 
e SR (figura 4.4). No exercício LP, cinco idosos apresentaram diferença de intensidade entre LAn e MFEL menor que 3\% de 1RM, cinco idosos apresentaram intensidade da MFEL superior à intensidade do LAn (mais que $3 \%$ de $1 \mathrm{RM}$ ) e um idoso apresentou intensidade do LAn superior à MFEL. Em relação ao SR, uma diferença menor que 3\% de 1RM entre LAn e MFEL foi encontrada em três idosos, intensidade da MFEL superior ao LAn em cinco voluntários e intensidade do LAn superior à MFEL em apenas um voluntário.

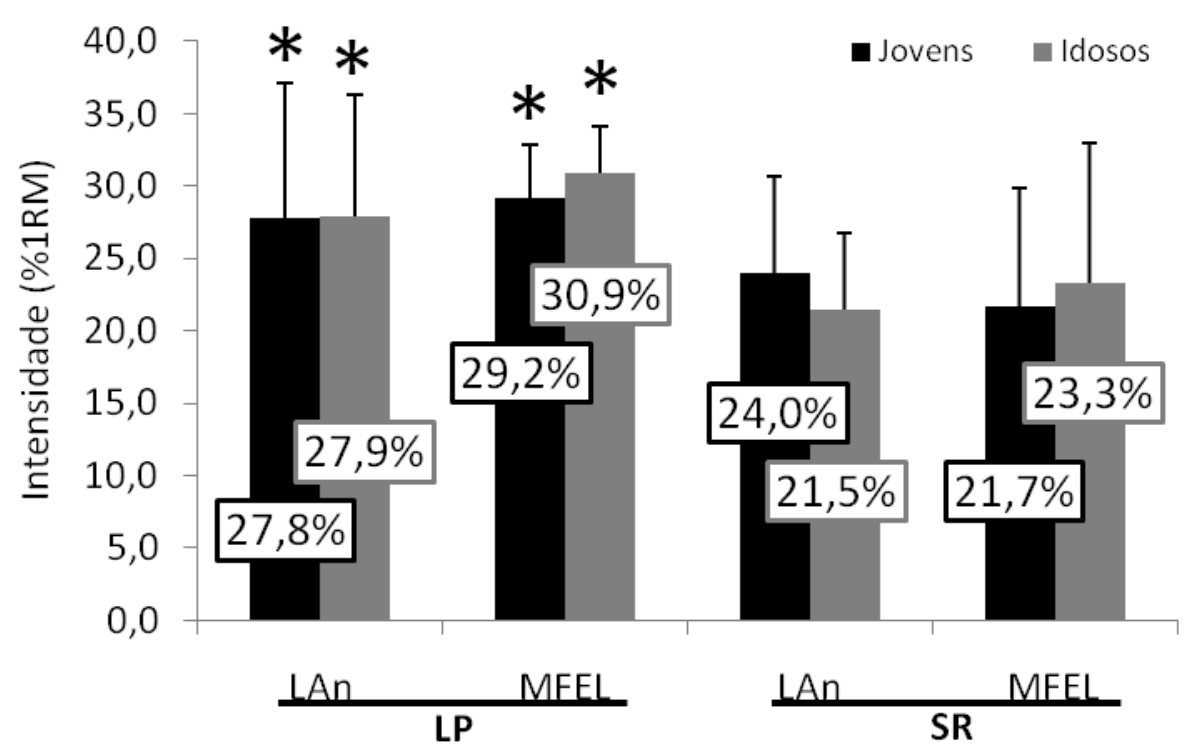

Figura 4.4 - Intensidade da MFEL e LAn nos exercícios LP e SR (média \pm desvio padrão). LAn: Limiar Anaeróbio; MFEL: Máxima Fase Estável do Lactato.

*Diferença entre LP e SR $(p \leq 0,05)$.

Do mesmo modo, nenhuma diferença foi significativa para o grupo de jovens quando comparadas as intensidades do LAn e da MFEL (figura 4.4). Para o exercício LP, quatro voluntários apresentaram diferença entre LAn e MFEL menor que $3 \%$ de 1 RM, seis sujeitos apresentaram intensidade da MFEL superior ao LAn e três voluntários apresentaram LAn superior à MFEL. Relativamente ao SR, diferença 
menor que 3\% de 1RM entre LAn e MFEL foi encontrada em seis voluntários, MFEL superior ao LAn em dois sujeitos e LAn superior à MFEL em quatro voluntários.

A lactacidemia de estabilização na intensidade da MFEL, como apresentado na figura 4.5, não apresentou diferença significativa entre os exercícios. Além disso, também não houve diferença estatisticamente significativa para a lactacidemia de estabilização entre jovens e idosos em cada exercício.

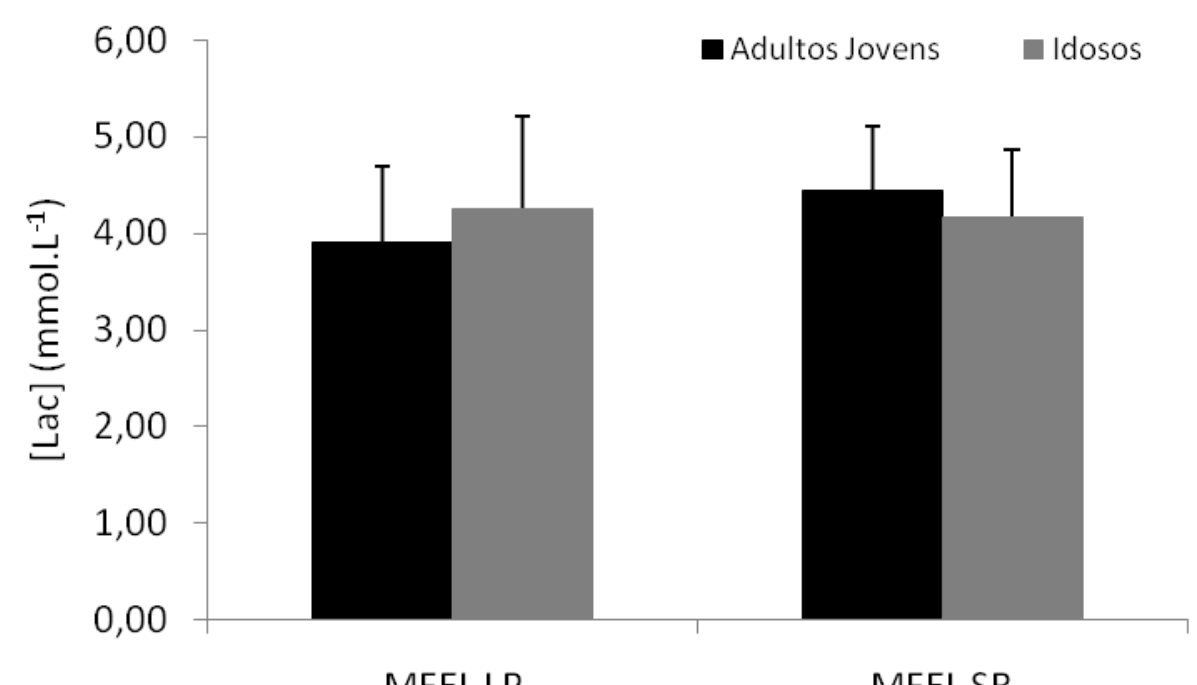

Figura 4.5 - Lactacidemia final durante o exercício na MFEL para os grupos jovens e idosos nos exercícios LP e SR (média \pm desvio padrão).

MFEL LP: máxima fase estável do lactato no exercício LP; MFEL SR: máxima fase estável do lactato no exercício SR.

Na figura 4.6 estão representados os valores médios da concentração de lactato sanguíneo do grupo de idosos nos três testes contínuos com intensidade constante no exercício LP. A cinética da concentração de lactato sanguíneo durante os testes para os dois grupos estudados foi bastante semelhante ao apresentado nesta figura, tanto para o LP como para o SR. 


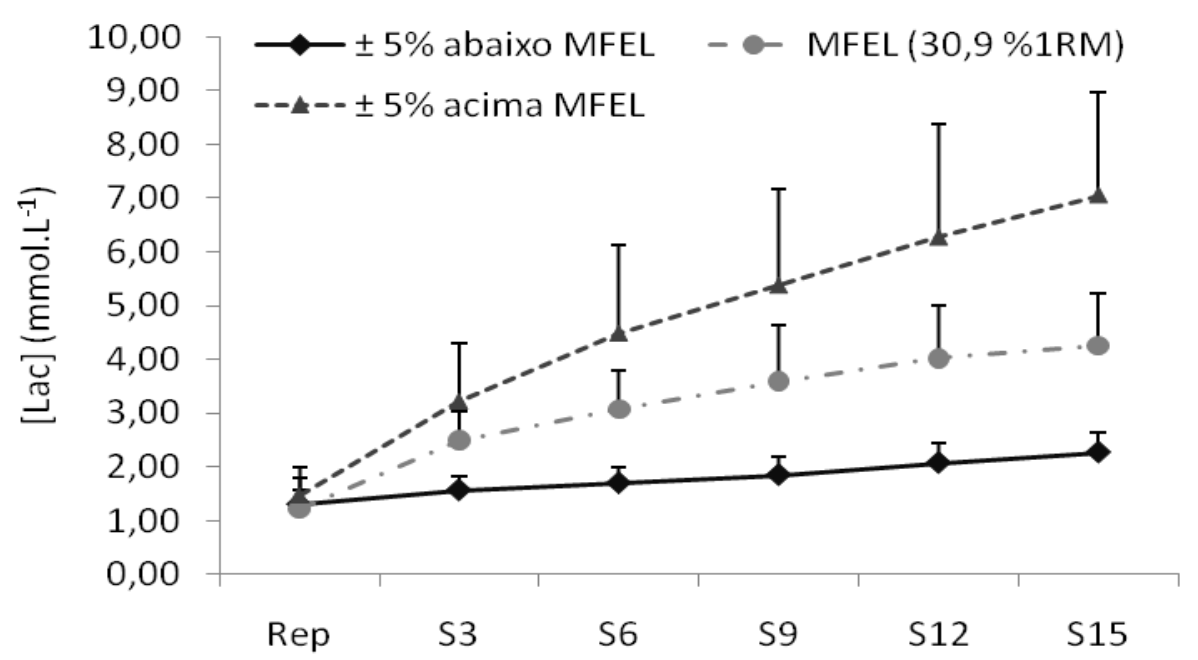

Figura 4.6 - Média e desvio padrão da concentração de lactato sanguíneo durante os testes contínuos com intensidade constante no exercício LP no grupo de idosos. Rep: repouso; S3: série 3; S6: série 6; S9: série 9; S12: série 12; S15: série 15.

Conhecida a cinética do lactato durante os exercícios em intensidade constante, a tabela 4.3 apresenta a concentração de lactato sanguíneo em S6, S9 e S15 para os grupos nos dois aparelhos estudados. A escolha pela representação de três pontos se deve ao fato de que S6 representa aproximadamente o décimo minuto de exercício, S9 o vigésimo minuto e S15 o final do exercício (trigésimo minuto).

Na intensidade correspondente à MFEL, a diferença de lactato entre S9 e S15 para o grupo de idosos no exercício LP foi $0,67 \mathrm{mmol}^{-1}$ e no exercício SR foi 0,56 mmol. $\mathrm{L}^{-1}$, caracterizando o exercício como MFEL. No grupo de jovens, a diferença da concentração de lactato entre S9 e S15 no exercício LP foi $0,59 \mathrm{mmol} \cdot \mathrm{L}^{-1}$ e no exercício SR foi $0,68 \mathrm{mmol} . \mathrm{L}^{-1}$, caracterizado também o exercício como MFEL.

Realizando a comparação entre S6 de S15, observa-se que o delta de lactato está muito próximo de $1,00 \mathrm{mmol} \cdot \mathrm{L}^{-1}$ em todos os exercícios, mais uma indicação de estabilidade da concentração de lactato. 
Continuando a análise da tabela 4.3, observa-se que o delta da concentração de lactato sanguíneo entre S9 e S15 na intensidade acima da MFEL é superior a 1,00 mmol. $\mathrm{L}^{-1}$, caracterizado os exercícios como acima da MFEL. Ademais, para a intensidade acima da MFEL, a concentração de lactato sanguíneo em S6 já é maior que em S15 na intensidade correspondente à MFEL, terminando os exercícios com valores de lactacidemia bastante elevados (tabela 4.3). Três idosos e um jovem no LP e três idosos e quatro jovens no SR não completaram o teste acima da MFEL.

Tabela 4.3 - Valores da concentração de lactato sanguíneo e da intensidade correspondente à MFEL e intensidade acima da MFEL para os dois grupos nos dois aparelhos estudados (média \pm desvio padrão).

\begin{tabular}{|c|c|c|c|c|c|}
\hline & & \multicolumn{2}{|c|}{ Idosos } & \multicolumn{2}{|c|}{ Jovens } \\
\hline & & LP & SR & LP & SR \\
\hline \multirow{4}{*}{ MFEL } & Int. (\%1RM) & $30,9 \pm 4,9$ & $23,3 \pm 6,6$ & $29,2 \pm 6,7$ & $21,7 \pm 4,4$ \\
\hline & S6 & $3,08 \pm 0,72$ & $3,22 \pm 0,55$ & $2,91 \pm 0,50$ & $3,18 \pm 0,48$ \\
\hline & s9 & $3,59 \pm 1,04$ & $3,61 \pm 0,59$ & $3,31 \pm 0,62$ & $3,76 \pm 0,59$ \\
\hline & S15 & $4,26 \pm 0,96$ & $4,17 \pm 0,70$ & $3,90 \pm 0,79$ & $4,44 \pm 0,68$ \\
\hline \multirow{4}{*}{ Acima MFEL } & Int. (\%1RM) & $36,5 \pm 6,6$ & $28,3 \pm 6,6$ & $34,2 \pm 7,6$ & $26,7 \pm 4,4$ \\
\hline & S6 & $4,49 \pm 1,65$ & $4,17 \pm 0,73$ & $4,21 \pm 0,90$ & $4,56 \pm 0,39$ \\
\hline & S9 & $5,38 \pm 1,80$ & $4,91 \pm 0,99$ & $5,01 \pm 1,10$ & $5,44 \pm 0,69$ \\
\hline & S15 & $7,05 \pm 1,90$ & $6,44 \pm 0,87$ & $6,47 \pm 1,12$ & $7,10 \pm 0,89$ \\
\hline
\end{tabular}

LP: leg press; SR: supino reto; MFEL: máxima fase estável do lactato; Int: intensidade; S6: série 6; S9:série 9; S15: série 15.

\subsubsection{Parâmetros ergoespirométricos}

Os valores dos parâmetros ergoespirométricos durante os exercícios na MFEL no grupo de idosos estão apresentados na tabela 4.4. Como a intensidade da 
MFEL é caracterizada pela estabilidade entre S9 e S15, o tratamento estatístico foi realizado apenas após S6.

Analisando os dados da tabela 4.4, podemos observar que existe estabilização de todos os parâmetros ventilatórios entre S6 e S15 para os dois exercícios. Assim, não foram apresentadas diferenças significativas para a $\mathrm{VE}, \mathrm{VO}_{2}$ e $\mathrm{VCO}_{2}$ entre $\mathrm{S} 6$ e $\mathrm{S} 15$. Os valores dos parâmetros $\mathrm{VE}, \mathrm{VO}_{2}$ e $\mathrm{VCO}_{2}$ foram significativamente superiores no exercício LP quando comparados com o SR para o grupo de idosos.

Tabela 4.4 - Parâmetros ergoespirométricos durante MFEL no exercício SR e LP para idosos. Valores médios \pm desvio padrão.

\begin{tabular}{|c|c|c|c|c|c|c|}
\hline & \multicolumn{2}{|c|}{ VE (L. $\left.\min ^{-1}\right)$} & \multicolumn{2}{|c|}{$\mathrm{VO}_{2}\left(\mathrm{~mL} \cdot \mathrm{kg}^{-1} \cdot \mathrm{min}^{-1}\right)$} & \multicolumn{2}{|c|}{$\mathrm{VCO}_{2}\left(\right.$ L. $\left.\min ^{-1}\right)$} \\
\hline & LP & SR & LP & SR & LP & SR \\
\hline REP & $7,5 \pm 1,5$ & $6,4 \pm 1,4$ & $2,89 \pm 0,97$ & $2,42 \pm 0,73$ & $0,23 \pm 0,07$ & $0,21 \pm 0,05$ \\
\hline S1 & $14,2 \pm 4,0$ & $13,5 \pm 4,5$ & $6,06 \pm 2,22$ & $5,83 \pm 1,82$ & $0,48 \pm 0,17$ & $0,49 \pm 0,16$ \\
\hline S3 & $18,5 \pm 3,5$ & $15,7 \pm 2,5$ & $9,41 \pm 1,95$ & $6,49 \pm 1,13$ & $0,78 \pm 0,17$ & $0,60 \pm 0,13$ \\
\hline S6 & $19,4 \pm 3,2 *$ & $15,1 \pm 3,3$ & $8,76 \pm 1,40^{*}$ & $6,41 \pm 1,30$ & $0,78 \pm 0,13^{*}$ & $0,56 \pm 0,13$ \\
\hline S9 & $21,4 \pm 3,5^{*}$ & $16,3 \pm 4,2$ & $9,21 \pm 1,65^{*}$ & $6,64 \pm 1,78$ & $0,82 \pm 0,14^{*}$ & $0,59 \pm 0,16$ \\
\hline S12 & $22,4 \pm 4,9 *$ & $17,5 \pm 2,9$ & $9,50 \pm 2,04^{*}$ & $7,42 \pm 1,75$ & $0,84 \pm 0,16^{*}$ & $0,63 \pm 0,12$ \\
\hline S15 & $22,8 \pm 4,8^{*}$ & $15,7 \pm 3,5$ & $9,09 \pm 1,72^{*}$ & $6,66 \pm 1,98$ & $0,83 \pm 0,17^{*}$ & $0,56 \pm 0,14$ \\
\hline
\end{tabular}

REP: repouso; S1: série 1; S3: série 3; S6: série 6; S9: série 9; S12: série 12; S15: série 15.

*Diferença entre LP e SR $(p \leq 0,05)$.

Do mesmo modo, a tabela 4.5 apresenta os valores dos parâmetros ergoespirométricos durante os exercícios na MFEL no grupo de jovens. 
Tabela 4.5 - Parâmetros ergoespirométricos durante MFEL no exercício SR e LP para jovens. Valores médios \pm desvio padrão.

\begin{tabular}{|c|c|c|c|c|c|c|}
\hline & \multicolumn{2}{|c|}{ VE $\left(L \cdot m^{-1}{ }^{-1}\right)$} & \multicolumn{2}{|c|}{$\mathrm{VO}_{2}\left(\mathrm{~mL} \cdot \mathrm{kg}^{-1} \cdot \mathrm{min}^{-1}\right)$} & \multicolumn{2}{|c|}{$\mathrm{VCO}_{2}\left(\mathrm{~L} \cdot \mathrm{min}^{-1}\right)$} \\
\hline & LP & $S R$ & LP & SR & LP & $S R$ \\
\hline REP & $8,8 \pm 2,2$ & 10,5 & $3,36 \pm 1,74$ & $4,20 \pm 1,62$ & $0,30 \pm 0,12$ & $0,40 \pm 0,13$ \\
\hline S1 & $14,4 \pm 4,3$ & $16,6 \pm 5,0$ & $5,83 \pm 2,89$ & $6,46 \pm 2,17$ & $0,50 \pm 0,21$ & $0,67 \pm 0,21$ \\
\hline S3 & $19,5 \pm 6,0$ & $19,7 \pm 4,8$ & $9,59 \pm 2,58$ & $7,86 \pm 1,70$ & $0,86 \pm 0,27$ & $0,85 \pm 0,18$ \\
\hline S6 & $18,5 \pm 4,8$ & $23,8 \pm 8,3$ & $8,66 \pm 2,21$ & $8,64 \pm 2,55$ & $0,81 \pm 0,20$ & $0,97 \pm 0,32$ \\
\hline S9 & $21,5 \pm 6,8$ & $22,1 \pm 6,8$ & $9,92 \pm 3,16$ & $8,51 \pm 2,64$ & $0,93 \pm 0,28$ & $0,88 \pm 0,28$ \\
\hline S12 & $21,8 \pm 4,9$ & $23,7 \pm 7,6$ & $10,10 \pm 2,22$ & $9,04 \pm 2,67$ & $0,94 \pm 0,21$ & $0,92 \pm 0,27$ \\
\hline S15 & $22,1 \pm 6,6$ & $23,4 \pm 8,6$ & $10,17 \pm 3,34$ & $8,91 \pm 2,76$ & $0,95 \pm 0,27$ & $0,92 \pm 0,32$ \\
\hline
\end{tabular}

REP: repouso; S1: série 1; S3: série 3; S6: série 6; S9: série 9; S12: série 12; S15: série 15.

Os resultados obtidos para o grupo de jovens foram bastante semelhantes ao grupo de idosos. Ou seja, todos os parâmetros ventilatórios apresentaram estabilização entre S6 e S15. No entanto, contrariamente ao grupo de idosos, não se observaram diferenças entre os exercícios LP e SR.

A figura 4.7 representa o comportamento da VE durante o exercício na MFEL no LP e SR para os dois grupos estudados. Como descrito anteriormente, a VE apresenta estabilização entre S6 e S15 nos dois exercícios estudados.

Assim, analisando o grupo de idosos, a diferença da VE entre S9 e S15 foi 1,4 L. $\min ^{-1}$ para o exercício LP e 0,6 L. $\mathrm{min}^{-1}$ para o exercício SR, caracterizando um comportamento estável. O mesmo se sucedeu para o grupo de jovens, onde a diferença de VE entre S9 e S15 foi 0,6 L. $\mathrm{min}^{-1}$ no LP e 1,3 L. $\mathrm{min}^{-1}$ no SR. Mais uma vez, estas diferenças caracterizam um comportamento estável do parâmetro VE. 
Não foram encontradas diferenças estatisticamente significativas entre os grupos na magnitude da resposta do parâmetro VE para o exercício LP. No entanto, para o exercício SR, a magnitude da resposta da VE foi significativamente maior no grupo de jovens.
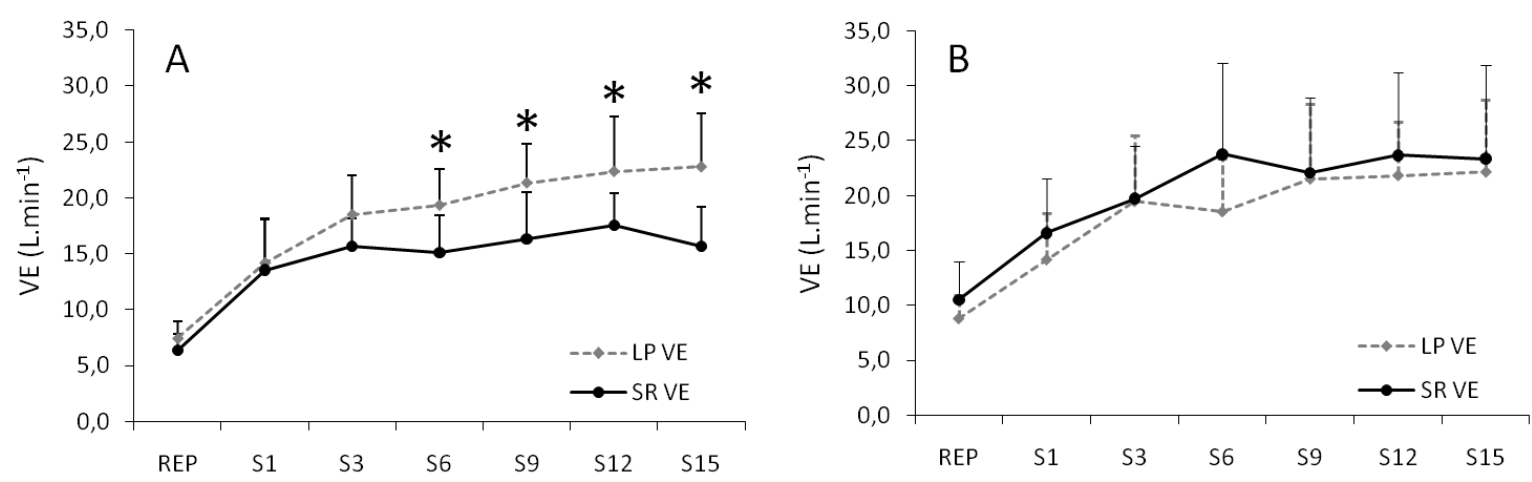

Figura 4.7 - Valores médios e desvio padrão da VE no grupo de idosos (A) e de jovens (B) durante exercício na MFEL para o LP e SR.

LP: Leg Press; SR: Supino Reto; REP: repouso; S1: série 1; S3: série 3; S6: série 6; S9: série 9; S12: série 12; S15: série 15.

*Diferença entre LP e SR $(p \leq 0,05)$

O comportamento do $\mathrm{VO}_{2}$ para os exercícios LP e SR na MFEL são apresentados na figura 4.8. Podemos observar que a diferença entre S9 e S15 é muito pequena, tanto para o grupo de idosos no LP $\left(0,12 \mathrm{~mL} \cdot \mathrm{kg}^{-1} \cdot \mathrm{min}^{-1}\right)$ e no SR $\left(0,02 \mathrm{~mL} \cdot \mathrm{kg}^{-1} \cdot \mathrm{min}^{-1}\right)$, como para o grupo de jovens também no aparelho LP $(0,25$ $\left.\mathrm{mL} \cdot \mathrm{kg}^{-1} \cdot \mathrm{min}^{-1}\right)$ e no SR $\left(0,40 \mathrm{~mL} \cdot \mathrm{kg}^{-1} \cdot \mathrm{min}^{-1}\right)$.

O consumo de oxigênio para o grupo idosos é significativamente maior no exercício LP em relação ao SR. Também houve diferença entre o grupo de idosos e o grupos de jovens no aparelho SR, com magnitude significativamente maior para o grupo de jovens. Não foram observadas diferenças entre os grupos para o parâmetro $\mathrm{VO}_{2}$ no aparelho LP. 

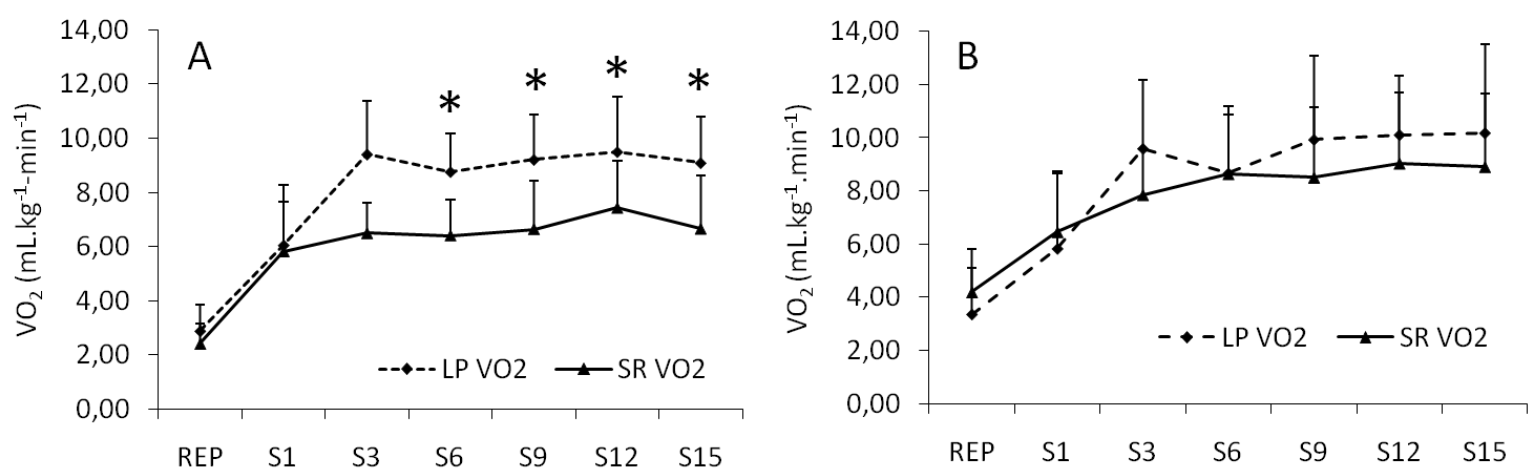

Figura 4.8 - Valores médios e desvio padrão do $\mathrm{VO}_{2}$ durante exercício na MFEL para o grupo de idosos (A) e de jovens (B) no exercício LP e SR.

LP: Leg Press; SR: Supino Reto; REP: repouso; S1: série 1; S3: série 3; S6: série 6; S9: série 9; S12: série 12; S15: série 15.

*Diferença entre LP e SR $(p \leq 0,05)$.

Comportamento muito semelhante é observado para o parâmetro $\mathrm{VCO}_{2}$ nos dois grupos, como apresentado na figura 4.9.
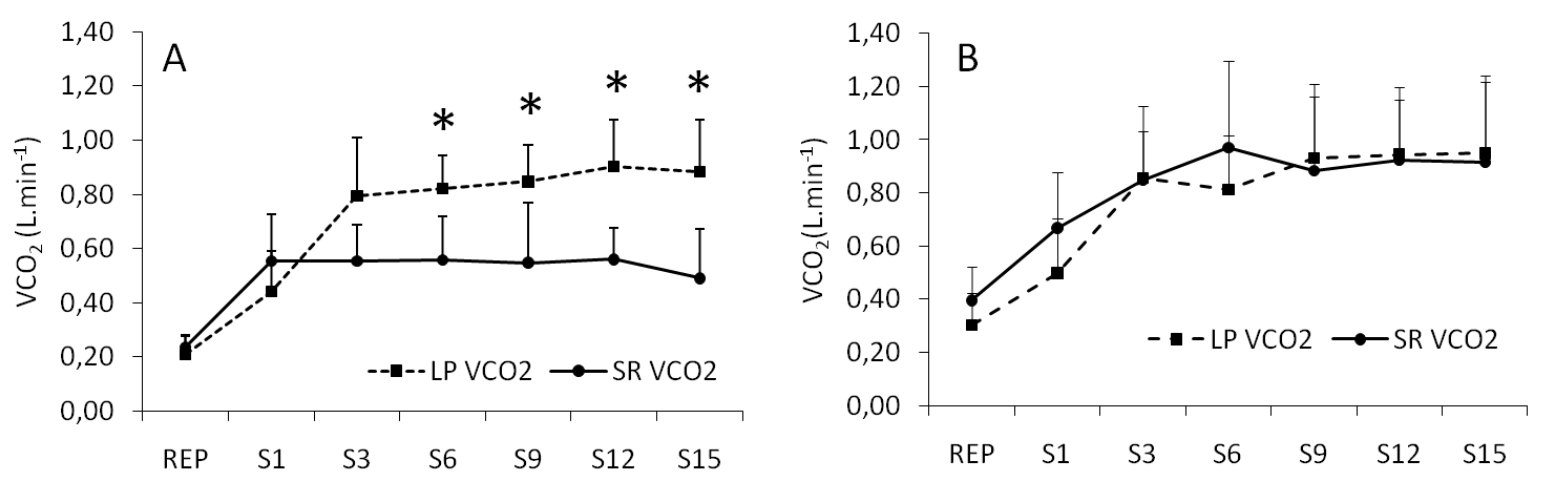

Figura 4.9 - Valores médios e desvio padrão do $\mathrm{VCO}_{2}$ durante exercício na MFEL para o grupo de idosos (A) e de jovens (B) no exercício LP e SR.

LP: Leg Press; SR: Supino Reto; REP: repouso; S1: série 1; S3: série 3; S6: série 6; S9: série 9; S12: série 12; S15: série 15.

* Diferença entre LP e SR $(p \leq 0,05)$.

No exercício LP, podemos observar a estabilização do parâmetro para o grupo de idosos (diferença entre S9 e S15 de 0,01 L.min ${ }^{-1}$ ) e grupo de jovens (diferença de 0,02 L. $\mathrm{min}^{-1}$ ). A mesma situação é observada no exercício SR para o grupo de idosos (diferença de 0,03 L.min ${ }^{-1}$ ) e de jovens (diferença de 0,04 L.min ${ }^{-1}$ ). 
Em relação ao grupo de idosos, a magnitude da resposta do $\mathrm{VCO}_{2}$ é significativamente maior no exercício LP. No que diz respeito ao SR, os valores de $\mathrm{VCO}_{2}$ são significativamente maiores no grupo jovem. Não houve diferença estatisticamente significativa entre os grupos etários no exercício LP.

\subsubsection{Freqüência cardíaca}

O comportamento da FC para o grupo de idosos e de jovens durante a MFEL nos exercícios LP e SR é apresentada na figura 4.10.
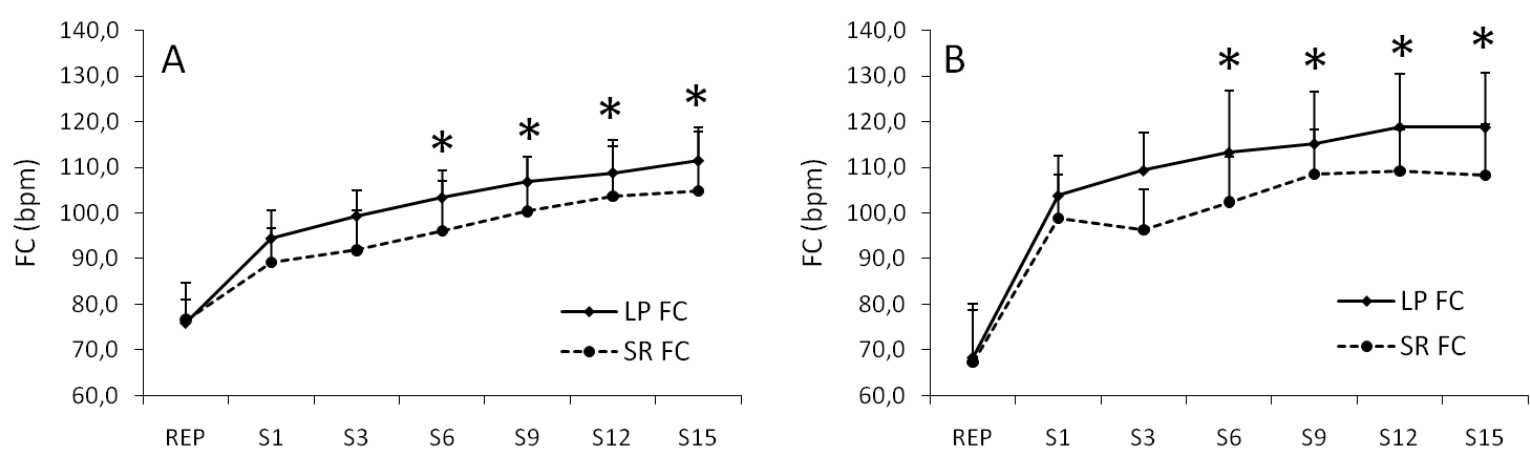

Figura 4.10 - Comportamento da FC no grupo de idosos (A) e de jovens (B) durante exercício na MFEL para LP e SR.

FC: Freqüência Cardíca; LP: Leg Press; SR: Supino Reto; REP: repouso; S1: série 1; S3: série 3; S6: série 6; S9: série 9; S12: série 12; S15: série 15.

*Diferença entre LP e SR $(p \leq 0,05)$.

Relativamente ao grupo de idosos (figura 4.10A), a FC no exercício LP não apresentou aumento considerável entre as séries S9 (106,8 \pm 5,5bpm) e S15 (111,5 \pm 7,3 bpm), estabilidade que foi alcançada a partir de S6 (103,4 $\pm 6,0 \mathrm{bpm})$. O mesmo se sucedeu no exercício SR, ou seja, estabilização da FC entre S6 $(96,1 \pm$ $10,9 \mathrm{bpm})$ e $\mathrm{S} 15(104,9 \pm 13,0 \mathrm{bpm})$. A FC foi significativamente superior no 
exercício LP em relação ao SR. Quando a FC é expressa em percentual da $\mathrm{FC}_{\max }$ prevista, no LP foi atingido $74 \%$ da $\mathrm{FC}_{\text {máx }}$ prevista e no SR $69 \%$ da $\mathrm{FC}_{\text {máx. }}$

Para o grupo de jovens (figura 4.10B), também foi observado a estabilização da FC entre S9 (115,2 $\pm 11,3$ bpm no LP e 108,6 \pm 9,8 bpm no SR) e S15 (118,8 \pm 11,9 bpm no LP e 108,3 $\pm 11,0$ bpm no SR). A FC foi significativamente superior no LP em relação ao SR, atingindo $61 \%$ da $\mathrm{FC}_{\text {máx }}$ prevista para o LP e $56 \%$ para o SR.

Analisando o percentual da FC, observa-se que, tanto no LP como no SR, os

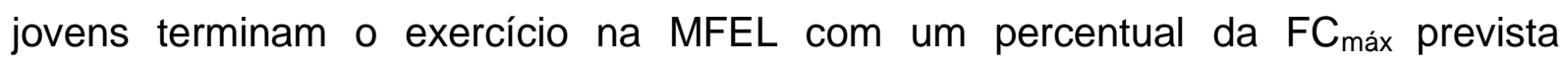
significativamente menor que os idosos.

\subsubsection{Pressão arterial}

Devido à dificuldade de mensuração no exercício SR, a PA apenas foi mensurada durante o exercício LP no grupo de idosos. Seu comportamento está representado na figura 4.11 .

A PAD manteve-se estável durante todo o exercício na intensidade correspondente à MFEL. Assim, entre S9 (109,0 $\pm 18,2$ mmHg) e S15 (109,5 $\pm 17,8$ $\mathrm{mmHg}$ ), não houve diferenças estatisticamente significativas. No que se refere à PAS, também ocorreu sua estabilização entre S9 (190,1 $\pm 21,5$ mmHg) e $S 15$ (201,4 $\pm 23,5 \mathrm{mmHg}$ ), estabilização que foi alcançada a partir de S6. Com isto, podemos afirmar que ocorreu a estabilização da PA durante o exercício na intensidade da MFEL. 


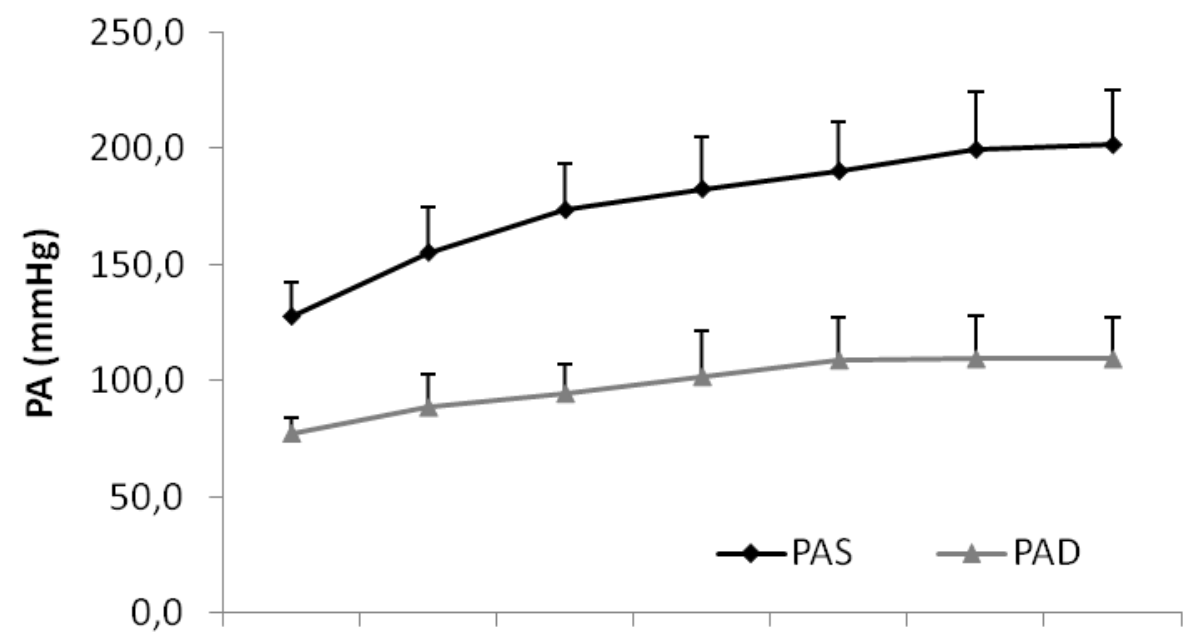

Figura 4.11 - Média e desvio padrão da PA durante exercício na MFEL para o LP no grupo de idosos.

REP: repouso; S1: série 1; S3: série 3; S6: série 6; S9: série 9; S12: série 12; S15:

série 15. PAS: Pressão Arterial Sistólica; PAD: Pressão Arterial Diastólica;

A PA para o grupo de jovens não foi mensurada através do método auscultatório. Por esse fato, não são apresentados os resultados da PA para o grupo de jovens.

\subsubsection{Duplo produto}

Durante o exercício na MFEL, o duplo produto (DP) para o grupo de idosos apresentou seu valor máximo em S15 (20742 \pm 3057 mmHg.bat.(min $\left.)^{-1}\right)$, não apresentando diferenças para S9 (19406 $\pm 2844 \mathrm{mmHg}$.bat.(min) $\left.{ }^{-1}\right)$. Assim, ocorreu a estabilização do DP durante o exercício na MFEL.

$\mathrm{Na}$ intensidade imediatamente acima da MFEL, o DP em S9 (22311 \pm 3720 mmHg.bat.(min) ${ }^{-1}$ ) já é maior que o DP em $\mathrm{S} 15$ na intensidade da MFEL, 
continuando a subir até $\mathrm{S} 15\left(25106 \pm 3489 \mathrm{mmHg} \cdot\right.$ bat. $\left.(\mathrm{min})^{-1}\right)$. Ou seja, na intensidade imediatamente acima da MFEL, o DP não apresenta mais estabilização.

O DP não pode ser calculado para o grupo de jovens, uma vez que não foi mensurada a PA para esse grupo.

\subsubsection{Percepção subjetiva de esforço}

A percepção subjetiva de esforço (BORG e OMNI) para os grupos de idosos e de jovens durante a intensidade correspondente à MFEL está representada na figura 4.12, nos exercícios LP e SR.

Em relação à escala de BORG no grupo de idosos durante o exercício LP, ocorreu um aumento do início do exercício até ao seu final, apresentando diferenças estatisticamente significativas entre $S 6(12,9 \pm 3,4)$ e $S 15(16,0 \pm 4,4)$. O mesmo comportamento foi observado durante o exercício SR, com aumento significativo de S6 $(11,7 \pm 3,6)$ para $S 15(15,7 \pm 4,5)$. Não foram observadas diferenças significativas entre o LP e o SR para cada série do exercício, na escala de BORG.

O comportamento da percepção subjetiva de esforço para o grupo de jovens, apesar de ter aumentado do início para o final do exercício, apresentou estabilização entre S9 $(11,7 \pm 3,1$ no LP e $12,7 \pm 3,2$ no SR) e S15 $(12,8 \pm 3,9$ no LP e $14,3 \pm 3,7$ no SR). Também não foram observadas diferenças significativas entre o LP e o SR na escala de BORG para o grupo de idosos, em cada série.

Entre S6 e S15 não houve diferenças estatisticamente significativas entre os grupos para os exercícios LP e SR.

No que diz respeito à escala de $\mathrm{OMNI}$, o grupo de idosos também apresentou diferença estatisticamente significativa entre $S 6(5,7 \pm 2,4)$ e $S 15(7,8 \pm 2,6)$ para 0 
exercício LP. Do mesmo modo, o esforço percebido através da escala de OMNI também apresentou diferença estatisticamente significativa entre S6 $(4,7 \pm 2,7)$ e S15 $(7,8 \pm 2,5)$ para o exercício SR.
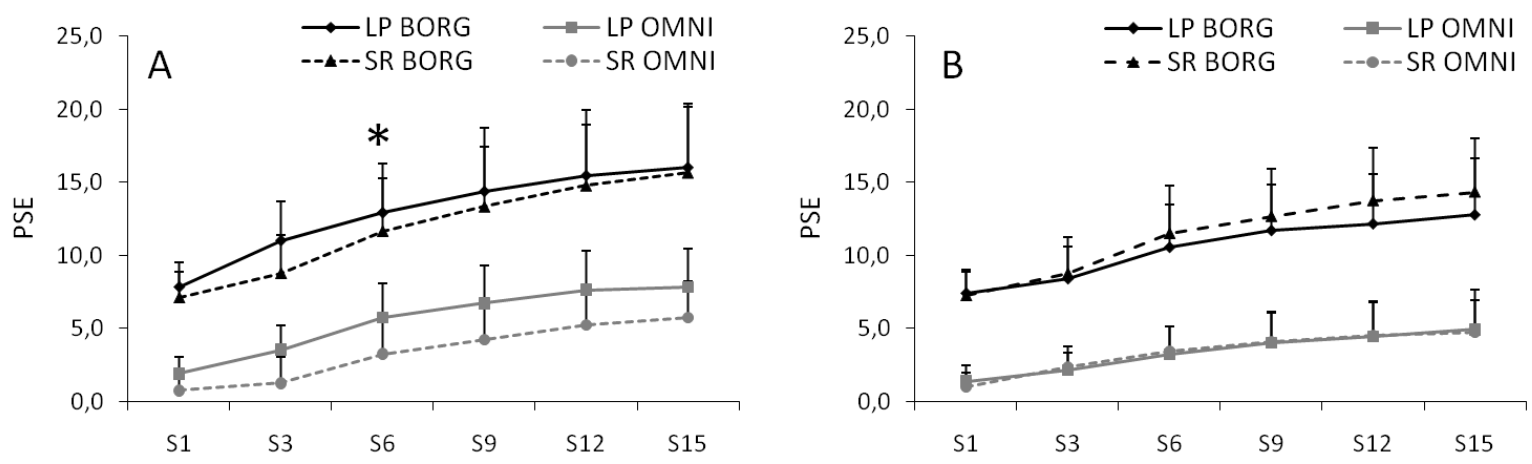

Figura 4.12 - Valores médios e desvio padrão da PSE durante exercício na MFEL no LP e SR para o grupo de idosos (A) e de jovens (B).

LP: Leg Press; SR: Supino Reto; S1: série 1; S3: série 3; S6: série 6; S9: série 9; S12: série 12; S15: série 15.

*Diferença entre S6 e S15 no LP e SR $(p \leq 0,05)$.

Mais uma vez, o grupo de jovens apresentou estabilização na escala de OMNI entre S9 e S15 para os dois exercícios estudados. Assim, durante o exercício LP a escala de OMNI apresentou valores de 4,0 $\pm 2,1$ em S9 e 4,9 \pm 2,9 em S15. Durante o SR, os valores foram muito semelhantes, ou seja, 4,1 $\pm 2,0$ em S9 e 4,7 \pm 2,2 em S15. Não foram observadas diferenças significativas entre LP e SR na escala de OMNI para o grupo de jovens.

O grupo de idosos apresenta maior sensação de esforço no exercício LP durante a sua fase de estabilização, diferença estatisticamente significativa. Não houve diferença estatisticamente significativa entre os grupos para o aparelho SR. 


\section{DISCUSSÃO}

Os principais resultados deste estudo sugerem que em exercícios resistidos é possível alcançar um nível estável de lactacidemia, o que pode ser considerado como MFEL. A intensidade da MFEL é semelhante à intensidade do LAn para os dois grupos estudados, determinado no teste crescente.

Durante o teste crescente, a intensidade máxima (\%1RM) atingida pelos dois grupos etários foi maior no exercício LP que no SR. São resultados esperados, uma vez que a massa muscular envolvida no movimento LP é maior, permitindo a realização de maior número de repetições sem instalação de fadiga, através da participação de maior número de músculos. Além disso, para uma mesma intensidade, expressa em percentual de 1RM, indivíduos realizam maior número de repetições em exercício para membros inferiores quando comparado a membros superiores, independente da velocidade de movimento ${ }^{112}$. No protocolo de teste crescente, o número de repetições a serem realizadas em cada intensidade era fixo, ou seja, sempre 20 repetições. Assim, a incapacidade por realizar maior número de repetições no SR foi traduzida pela menor intensidade alcançada no teste crescente máximo. Desta forma, os músculos dos membros inferiores apresentam maiores características de endurance que os músculos dos membros superiores ${ }^{113}$.

A lactacidemia, significativamente maior no final do exercício LP em comparação com o SR, está de acordo com Shephard e Astrand ${ }^{114}$. Os autores afirmam que exercícios que utilizem pequena massa muscular promovem menores aumentos de lactato sanguíneo. Além disso, pode ser justificada como resultado dos voluntários terminarem o exercício LP em maiores intensidades. Ao atingirem maiores intensidades no LP (perto de 70\% 1RM no LP contra cerca de 50\% 1RM no 
SR), realizaram maior número de repetições, contribuindo para maior produção de lactato, lançado na corrente sanguínea. Ainda assim, quando a concentração de lactato é corrigida pelo tempo de exercício, a maior produção de lactato sanguíneo por unidade de tempo continua a ser para o exercício LP. Entretanto, segundo Hargreaves ${ }^{115}$, para a mesma intensidade relativa de esforço, há maior liberação de lactato nos exercícios realizados com os braços em comparação com as pernas, sendo isto devido à maior glicogenólise muscular nos exercícios dos membros superiores. Tal fato foi confirmado no nosso estudo, principalmente na intensidade correspondente ao LAn, onde a lactacidemia é maior no exercício SR, como se pode observar nas tabelas 4.1 e 4.2. Esta maior liberação de lactato, relativa à massa muscular envolvida, será diluída no volume plasmático total, e dessa forma aparecerá durante sua mensuração em menores concentrações que a dos membros inferiores, os quais utilizam grandes massas musculares, e desta forma a produção muscular absoluta será menor.

A lactacidemia no final do teste crescente máximo nos dois exercícios estudados foi superior em indivíduos jovens, resultado que está de acordo com a literatura ${ }^{116-118}$. Durante o processo de envelhecimento, a enzima LDH sofre uma alteração na sua isoforma muscular (MLDH) para a isoforma do coração (HLDH), que favorece o aumento da concentração de piruvato, ao invés da formação de lactato $^{119}$. A forte correlação que existe entre a isoforma MLDH e a produção de lactato $^{120}$ poderá explicar as maiores concentrações de lactato sanguíneo nos jovens. Deste modo, com o aumento da idade, existe o decréscimo da capacidade de produzir energia através da via glicolítica, devido à diminuição da atividade da isoforma muscular da enzima LDH. Além disso, a redução da concentração de lactato em indivíduos idosos também pode estar relacionada com a diminuição da 
atividade da enzima reguladora fosfofrutoquisase (PFK), observada em indivíduos idosos $^{121}$.

Relativamente aos parâmetros ergoespirométricos analisados na intensidade máxima do exercício ( $\mathrm{VE}, \mathrm{VO}_{2}$ e $\mathrm{VCO}_{2}$ ), apesar dos mesmos serem sempre maiores durante o LP, apenas o $\mathrm{VCO}_{2}$ foi significativamente superior nos dois grupos. Kalb e Hunter ${ }^{122}$ e Scala et al. ${ }^{123}$ demonstraram, em exercício resistido, maiores elevações do $\mathrm{VO}_{2}$ em exercícios de grande massa muscular quando comparados com os de pequena massa muscular. Apesar de não mostrar diferença significativa, o nosso estudo está de acordo com estes estudos prévios, apresentando valores de $\mathrm{VO}_{2}$ superiores no LP que no SR. Não foram analisados os valores de $\mathrm{VCO}_{2}$ nos estudos citados anteriormente, mas sugere-se que a maior massa muscular envolvida no exercício LP provoca maior produção de $\mathrm{CO}_{2}$, que é eliminado através do sistema respiratório ${ }^{54,124}$.

No entanto, considerando que são valores máximos atingidos em um teste máximo realizado em exercício resistido, todos os parâmetros ergoespirométricos apresentam valores muito pequenos em relação a um teste máximo em exercício aeróbio dinâmico, como em esteira ou cicloergômetro ${ }^{125}$. Mais uma vez, a diferença de massa muscular envolvida em cada exercício é apontada como a principal causa dos valores baixos encontrados no presente estudo. Citando estudos realizados apenas em exercício resistido ${ }^{126-130}, \mathrm{O} \mathrm{VO}_{2}$ absoluto apresenta valores na faixa dos 1,3 - 2,3 L.min ${ }^{-1}$ e a VE na faixa dos 24 - 63 L.min ${ }^{-1}$. As respostas ergoespirométricas no nosso estudo estão um pouco abaixo das respostas encontradas na literatura, possivelmente porque apenas incluímos um exercício em cada protocolo e de forma tradicional, sendo que outros estudos avaliaram cada exercício dentro de um protocolo de exercícios múltiplos em forma de circuito. A 
avaliação de um exercício em forma de circuito pode ser afetada pela execução do exercício anterior, não demonstrando especificamente a resposta do exercício a ser avaliado. Tal afirmação é comprovada através do estudo de Farinatti et $a l^{131}$, onde o consumo de oxigênio durante a realização do SR após a realização de dois exercícios prévios é significativamente maior quando realizado primeiramente. Outro fator que pode ter influenciado as menores respostas ergoespirométricas foi a utilização do tempo de coleta de valores médios de 20 em 20 segundos, contrariamente à maioria dos estudos aqui apresentados que realizaram a coleta ciclo a ciclo. Com isso, as respostas ergoespirométricas encontrados em nossa pesquisa podem ser consideradas normais para exercícios isolados, como o LP e SR.

A faixa etária dos sujeitos também influenciou as respostas ergoespirométricas, sendo que os idosos apresentaram menores valores de $\mathrm{VE}, \mathrm{VO}_{2}$ e $\mathrm{VCO}_{2}$ que os jovens durante o teste crescente, como apresentado por Prioux et al. em exercício dinâmico ${ }^{118}$. Estes resultados são uma evidência de declínio da capacidade aeróbia em indivíduos idosos ${ }^{35}$, mesmo em exercícios onde as respostas ergoespirométricas não atingem valores considerados altos para as populações estudadas.

Outro importante resultado do presente estudo foi a determinação do LAn nos exercícios LP e SR para as duas populações estudadas (tabelas 4.1 e 4.2 e figura 4.2). No entanto, estes dados contrariam a existência de um padrão similar de ocorrência do LAn para exercício resistido apresentado em estudos prévios ${ }^{86,87}$. Ou seja, a intensidade do LAn no exercício SR ( 21,5 \%1RM nos idosos e 24,0 \%1RM nos jovens) foi significativamente menor que no LP ( $27,9 \% 1 \mathrm{RM}$ nos idosos e 27,8 \%1RM nos jovens). Baseado no princípio que exercícios realizados com os 
membros superiores produzem maior concentração de lactato que os realizados com os membros inferiores ${ }^{115}$, a intensidade do LAn no SR deveria ser menor que no LP, como apresentado no nosso estudo. O LAn, expresso em percentual de 1RM, acontece em intensidades menores para exercícios com os membros superiores.

Além das diferenças entre exercícios, a intensidade do LAn (expressa em percentual de $1 \mathrm{RM}$ ) parece ser um pouco menor que $30 \%$ de $1 \mathrm{RM}$, como identificado na literatura em estudos prévios ${ }^{86-88}$. Estas diferenças podem ser justificadas pelo método de identificação do LAn no presente estudo, não utilizado em outras pesquisas. De qualquer modo, a intensidade do LAn ficou muito próxima de $30 \%$ de $1 \mathrm{RM}$, estando de acordo com a afirmação de Villiger et $a^{132}$, onde sem mencionar o conceito de LAn, afirma que durante uma ação muscular resistida dinâmica, a solicitação metabólica é aeróbia em cargas até aproximadamente $30 \%$ de 1RM. A principal teoria para a ocorrência do LAn em exercícios resistidos é a teoria hemodinâmica ${ }^{86,87}$. De acordo com a teoria, a produção aumentada de lactato sanguíneo se deve à hipóxia muscular provocada principalmente pelo colabamento dos capilares $^{132}$. A pressão intramuscular, que aumenta de forma linear com a tensão muscular ${ }^{133}$, apresenta valores superiores à pressão capilar, e por conseqüência promove colabamento dos mesmos ${ }^{134}$, podendo, desta maneira, levar à hipóxia muscular.

A freqüência cardíaca para os dois grupos não atingiu valores máximos previstos para um teste máximo no exercício aeróbio dinâmico ${ }^{135}$. No entanto, os valores pico encontrados são muito semelhantes a estudos prévios ${ }^{125,} 128,129$. Os parâmetros ergoespirométricos em exercício resistido com valores inferiores aos encontrados em exercício aeróbio dinâmico podem servir de justificativa para que a 
FC não atinja seus valores máximos previstos, uma vez que a demanda cardíaca não é o fator limitante para a exaustão no teste máximo em exercício resistido.

Além da determinação do LAn, o presente estudo conseguiu evidenciar a existência de MFEL no exercício LP e SR, através da estabilização da lactacidemia em um exercício de 30 minutos. A MFEL ocorreu na mesma intensidade relativa do LAn, indicando que a MFEL pode ser determinada através de um teste crescente com a determinação do LAn. Svedahl et al. ${ }^{77}$ afirma que a MFEL representa efetivamente a intensidade do exercício correspondente ao LAn, como apresentado neste estudo e também encontrado na literatura para exercícios aeróbios dinâmicos, especificamente corrida ${ }^{81,136}$.

Um aspecto muito importante é a intensidade que ocorre a MFEL, especificamente para cada exercício. No LP, a intensidade da MFEL foi 30,9\%1RM para os idosos e 29,2 \%1RM para os jovens. Já para o SR, os idosos apresentam MFEL em 23,3 \%1RM e os jovens em 21,7 \%1RM. Diante disso, a intensidade da MFEL é especifica do exercício realizado, maior para o exercício LP e menor para o SR. Devido à lacuna de dados em exercício resistido, baseamo-nos em pesquisas envolvendo exercícios aeróbios dinâmicos. Beneke ${ }^{137}$ propôs que a MFEL depende do padrão motor de cada exercício, causada pela inter-relação entre a produção de energia por unidade de massa muscular e a massa específica dos músculos primários do movimento. Como exemplo, em atletas de elite, a MFEL parece ser diferente durante corrida, ciclismo ou skate ${ }^{91,137}$. Mais recentemente, diferenças foram encontradas entre o exercício de remo e ciclismo, em atletas remadores ${ }^{102}$. Realizando um paralelo com os exercícios realizados em nossa pesquisa, Heck et al. ${ }^{90,138}$ observaram diferentes resultados na intensidade da MFEL para o exercício pedalar relativamente ao manalar. Desta forma, diferentes exercícios resistidos 
podem apresentar diferentes respostas, especificamente quando falamos de dois exercícios tão diferentes como o LP (membros inferiores) e o SR (membros superiores).

Por outro lado, a MFEL não é influenciada pela faixa etária dos indivíduos, uma vez que tanto o grupo de jovens como o de idosos apresentaram MFEL em intensidades semelhantes para cada exercício. Estes resultados contrariam o estudo de Mattern et al. ${ }^{106}$, onde os autores afirmam que em exercício aeróbio dinâmico a intensidade da MFEL diminui com o processo de envelhecimento, independente da redução do $\mathrm{VO}_{2 \max }$. Os autores acima citados apresentam como hipótese que, devido às mudanças no perfil da isoforma da cadeia pesada da miosina no músculo esquelético e das enzimas aeróbias durante o processo de envelhecimento, a MFEL ocorreria em intensidades menores em atletas idosos. No entanto, apesar da MFEL apresentar redução com o processo de envelhecimento, os mecanismos para tal redução não foram comprovados.

Na base da hipótese estaria a mudança da expressão da isoforma da cadeia pesada da miosina em favor das fibras do tipo I com o processo de envelhecimento $^{139}$. Em relação ao exercício resistido, esta mudança poderia influenciar negativamente a intensidade da MFEL, diminuindo a velocidade de contração das fibras musculares. Além disso, a diminuição da atividade das enzimas aeróbias e manutenção das enzimas do metabolismo anaeróbio com o processo de envelhecimento ${ }^{140}$, também poderiam justificar tal hipótese, o que não aconteceu.

Não pode ser desconsiderado que a pesquisa mencionada anteriormente diz respeito a exercício aeróbio dinâmico, limitando suas conclusões para exercícios resistidos. Assim, no caso de exercício resistido, a utilização de uma escala relativa (\% de 1RM) poderá ter sido fundamental para obter estes resultados, facilitando a 
prescrição para futuros treinamentos. No entanto, apesar dos voluntários serem treinados em exercício resistido, o regime de treinamento dos voluntários não foi previamente controlado. Deste modo, os resultados obtidos podem ser conseqüência da variação das práticas de treinamento e não do processo de envelhecimento. Estudos com controle dos tipos de treinamento nas diferentes faixas etárias, como realizado por Mattern et al. ${ }^{106}$, são necessários para diferenciar a origem da adaptação.

Apesar de em exercício crescente máximo o lactato sanguíneo apresentar concentrações superiores para o grupo de jovens, a lactacidemia final durante o exercício na MFEL não apresentou diferenças entre os grupos, apresentando estabilização em concentrações muito próximas de $4 \mathrm{mmol} . \mathrm{L}^{-1}$, tanto para LP como para SR. Heck et al. ${ }^{90}$, em seu artigo clássico, apresentam resultados que sugerem os $4 \mathrm{mmol} . \mathrm{L}^{-1}$ como a concentração de início da acumulação de lactato sanguíneo para uma determinada população. A concentração de $4 \mathrm{mmol}^{-\mathrm{L}^{-1}}$ na intensidade da MFEL também foi observada na pesquisa de Mattern et al. ${ }^{106}$, além de também não terem sido observadas diferenças entre os três grupos etários estudados.

A menor intensidade (\% $1 \mathrm{RM})$ referente á MFEL no SR é, possivelmente, devido à maior lactacidemia atingida em menores intensidades de exercício, como explicado anteriormente. Com isto, concentrações próximas de $4 \mathrm{mmol}^{-1}$ são atingidas em intensidades menores para o SR, relativamente ao LP, apresentando MFEL em intensidade menor (quase $10 \% 1 \mathrm{RM}$ ).

Devido à inexistência de protocolos para determinação de MFEL em exercício resistido, foi elaborado um protocolo baseado no aumento da concentração de lactato entre S9 e S15 em exercício contínuo, contemplando a cinética do lactato nos últimos 10 minutos. A diferença de lactato entre $S 9$ e $S 15$ foi baseada nos 
resultados da concentração de lactato obtidas em exercício resistido (figuras 4.3 e 4.6 e tabela 4.3). Desta forma, a elaboração do protocolo de exercício resistido contínuo, com o objetivo de determinação da MFEL, procurou seguir o modelo de protocolo para exercício aeróbio dinâmico. Com isso, procurou-se seguir a seguinte linha: (1) tempo de exercício de 30 minutos, como proposto largamente na literatura; (2) intensidade de exercício contínua, iniciando-se na carga do LAn, uma vez que estudos em exercícios aeróbios dinâmicos demonstram intensidades muito próximas entre LAn e MFEL; (3) devido à característica específica do treinamento com pesos, a realização de séries de exercício com tempo de recuperação foi inevitável; (4) modelo experimental contemplando séries com duração de um minuto e recuperação de um minuto apresentou-se o mais adequado, na tentativa de evitar alterações bruscas no metabolismo entre o tempo de exercício e o tempo de recuperação; (5) os últimos 10 minutos de exercício foram suficientes para distinguir entre um exercício numa fase estável e um exercício acima da fase estável, por isso a escolha da análise da lactacidemia entre S9 e S15.

Deste modo, o protocolo mostrou-se favorável para a determinação da MFEL, uma vez que lactacidemia superior a $1 \mathrm{mmol}^{-1} \mathrm{~L}^{-1}$ entre $\mathrm{S} 9$ e $\mathrm{S} 15$ permite observar um estado de exercício que não é mais estável, aumentado significativamente a concentração de lactato até ao final do exercício (figuras 4.3 e 4.6 e tabela 4.3). Durante o protocolo na intensidade considerada acima da MFEL, nem todos os indivíduos conseguiram terminar o exercício, ou quando terminavam o faziam com valores muito altos de lactato e diferença entre $\mathrm{S} 9$ e $\mathrm{S} 15$ superior a $1 \mathrm{mmol} . \mathrm{L}^{-1}$, não representando fase estável do exercício ${ }^{89}, 90,137$. Assim, acima da intensidade da MFEL, a cinética do lactato apresentou um aumento identificável e considerável com o tempo ${ }^{89,90}$. Do mesmo modo, ao analisar as escalas de percepção de esforço, 
observa-se que, tanto a escala de BORG como a escala de OMNI, também apresentam aumento até ao final do exercício na intensidade acima da MFEL, chegando mesmo a valores máximos na maioria dos voluntários. Estes resultados sustentam a idéia de que realmente o exercício não se apresentava em fase estável. Da mesma forma, analisando as mesmas escalas na intensidade referente à MFEL, observa-se seu aumento durante o exercício, mas terminando em valores próximos de 15 para a escala de BORG e de 5 para a escala de OMNI. Ou seja, além de diferença de lactato sanguíneo entre S9 e S15 ser menor ou igual que 1,0 mmol. $\mathrm{L}^{-1}$, o esforço percebido pelos voluntários foi bem menor que na intensidade acima da MFEL, apesar do seu aumento desde o início até ao final do exercício.

Considerando a diferença de concentração de lactato sanguíneo não superior a $1 \mathrm{mmol.L} \mathrm{L}^{-1}$ entre S9 e S15, podemos constatar que todas a variáveis fisiológicas analisadas mantêm-se estáveis durante esse período de tempo, inclusive a partir de S3. Como descrito por Beneke ${ }^{89,93}$, após adaptação inicial necessária após o início do exercício, a MFEL caracteriza-se por um equilíbrio fisiológico.

Analisando os parâmetros ergoespirométricos para o grupo de idosos, observa-se uma estabilização entre S9 e S15 em valores superiores para o LP em relação ao SR. Estabilização também observada no grupo de jovens, no entanto, apesar de também apresentar valores superiores no LP, não foram diferentes do SR. Valores superiores podem ser justificados devido à maior massa muscular utilizada no exercício $\mathrm{LP}^{122,123}$, assim como sua maior carga de trabalho, em percentual de 1RM. Estes resultados também podem ser explicados devido à diferença de carga relativa ao peso corporal levantada pelos grupos, onde 1RM para os idosos representou apenas $76 \%$ do peso corporal e para os jovens representou $110 \%$ do peso corporal. Estas diferenças poderão ter sido cruciais para que nos 
idosos os parâmetros ergoespirométricos tenham sido superiores no LP em relação ao SR e nos jovens essa diferença não tenha sido apresentada. Entretanto, o importante a destacar é o fato de $\mathrm{VE}, \mathrm{VO}_{2}$ e $\mathrm{VCO}_{2}$ apresentarem estabilização durante o exercício nos dois grupos, característica de MFEL em exercícios aeróbios dinâmicos ${ }^{95,96}$.

Comparando os grupos etários, os parâmetros ergoespirométricos $\mathrm{VE}, \mathrm{VO}_{2} \mathrm{e}$ $\mathrm{VCO}_{2}$ apresentaram valores menores apenas durante o exercício SR para o grupo de idosos. Estes resultados estão, apenas em parte, de acordo com os apresentados por Mattern et al. ${ }^{106}$, onde os autores afirmam que o $\mathrm{VO}_{2}$ apresenta uma redução na intensidade da MFEL com o processo de envelhecimento. Apesar de os autores relacionarem tal redução com a diminuição do $\mathrm{VO}_{2 \max } \operatorname{com}$ o processo de envelhecimento, eles afirmam que não é conclusiva. Relativamente ao nosso estudo, em exercício resistido, a diferença pode ser explicada devido à grande diferença de carga relativa entre os exercícios. Da mesma forma, os idosos apresentaram 1RM aproximadamente de $76 \%$ do seu peso corporal no SR, enquanto que nos jovens foi superior a $100 \%$ do seu peso corporal. Esta diferença pode levar a diferentes gastos energéticos entre os grupos, uma vez que os idosos necessitam vencer uma carga absoluta bem menor que os jovens.

Em relação à função cardíaca, destacamos principalmente o grupo de idosos, grupo que requer especial atenção com o objetivo de proteção do sistema cardiovascular durante a realização de exercícios físicos. Como esperado, ocorreu a estabilização da FC durante o exercício na MFEL para o SR e LP, atingindo valores inferiores a $74 \%$ da $\mathrm{FC}_{\text {máx }}$ prevista para o LP e $69 \%$ para o SR. Estes resultados estão de acordo com estudos que evidenciam um maior aumento da FC em exercícios de maior massa muscular ${ }^{60}$. 0 mesmo padrão é observado para o grupo 
de jovens, no entanto, quando comparados os grupos etários, observa-se que a estabilização da FC ocorre em valores superiores (\%FCmáx prevista) para os idosos. Estes resultados podem evidenciar uma menor reserva cardíaca para o grupo de idosos na MFEL.

Além da FC, a PA também apresentou um comportamento estável entre S9 e S15, com valores muito próximos de $200 \mathrm{mmHg}$. Através destas duas variáveis, podemos calcular o DP durante o exercício LP, que atingiu valores máximos muito perto de $20000 \mathrm{mmHg} \cdot$ bat.(min) ${ }^{-1}$. Estes resultados são bons indicativos para segurança cardiovascular na realização do exercício LP. Além disso, estudos evidenciam que o DP em exercícios aeróbio dinâmicos é maior que em exercício resistido $^{141-143}$, principalmente devido ao aumento acentuado da FC em exercícios aeróbios, contrariamente ao exercício resistido.

Todos estes valores referentes à função cardíaca são valores que indicam segurança na realização do exercício LP para idosos. Resultado ainda mais importante quando se analisa o DP em uma sessão com intensidade cerca de $5 \%$ maior que na MFEL. Nessa intensidade, o DP já apresenta valores superiores a $26000 \mathrm{mmHg}$.bat.(min) ${ }^{-1}$, ou seja, superior ao recomendado na literatura. Assim, para este tipo de protocolo, a intensidade da MFEL pode representar uma mudança no comportamento das variáveis cardiovasculares. 


\section{CONCLUSÃO}

As principais conclusões advindas deste estudo podem ser resumidas nos seguintes pontos:

1. Foi confirmado a existência do LAn em exercício resistido. O LAn ocorreu em intensidade maior no LP comparado com o SR, para os dois grupos estudados (aproximadamente $25 \% 1 \mathrm{RM}$ no LP e $21 \% 1 \mathrm{RM}$ no SR para os idosos e $28 \% 1 \mathrm{RM}$ no LP e $24 \% 1 R M$ no SR para os jovens);

2. Foi possível determinar a MFEL em exercício resistido nas duas populações estudadas, através de um protocolo elaborado em nosso laboratório. A intensidade da MFEL, relativa ao percentual de $1 \mathrm{RM}$, é maior no LP (aproximadamente 30 \%1RM) que no SR (aproximadamente $21 \% 1 \mathrm{RM}$ ). Esta intensidade é semelhante nos dois grupos estudados;

3. A intensidade da MFEL, expressa em percentual de $1 \mathrm{RM}$, é semelhante à intensidade do LAn;

4. Os idosos apresentam concentração de lactato sanguíneo menor que os jovens no final do exercício crescente, mesmo atingindo intensidade máxima semelhante, quando expresso em \%1RM; 
5. Os parâmetros ergoespirométricos apresentam estabilidade durante o exercício na MFEL. As respostas da VE, VO2 e VCO2 tendem a serem maiores no exercício LP que no SR;

6. A percepção subjetiva de esforço estabilizou nos dois exercícios para os dois grupos, apesar de aumentar durante todo o exercício;

7. Durante exercício na MFEL, a FC e PA e DP também apresentam estabilização, indicando segurança cardiovascular em exercícios desta natureza, e em especial para idosos. 


\section{REFERÊNCIAS}

1. Censo Demográfico 2000. In: IBJE, editor. Rio de Janeiro2002.

2. Lima J, Silva Al. Ser idoso: estudo de uma população. Revista Geriatria. 2002;14( 140): :12-17.

3. Spidurso W. Physical dimensions of aging. Champaign: Human Kinetics; 1995.

4. Barata T, Clara H. Actividade Física e Medicina Moderna. In: Europress, editor. Actividade Física nos idosos. Odivelas 1997.

5. Lunney JR, Lynn J, Foley DJ, et al. Patterns of functional decline at the end of life. JAMA. 2003;289(18): :2387-2392.

6. American College of Sports Medicine Position Stand. Exercise and physical activity for older adults. Med Sci Sports Exerc. 1998;30( 6) :992-1008.

7. Spidurso W, Eckert H. Physical Activity and Aging. American Academy of Physical Education. Kinetics $\mathrm{H}$, editor. Champaign, Illionais1989.

8. Dias I, Afonso A. A pessoa idosa na cidade do Porto. Revista Horizonte. 1999;15) 88) :20-26.

9. Silvestre J, Araújo D. Motivação para a prática de actividades Motoras em idosos. Revista Ludens. 1999;16( 3) :61-66.

10. Matsudo S, Matsudo V. Prescrição e benefícios da actividade física na terceira idade. Revista Horizonte. 1993;9( 54) :221-227.

11. Lakatta EG, Levy D. Arterial and cardiac aging: major shareholders in cardiovascular disease enterprises: Part I: aging arteries: a "set up" for vascular disease. Circulation. 2003;107( 1) :139-146.

12. DeSouza CA, Shapiro LF, Clevenger CM, et al. Regular aerobic exercise prevents and restores age-related declines in endothelium-dependent vasodilation in healthy men. Circulation. 2000;102( 12): 1351-1357.

13. Kitzman DW. Diastolic heart failure in the elderly. Heart Fail Rev. 2002;7( 1): 17-27.

14. Grewal J, McCully RB, Kane GC, et al. Left ventricular function and exercise capacity. JAMA. 2009;301( 3): 286-294.

15. Xiao RP, Tomhave ED, Wang DJ, et al. Age-associated reductions in cardiac beta1and beta2-adrenergic responses without changes in inhibitory $\mathrm{G}$ proteins or receptor kinases. J Clin Invest. 1998;101( 6) : 1273-1282.

16. Kleiger RE, Stein PK, Bigger JT, Jr. Heart rate variability: measurement and clinical utility. Ann Noninvasive Electrocardiol. 2005;10( 1) :88-101. 
17. Sattelmair JR, Pertman JH, Forman DE. Effects of physical activity on cardiovascular and noncardiovascular outcomes in older adults. Clin Geriatr Med. 2009;25( 4) :677-702, viii-ix.

18. Grimby G, Saltin B. The ageing muscle. Clin Physiol. 1983;3( 3) :209-218.

19. Visser M, Goodpaster BH, Kritchevsky SB, et al. Muscle mass, muscle strength, and muscle fat infiltration as predictors of incident mobility limitations in well-functioning older persons. J Gerontol A Biol Sci Med Sci. 2005;60(3) :324-333.

20. Frontera WR, Hughes VA, Lutz KJ, et al. A cross-sectional study of muscle strength and mass in 45- to 78-yr-old men and women. J Appl Physiol. 1991;71( 2) :644-650.

21. Kallman DA, Plato CC, Tobin JD. The role of muscle loss in the age-related decline of grip strength: cross-sectional and longitudinal perspectives. J Gerontol. 1990;45( 3) :M8288.

22. Reed RL, Pearlmutter L, Yochum K, et al. The relationship between muscle mass and muscle strength in the elderly. J Am Geriatr Soc. 1991;39(6) :555-561.

23. Danneskiold-Samsoe B, Kofod V, Munter J, et al. Muscle strength and functional capacity in 78-81-year-old men and women. Eur J Appl Physiol Occup Physiol. 1984;52( 3) :310-314.

24. Brown AB, McCartney N, Sale DG. Positive adaptations to weight-lifting training in the elderly. J Appl Physiol. 1990;69(5) : 1725-1733.

25. Kent-Braun JA, Ng AV. Specific strength and voluntary muscle activation in young and elderly women and men. J Appl Physiol. 1999;87( 1) :22-29.

26. Lexell J, Henriksson-Larsen K, Winblad B, et al. Distribution of different fiber types in human skeletal muscles: effects of aging studied in whole muscle cross sections. Muscle Nerve. 1983;6( 8) :588-595.

27. Lexell J, Downham D, Sjostrom M. Distribution of different fibre types in human skeletal muscles. Fibre type arrangement in $\mathrm{m}$. vastus lateralis from three groups of healthy men between 15 and 83 years. J Neurol Sci. 1986;72( 2-3) :211-222.

28. Aniansson A, Hedberg M, Henning GB, et al. Muscle morphology, enzymatic activity, and muscle strength in elderly men: a follow-up study. Muscle Nerve. 1986;9( 7 ) :585-591.

29. Klitgaard $H$, Mantoni $M$, Schiaffino $S$, et al. Function, morphology and protein expression of ageing skeletal muscle: a cross-sectional study of elderly men with different training backgrounds. Acta Physiol Scand. 1990;140( 1) :41-54.

30. Lexell J, Taylor CC, Sjostrom M. What is the cause of the ageing atrophy? Total number, size and proportion of different fiber types studied in whole vastus lateralis muscle from 15- to 83-year-old men. J Neurol Sci. 1988;84( 2-3) :275-294. 
31. Hortobagyi $T$, Zheng D, Weidner $M$, et al. The influence of aging on muscle strength and muscle fiber characteristics with special reference to eccentric strength. J Gerontol A Biol Sci Med Sci. 1995;50( 6) :B399-406.

32. Sato $\mathrm{T}$, Akatsuka $\mathrm{H}$, Kito $\mathrm{K}$, et al. Age changes in size and number of muscle fibers in human minor pectoral muscle. Mech Ageing Dev. 1984;28( 1) :99-109.

33. Coggan AR, Spina RJ, King DS, et al. Histochemical and enzymatic comparison of the gastrocnemius muscle of young and elderly men and women. $J$ Gerontol. 1992;47( 3) :B71-76.

34. Balagopal P, Schimke JC, Ades $P$, et al. Age effect on transcript levels and synthesis rate of muscle $\mathrm{MHC}$ and response to resistance exercise. Am J Physiol Endocrinol Metab. 2001;280( 2) :E203-208.

35. Fleg JL, Morrell $\mathrm{CH}$, Bos AG, et al. Accelerated longitudinal decline of aerobic capacity in healthy older adults. Circulation. 2005;112(5) :674-682.

36. Koopman R, van Loon LJ. Aging, exercise, and muscle protein metabolism. J Appl Physiol. 2009;106( 6) :2040-2048.

37. Fleg JL, Lakatta EG. Role of muscle loss in the age-associated reduction in VO2 max. J Appl Physiol. 1988;65( 3) :1147-1151.

38. Fleg JL, O'Connor F, Gerstenblith G, et al. Impact of age on the cardiovascular response to dynamic upright exercise in healthy men and women. J Appl Physiol. 1995;78( 3 ): :890-900.

39. Mancini DM, Eisen $H$, Kussmaul W, et al. Value of peak exercise oxygen consumption for optimal timing of cardiac transplantation in ambulatory patients with heart failure. Circulation. 1991;83( 3) :778-786.

40. McCartney N. Acute responses to resistance training and safety. Med Sci Sports Exerc. 1999;31( 1) :31-37.

41. Stratton JR, Levy WC, Cerqueira MD, et al. Cardiovascular responses to exercise. Effects of aging and exercise training in healthy men. Circulation. 1994;89( 4) :1648-1655.

42. Folland JP, Williams AG. The adaptations to strength training : morphological and neurological contributions to increased strength. Sports Med. 2007;37( 2) :145-168.

43. Santarem JM. Treinamento de Força e Potência. O Exercício. Gorayeb N, Neto B, editors: Atheneu; 1999.

44. Kraemer WJ, Ratamess NA. Fundamentals of resistance training: progression and exercise prescription. Med Sci Sports Exerc. 2004;36( 4) :674-688.

45. Fry AC. The role of resistance exercise intensity on muscle fibre adaptations. Sports Med. 2004;34( 10): :663-679. 
46. Wernbom M, Augustsson J, Thomee R. The influence of frequency, intensity, volume and mode of strength training on whole muscle cross-sectional area in humans. Sports Med. 2007;37( 3) :225-264.

47. Fleck SJ, Kraemer WJ. Designing resistance training programs: Human Kinetics; 1997.

48. Verrill DE, RibisI PM. Resistive exercise training in cardiac rehabilitation. An update. Sports Med. 1996;21( 5) :347-383.

49. Kelley G. Dynamic resistance exercise and resting blood pressure in adults: a metaanalysis. J Appl Physiol. 1997;82( 5) :1559-1565.

50. McCartney N. Role of resistance training in heart disease. Med Sci Sports Exerc. 1998;30( 10 Suppl) :S396-402.

51. Pollock ML, Franklin BA, Balady GJ, et al. AHA Science Advisory. Resistance exercise in individuals with and without cardiovascular disease: benefits, rationale, safety, and prescription: An advisory from the Committee on Exercise, Rehabilitation, and Prevention, Council on Clinical Cardiology, American Heart Association; Position paper endorsed by the American College of Sports Medicine. Circulation. 2000;101( 7) :828-833.

52. Banz WJ, Maher MA, Thompson WG, et al. Effects of resistance versus aerobic training on coronary artery disease risk factors. Exp Biol Med ( Maywood) . 2003;228(4): :434-440.

53. Taylor NF, Dodd KJ, Damiano DL. Progressive resistance exercise in physical therapy: a summary of systematic reviews. Phys Ther. 2005;85( 11) :1208-1223.

54. Gotshalk LA, Berger RA, Kraemer WJ. Cardiovascular responses to a high-volume continuous circuit resistance training protocol. J Strength Cond Res. 2004;18(4) :760-764.

55. Costa T. Análise do gasto energético em diferentes exercícios físicos realizados na intensidade do limiar anaeróbio. São Carlos: Universidade de São Paulo; 2009.

56. Cheetham C, Green D, Collis J, et al. Effect of aerobic and resistance exercise on central hemodynamic responses in severe chronic heart failure. J Appl Physiol. 2002;93( 1): :175-180.

57. Bloomer RJ. Energy cost of moderate-duration resistance and aerobic exercise. J Strength Cond Res. 2005;19(4): :878-882.

58. Taylor HL, Buskirk E, Henschel A. Maximal oxygen intake as an objective measure of cardio-respiratory performance. J Appl Physiol. 1955;8( 1): 1 (73-80.

59. Denis C, Dormois D, Lacour JR. Endurance training, VO2 max, and OBLA: a longitudinal study of two different age groups. Int J Sports Med. 1984;5( 4) :167-173.

60. Baum K, Ruther T, Essfeld D. Reduction of blood pressure response during strength training through intermittent muscle relaxations. Int J Sports Med. 2003;24( 6) : 441-445. 
61. Meyer K, Hajric R, Westbrook S, et al. Hemodynamic responses during leg press exercise in patients with chronic congestive heart failure. Am J Cardiol. 1999;83( 11) :15371543.

62. MacDougall JD, Tuxen D, Sale DG, et al. Arterial blood pressure response to heavy resistance exercise. J Appl Physiol. 1985;58(3) :785-790.

63. Lamotte $M$, Niset $G$, van de Borne P. The effect of different intensity modalities of resistance training on beat-to-beat blood pressure in cardiac patients. Eur J Cardiovasc Prev Rehabil. 2005;12( 1): :12-17.

64. Fiatarone MA, O'Neill EF, Ryan ND, et al. Exercise training and nutritional supplementation for physical frailty in very elderly people. $\mathrm{N}$ Engl $\mathrm{J}$ Med. 1994;330( 25): :1769-1775.

65. Catai AM, Chacon-Mikahil MP, Martinelli FS, et al. Effects of aerobic exercise training on heart rate variability during wakefulness and sleep and cardiorespiratory responses of young and middle-aged healthy men. Braz J Med Biol Res. 2002;35( 6) :741-752.

66. Mitchell JH, Victor RG. Neural control of the cardiovascular system: insights from muscle sympathetic nerve recordings in humans. Med Sci Sports Exerc. 1996;28( 10 Suppl) :S60-69.

67. Bean JF, Kiely DK, Herman S, et al. The relationship between leg power and physical performance in mobility-limited older people. J Am Geriatr Soc. 2002;50(3) :461-467.

68. Chtara M, Chaouachi A, Levin GT, et al. Effect of concurrent endurance and circuit resistance training sequence on muscular strength and power development. J Strength Cond Res. 2008;22( 4) :1037-1045.

69. Karinkanta S, Heinonen A, Sievanen $\mathrm{H}$, et al. Maintenance of exercise-induced benefits in physical functioning and bone among elderly women. Osteoporos Int. 2009;20( 4 ) :665-674.

70. Schjerve IE, Tyldum GA, Tjonna AE, et al. Both aerobic endurance and strength training programmes improve cardiovascular health in obese adults. Clin Sci ( Lond) . 2008;115(9): :283-293.

71. Dekerle J, Brickley G, Hammond AJ, et al. Validity of the two-parameter model in estimating the anaerobic work capacity. Eur J Appl Physiol. 2006;96( 3) :257-264.

72. Wasserman K, Hansen JE, Sue DE, et al. Principles of exercise testing and interpretation. Philadelphia: Lea \& Febiger; 1986.

73. Katz A, Sahlin K. Regulation of lactic acid production during exercise. J Appl Physiol. 1988;65( 2): :509-518.

74. Brooks GA, Gaesser GA. End points of lactate and glucose metabolism after exhausting exercise. J Appl Physiol. 1980;49( 6) : :1057-1069. 
75. Wasserman K, Mcllroy MB. Detecting the Threshold of Anaerobic Metabolism in Cardiac Patients during Exercise. Am J Cardiol. 1964;14:844-852.

76. Wasserman K. Lactate and related acid base and blood gas changes during constant load and graded exercise. Can Med Assoc J. 1967;96( 12): :775-783.

77. Svedahl K, Maclntosh BR. Anaerobic threshold: the concept and methods of measurement. Can J Appl Physiol. 2003;28( 2) :299-323.

78. Robergs RA, Ghiasvand F, Parker D. Biochemistry of exercise-induced metabolic acidosis. Am J Physiol Regul Integr Comp Physiol. 2004;287( 3) :R502-516.

79. Mazzeo RS, Marshall P. Influence of plasma catecholamines on the lactate threshold during graded exercise. J Appl Physiol. 1989;67( 4) :1319-1322.

80. Denadai BS. Indices fisiológicos da avaliação aeróbica: Conceitos e aplicações. Ribeirão Preto: B.S.D.; 1999.

81. Simoes HG, Grubert Campbell CS, Kokubun E, et al. Blood glucose responses in humans mirror lactate responses for individual anaerobic threshold and for lactate minimum in track tests. Eur J Appl Physiol Occup Physiol. 1999;80(1) :34-40.

82. Soler AM, Folledo M, Martins LE, et al. Anaerobic threshold estimation by statistical modelling. Braz J Med Biol Res. 1989;22( 6) : :795-797.

83. Orr GW, Green HJ, Hughson RL, et al. A computer linear regression model to determine ventilatory anaerobic threshold. J Appl Physiol. 1982;52( 5) : 1349-1352.

84. Beaver WL, Wasserman K, Whipp BJ. Improved detection of lactate threshold during exercise using a log-log transformation. J Appl Physiol. 1985;59(6) :1936-1940.

85. Podolin DA, Munger PA, Mazzeo RS. Plasma catecholamine and lactate response during graded exercise with varied glycogen conditions. J Appl Physiol. 1991;71(4): 14271433.

86. Barros CLM, Agostini GG, Garcia ES, et al. Limiar de lactato em exercício resistido. Motriz. 2004;10( 1) :31-36.

87. Moreira SR, Arsa G, Oliveira HB, et al. Methods to identify the lactate and glucose thresholds during resistance exercise for individuals with type 2 diabetes. J Strength Cond Res. 2008;22( 4): :1108-1115.

88. Simoes RP, Mendes RG, Castello V, et al. Heart-rate variability and blood-lactate threshold interaction during progressive resistance exercise in healthy older men. J Strength Cond Res. 2010;24( 5) :1313-1320.

89. Beneke R. Anaerobic threshold, individual anaerobic threshold, and maximal lactate steady state in rowing. Med Sci Sports Exerc. 1995;27( 6) :863-867.

90. Heck H, Mader A, Hess $\mathrm{G}$, et al. Justification of the 4-mmol// lactate threshold. Int J Sports Med. 1985;6( 3) :117-130. 
91. Beneke R, von Duvillard SP. Determination of maximal lactate steady state response in selected sports events. Med Sci Sports Exerc. 1996;28(2) :241-246.

92. Freund $\mathrm{H}$, Oyono-Enguelle $\mathrm{S}$, Heitz $\mathrm{A}$, et al. Work rate-dependent lactate kinetics after exercise in humans. J Appl Physiol. 1986;61( 3) :932-939.

93. Beneke R. Methodological aspects of maximal lactate steady state-implications for performance testing. Eur J Appl Physiol. 2003;89( 1) :95-99.

94. Billat VL, Sirvent P, Py G, et al. The concept of maximal lactate steady state: a bridge between biochemistry, physiology and sport science. Sports Med. 2003;33( 6) : 407-426.

95. Baron B, Noakes TD, Dekerle J, et al. Why does exercise terminate at the maximal lactate steady state intensity? Br J Sports Med. 2008;42( 10) :828-833.

96. Baron B, Dekerle J, Robin S, et al. Maximal lactate steady state does not correspond to a complete physiological steady state. Int J Sports Med. 2003;24( 8) :582-587.

97. Billat $V$, Sirvent $P$, Lepretre $P M$, et al. Training effect on performance, substrate balance and blood lactate concentration at maximal lactate steady state in master endurance-runners. Pflugers Arch. 2004;447( 6) :875-883.

98. Philp A, Macdonald AL, Carter $\mathrm{H}$, et al. Maximal lactate steady state as a training stimulus. Int J Sports Med. 2008;29( 6) : 475-479.

99. Denadai BS, Ruas VD, Figueira TR. Maximal lactate steady state concentration independent of pedal cadence in active individuals. Eur J Appl Physiol. 2006;96(4) :477480.

100. Van Schuylenbergh R, Vanden Eynde B, Hespel P. Correlations between lactate and ventilatory thresholds and the maximal lactate steady state in elite cyclists. Int J Sports Med. 2004;25( 6): :403-408.

101. Harnish CR, Swensen TC, Pate RR. Methods for estimating the maximal lactate steady state in trained cyclists. Med Sci Sports Exerc. 2001;33( 6) :1052-1055.

102. Beneke R, Leithauser RM, Hutler M. Dependence of the maximal lactate steady state on the motor pattern of exercise. Br J Sports Med. 2001;35( 3) :192-196.

103. Van Schuylenbergh R, Eynde BV, Hespel P. Prediction of sprint triathlon performance from laboratory tests. Eur J Appl Physiol. 2004;91( 1) :94-99.

104. Ferreira JC, Rolim NP, Bartholomeu JB, et al. Maximal lactate steady state in running mice: effect of exercise training. Clin Exp Pharmacol Physiol. 2007;34( 8) :760-765.

105. Gobatto CA, de Mello MA, Sibuya CY, et al. Maximal lactate steady state in rats submitted to swimming exercise. Comp Biochem Physiol A Mol Integr Physiol. 2001;130(1): 21-27.

106. Mattern CO, Gutilla MJ, Bright DL, et al. Maximal lactate steady state declines during the aging process. J Appl Physiol. 2003;95( 6) :2576-2582. 
107. Hoeger W, Barette S, Hale D, et al. Relationship between repetitions and selected percentages of one repetition maximum. Journal of Applied Sport Science Research. 1987;1:11-13.

108. Matuszak ME, Fry AC, Weiss LW, et al. Effect of rest interval length on repeated 1 repetition maximum back squats. J Strength Cond Res. 2003;17( 4) :634-637.

109. Karvonen MJ, Kentala E, Mustala O. The effects of training on heart rate; a longitudinal study. Ann Med Exp Biol Fenn. 1957;35( 3) : 307-315.

110. Borg G, Hassmen P, Langestrom M. Perceived exertion in relation to heart rate and blood lactate during arm and leg exercise. Eur J Appl Physiol. 1985;65:675 - 685.

111. Robertson RJ, Goss FL, Rutkowski J, et al. Concurrent validation of the OMNI perceived exertion scale for resistance exercise. Med Sci Sports Exerc. 2003;35( 2) :333341.

112. Hatfield DL, Kraemer WJ, Spiering BA, et al. The impact of velocity of movement on performance factors in resistance exercise. J Strength Cond Res. 2006;20( 4) :760-766.

113. Willardson JM, Burkett LN. The effect of rest interval length on the sustainability of squat and bench press repetitions. J Strength Cond Res. 2006;20( 2) :400-403.

114. Shephard RJ, Astrand PO. Endurance in sport. The encyclopaedia of sports medicine1992.

115. Hargreaves M, Richter EA. Regulation of skeletal muscle glycogenolysis during exercise. Can J Sport Sci. 1988;13(4) :197-203.

116. Marsh GD, Paterson DH, Govindasamy D, et al. Anaerobic power of the arms and legs of young and older men. Exp Physiol. 1999;84( 3) :589-597.

117. Tzankoff SP, Norris AH. Age-related differences in lactate distribution kinetics following maximal exercise. Eur J Appl Physiol Occup Physiol. 1979;42( 1) :35-40.

118. Prioux J, Ramonatxo $M$, Hayot $M$, et al. Effect of ageing on the ventilatory response and lactate kinetics during incremental exercise in man. Eur J Appl Physiol. 2000;81( 12) :100-107.

119. Larsson L, Sjodin B, Karlsson J. Histochemical and biochemical changes in human skeletal muscle with age in sedentary males, age 22--65 years. Acta Physiol Scand. 1978;103(1) :31-39.

120. Thorstensson A, Sjodin B, Tesch P, et al. Actomyosin ATPase, myokinase, CPK and LDH in human fast and slow twitch muscle fibres. Acta Physiol Scand. 1977;99(2) :225229.

121. Evans L, Rice CL, Noble EG, et al. Comparison of histochemical, biochemical and contractile properties of triceps sums of trained aged subjects. Can J Aging. 1992;11:412425. 
122. Kalb JS, Hunter GR. Weight training economy as a function of intensity of the squat and overhead press exercise. J Sports Med Phys Fitness. 1991;31( 2) :154-160.

123. Scala D, Mcmillan J, Blessing D, et al. Metabolic cost of a preparatory phase of training in weight lifting: a pratical observation. J Appl Sports Sci Res. 1987;1:48-52.

124. Medelli J, Maingourd Y, Bouferrache B, et al. Maximal oxygen uptake and aerobicanaerobic transition on treadmill and bicycle in triathletes. Jpn J Physiol. 1993;43( 3) :347360.

125. Kang J, Hoffman JR, Im J, et al. Evaluation of physiological responses during recovery following three resistance exercise programs. J Strength Cond Res. 2005;19( 2): 305-309.

126. Ballor DL, Becque MD, Katch VL. Metabolic responses during hydraulic resistance exercise. Med Sci Sports Exerc. 1987;19( 4) :363-367.

127. Burleson MA, Jr., O'Bryant HS, Stone MH, et al. Effect of weight training exercise and treadmill exercise on post-exercise oxygen consumption. Med Sci Sports Exerc. 1998;30(4): $: 518-522$.

128. Collins MA, Cureton KJ, Hill DW, et al. Relation of plasma volume change to intensity of weight lifting. Med Sci Sports Exerc. 1989;21( 2) :178-185.

129. Ratamess NA, Falvo MJ, Mangine GT, et al. The effect of rest interval length on metabolic responses to the bench press exercise. Eur J Appl Physiol. 2007;100(1):1-17.

130. Thornton MK, Potteiger JA. Effects of resistance exercise bouts of different intensities but equal work on EPOC. Med Sci Sports Exerc. 2002;34(4) :715-722.

131. Farinatti PT, Simao R, Monteiro WD, et al. Influence of exercise order on oxygen uptake during strength training in young women. J Strength Cond Res. 2009;23( 3) :10371044.

132. Villiger B, Egger K, Lerch R, et al. Resistência: Livraria Santos; 1995.

133. Petrofsky JS, Hendershot DM. The interrelationship between blood pressure, intramuscular pressure, and isometric endurance in fast and slow twitch skeletal muscle in the cat. Eur J Appl Physiol Occup Physiol. 1984;53( 2) :106-111.

134. Hollmann W, Hettinger T. Medicina de Esporte. São Paulo: Ed. Manole LTDA; 1989.

135. Foster C, Kuffel E, Bradley N, et al. VO2max during successive maximal efforts. Eur J Appl Physiol. 2007;102( 1) :67-72.

136. Denadai BS, Gomide E, Greco CC, et al., editors. Validity of critical velocity to determinde the maximal lactate steady state in soccer players. 5th World Congress on Science and Football; 2003; Lisboa, Portugal.

137. Beneke R. Maximal lactate steady state concentration ( MLSS) : experimental and modelling approaches. Eur J Appl Physiol. 2003;88( 4-5) :361-369. 
138. Heck H, von Rosen I, Rosskopf P. Dynamik des Blutlaktats bei konstanter Fahrradund Drehkurbelarbeit1994.

139. Brooks SV, Faulkner JA. Skeletal muscle weakness in old age: underlying mechanisms. Med Sci Sports Exerc. 1994;26( 4) :432-439.

140. Thompson LV. Effects of age and training on skeletal muscle physiology and performance. Phys Ther. 1994;74( 1) :71-81.

141. Farinatti $P$, Assis BF. Estudo da frequência cardíaca, pressão arterial e duplo-produto em exercícios contra-resistência e aeróbio contínuo. Rev Bras Ativ Física Saúde. 2000;5:516.

142. Gould BA, Hornung RS, Altman DG, et al. Indirect measurement of blood pressure during exercise testing can be misleading. Br Heart J. 1985;53(6) :611-615.

143. Rasmussen PH, Staats BA, Driscoll DJ, et al. Direct and indirect blood pressure during exercise. Chest. 1985;87( 6) :743-748. 
ANEXO A - Escala de BORG

\begin{tabular}{|c|c|}
\hline 6 & - \\
\hline 7 & Muito fácil \\
\hline 8 & - \\
\hline 9 & Fácil \\
\hline 10 & - \\
\hline 11 & Relativamente fácil \\
\hline 12 & - \\
\hline 13 & Lansativo \\
\hline 14 & - \\
\hline 15 & Muito cansativo \\
\hline 16 & - \\
\hline 17 & Exaustivo \\
\hline 18 & - \\
\hline 19 & \\
\hline 20 & \\
\hline
\end{tabular}




\section{ANEXO B - Escala de OMNI}

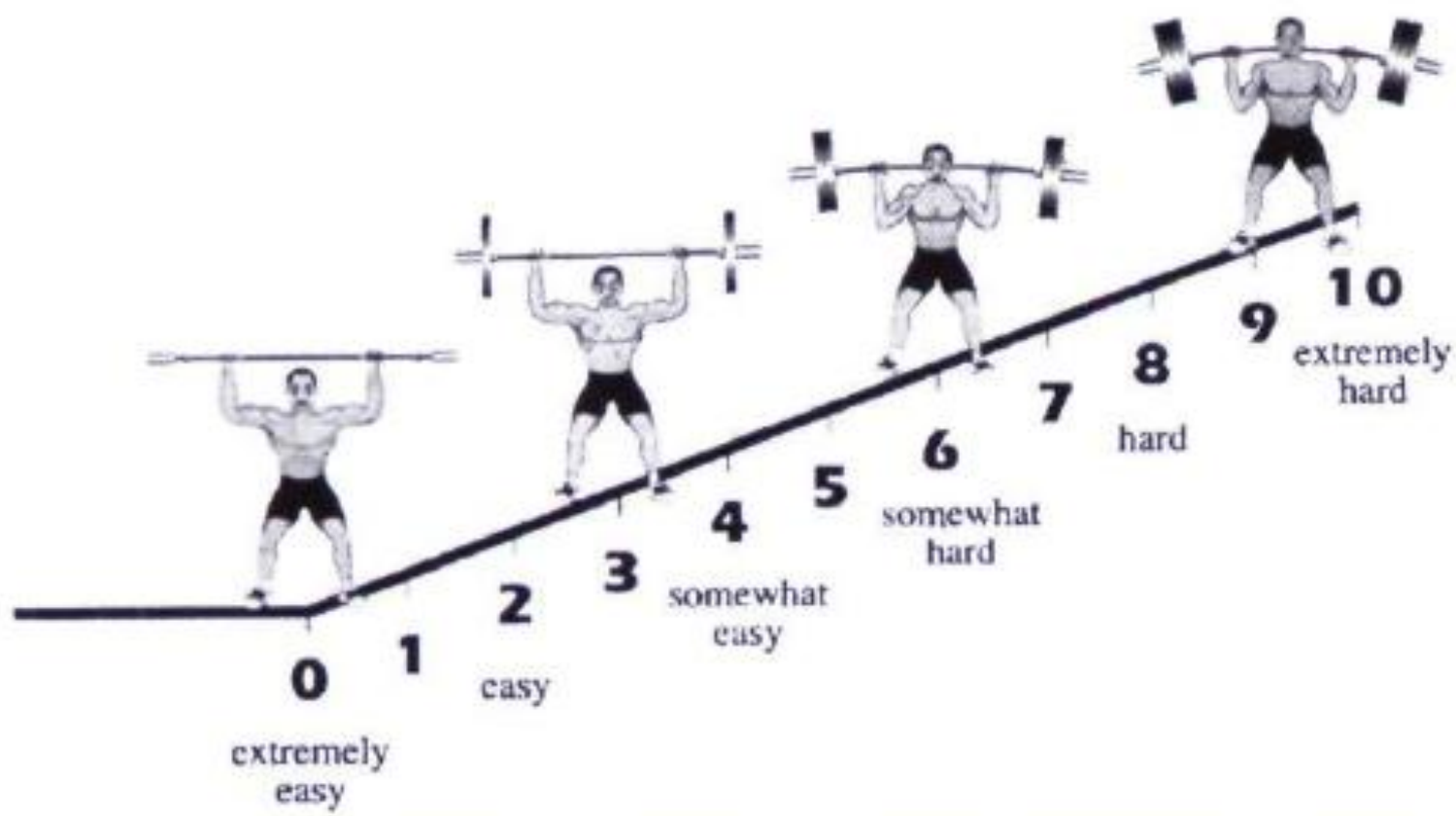




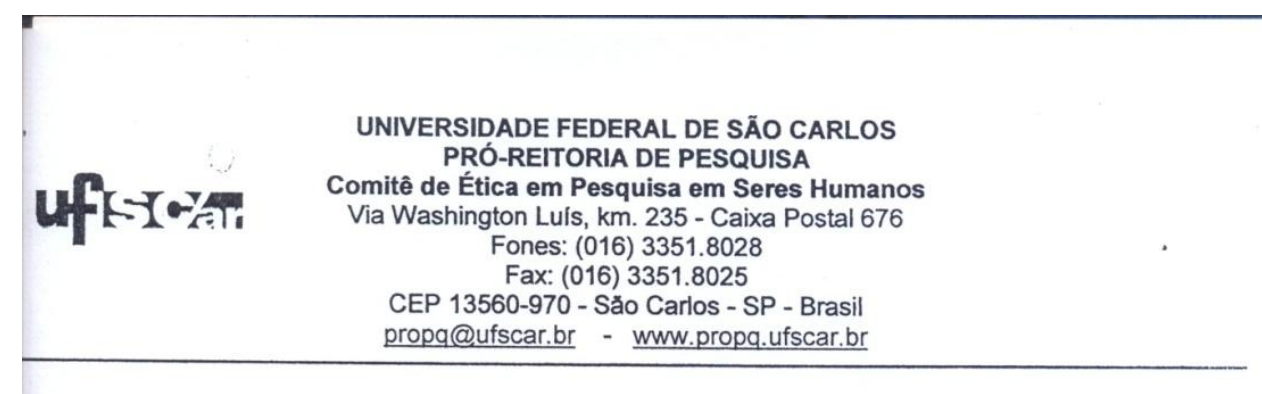

CAAE 0166.0.135.000-09

Título do Projeto: Determinação da Máxima Fase Estável de Lactato em Exercícios Resistidos Classificação: Grupo I/ Fase: Não se aplica

Pesquisadores (as): Ilmo. Sr. Rodrigo Ferro Magosso, Vilmar Baldissera (orientador), Nuno Manuel Frade de Sousa (colaborador)

Processo: 23112.004532/2009-14

\section{Parecer No. 494/2009}

\section{Avaliação}

O Comitê de Ética em Pesquisa em Seres Humanos da Universidade Federal de São Carlos (CEP/UFSCar) analisou o projeto de pesquisa acima identificado e considerando os pareceres do relator e do revisor DELIBEROU:

O propósito geral da pesquisa é verificar se ocorre uma máxima fase estável de lactato durante a realização dos exercícios resistidos Leg Press 450 e supino reto em diferentes idades. Os trabalhos ocorrerão no Departamento de Ciências Fisiológicas da UFSCar, tendo como alvo de pesquisa 25 pessoas adultas de 20 a 35 anos e de 50 a 75 anos, sexo masculino, sem distinção étnica.

Como justificativa, a pesquisadora apontou resultado de pesquisa $\mathrm{\epsilon m}$ corredores obtidos por outros pesquisadores no mesmo tema, indicando que indivíduos com menor grau de treinamento podem ser mais beneficiados pelo treino na VMFEL- Máxima Fase Estável de Lactato. Embora já pesquisada a matéria e resultados publicados, a pesquisadora entende que não há estudos na literatura que tenham estabelecidos a existencia da MFEL em exercícios resistidos, particularmente com idosos, planos de periodização fidedignos ainda não foram apresentados, principalmente porque os métodos para determinar a intensidade do exercício em movimentos resistidos ainda não estão totalmente desenvolvidos. Na metodologia os sujeitos de pesquisa realizarão o teste de carga máxima (1RM), seguido teste crescentes para determinação do AT e mais tr6es sessões para determinação da máxima fase estável de lacto, sendo uma na intensidade correspondente ao AT, uma abaixo e uma acima desta intensidade, para os exercícios Supino reto e Leg Press 450, realizadas de maneira aleatória e separadas por 48 horas. Todas as sessões ocorrerão no mesmo horário do dia para evitar influências do ciclo circadiano. para análise de parâmetros ventilatórios.

Os riscos são possiveis desconfortos para utilização de bucal e clipe nasa

Os benefícios envolvem conhecimento de sua carga máxima e máxima fase estável de lactato para estes exercícios, sendo que o primeiro é bem descrito como parâmetro importante na prescrição de treinamento resistido.

$O$ recrutamento dos sujeitos será feito através de cartazes gerais sobre a pesquisa e um contato telefônico e e- mails, caso o indivíduo se interesse e queira saber maiores detalhes. Outros meios serão utilizados contatos verbais.

ordem. Orçamento, cronograma, currículo, folha de rosto e TCLE estão em

O projeto atende o comando da Resolução 196/96 do CNS e suas complementares, prevê os riscos, com a devida avaliação e minimização. É claro quanto aos critérios de inclusão e exclusão. Respeita a confidencialidade. Sem vislumbrar quaisquer prejuízos o sujeito de pesquisa no estuda a se realizar.

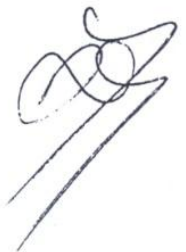

